\title{
Planning Ahead for Better Neighborhoods: Long Run Evidence from Tanzania*
}

\author{
Guy Michaels (LSE) Dzhamilya Nigmatulina (LSE) Ferdinand Rauch (Oxford) \\ Tanner Regan (LSE) Neeraj Baruah (LSE) Amanda Dahlstrand (LSE)
}

November 14, 2020

\begin{abstract}
Africa's demand for urban housing is soaring, even as it faces a proliferation of slums. In this setting, can modest infrastructure investments in greenfield areas where people subsequently build their own houses facilitate long run neighborhood development? We study "Sites and Services" projects implemented in seven Tanzanian cities during the 1970s and 1980s, and we use a spatial regression discontinuity design to compare greenfield areas that were treated ("de novo") to nearby greenfield areas that were not. We find that by the 2010s, de novo areas developed into neighborhoods with larger and more regularly laid out buildings and better quality housing.
\end{abstract}

KEYWORDS: Urban Economics, Economic Development, Slums, Africa.

JEL CLASSIFICATION: R31, O18, R14

\footnotetext{
*Corresponding author: Michaels, CEP, LSE, Houghton Street, WC2A 2AE, London, UK. Email: g.michaels@lse.ac.uk. Tel: +44(0)20-7852-3518. Nigmatulina, Regan, Baruah, and Dahlstrand: CEP, LSE, Houghton Street, WC2A 2AE, London, UK. Rauch: Department of Economics, University of Oxford, Manor Road, Oxford, OX1 3UQ, UK. We thank Lino Ferreira and Ilia Samsonov for excellent research assistance. We thank Richard Bakubiye, Chyi-Yun Huang, Ezron Kilamhama, George Miringay, Hans Omary, Elizabeth Talbert and the Tanzanian President's Office Regional Administration and Local Government, and especially Charles Mariki, for help in obtaining the data. We thank the editor, Magne Mogstad, and six anonymous referees for helpful and constructive comments. For further helpful comments and discussions we thank Shlomo Angel, Julia Bird, Paul Collier, Matt Collin, Gilles Duranton, Simon Franklin, Ed Glaeser, Michael Greenstone, Vernon Henderson, Wilbard Kombe, Sarah Kyessi, Somik Lall, Joseph Mukasa Lusugga Kironde, Amulike Mahenge, Alan Manning, Anna Mtani, Ally Hassan Namangaya, Steve Pischke, Shaaban Sheuya, Tony Venables, and Sameh Wahba. We also thank participants in the World Bank Annual Bank Conference on Africa in Oxford; World Bank Land and Poverty Conference 2016: Scaling up Responsible Land Governance, in Washington, DC; World Bank conference on Spatial Development of African Cities, Washington, DC; and workshop and seminar participants at LSE, Queen Mary, and Stanford. We gratefully acknowledge the generous support of a Global Research Program on Spatial Development of Cities, funded by the Multi Donor Trust Fund on Sustainable Urbanization of the World Bank and supported by the UK Department for International Development. The usual disclaimer applies.
} 


\section{Introduction}

Africa's cities are growing rapidly. With its expanding population (United Nations 2015) and rising urbanization rate (Freire et al. 2014), we expect that almost a billion people will join the continent's cities by 2050. But many of these cities, especially in Sub-Saharan Africa, already face problems of poor infrastructure and low quality housing (Henderson et al. 2016 and Castells-Quintana 2017). According to UN Habitat (2012), as many as 62\% of this region's urban dwellers live in slums, whose population was expected to double within 15 years. The poor living conditions in those slums have important consequences for residents' lives (Marx et al. 2013).

There are various policy options for addressing the immense challenges posed by African urbanization. One option, which is often the default, is to allow neighborhoods to develop organically without much planning or infrastructure. At the other end of the spectrum, a second option is for the state to not only plan but actually build public housing. This is expensive, but has been done for example in South Africa (Franklin 2020). Between these two alternatives lies a third option of laying out basic infrastructure on the fringes of cities, and allowing people to build their own homes, an option advocated by Romer (2012) and Angel (2012). A fourth option is to improve infrastructure in areas where low quality housing develops.

Understanding the implications of these options is important for current policy discussions. For example, there are debates about the respective merits of upgrading and starting anew (e.g. Duranton and Venables 2020). But we know relatively little about these options' implications for private investments and the survival of infrastructure, or about their distributional consequences. One of the main contributions of this paper is to shed light on these issues. To do so, we study the long run development of neighborhoods, which were part of the "Sites and Services" projects (described below). ${ }^{1}$ These took place not only in Tanzania's biggest city, Dar es Salaam, but also in six of its secondary cities. $^{2}$

Our paper focuses on the long run consequences of the third option discussed above (de novo) compared to the first (default) option of unregulated development. We study de novo neighborhoods, which were developed in greenfield areas on what were then the fringes of Tanzanian cities. The developments included the delineation of formal residential plots and the provision of basic infrastructure, consisting primarily of roads and water mains. People were then offered an opportunity to build homes on these plots in exchange for a fee. To provide a counterfactual, we use nearby control areas that were also greenfields before the Sites and Services projects began. We also provide descriptive evidence on the fourth approach discussed above by studying upgrading areas, which received infrastructure investments similar to the de novo areas, but only after people had built low

\footnotetext{
${ }^{1}$ Throughout the paper we refer interchangeably to: "areas" and to the "neighborhoods" that develop in them; houses and housing units; and squatter settlements and slums. Finally, we refer to "owners" as those with de-facto rights to reside in a house or rent it out. Legally, even formal ownership consists of a long and renewable lease from the state.

${ }^{2}$ This is important because Africa's secondary cities are relatively understudied, despite being home to the majority of its urban population. See for example Brinkhoff (2017), Agence Française de Développement (2011), National Oceanic and Atmospheric Administration (2012), and Tanzania National Bureau of Statistics (2011).
} 
quality housing. ${ }^{3}$ We compare these upgrading areas to nearby areas and also, for Dar es Salaam only, to slums that were not upgraded.

We investigate how different neighborhoods developed over more than three decades, and we ask a number of questions. First, do de novo investments solve coordination failures and facilitate neighborhood development in the long run? Second, how do they shape private housing investments and the survival of public infrastructure? And finally, what characterizes the sorting of owners and residents across neighborhoods, and to what extent can owners' sorting account for the differences in outcomes across neighborhoods?

Concretely, we study Sites and Services projects, which were co-funded by the World Bank and the Tanzanian government, and were similar to projects carried out in other countries. In Tanzania they were implemented in two rounds: one began in the 1970s and the other in the early 1980s. Altogether, 12 de novo neighborhoods and 12 upgrading neighborhoods were developed in Dar es Salaam, Iringa, Morogoro, Mbeya, Mwanza, Tabora, and Tanga. (World Bank 1974a,b, 1977a,b, 1984, and 1987). ${ }^{4}$

To study the consequences of de novo investments, we combine high resolution spatial imagery on all seven cities and building-level survey data on three of the cities with historical imagery and maps. We analyze these data using a spatial regression discontinuity (RD) design. We find that in de novo areas, houses are larger and more densely and regularly laid out, are better connected to electricity, and (in some specifications) also have better sanitation. A "family of outcomes" index and a hedonic measure of house values show that de novo areas have higher quality housing. These results, which are robust to the inclusion of various controls and robustness checks, demonstrate the crowding-in of private investment in response to the public de novo infrastructure investments. We also find that de novo areas have better access to roads and water mains, reflecting the persistence of the Sites and Services infrastructure investments over several decades.

To shed light on the mechanisms that underlie our findings, we develop a simple model of owners' investment decisions, which features complementarity between public and private investments. In de novo neighborhoods, where a sufficient fraction of owners can invest in housing quality, infrastructure investment crowds in private investment in housing quality, which in turn preserves infrastructure quality. This virtuous feedback, however, does not occur in upgrading areas, both because the existing stock of (low quality) housing disincentivizes wholesale reconstruction of housing, and because owners' credit constraints prevent them from investing sufficiently, and as a result infrastructure deteriorates. At the same time, in control areas the infrastructure investments are lower, so no high quality housing is built.

The model helps us interpret our empirical findings in two important ways. First, it allows us to separate the roles of owners' different credit constraints from the effect of infrastructure investments, when comparing de novo and control areas. In practice, we find that adding owner fixed effects

\footnotetext{
${ }^{3}$ Unlike de novo areas, however, upgrading areas did not receive formal plots.

${ }^{4}$ Until recent years the government maintained sole authority for creating new formal plots in Tanzania, so we cannot study the long run consequences of privately provided plots.
} 
reduces the quality differences between de novo and control areas by up to one-third, but these differences remain large and precisely estimated. Second, the model allows us to infer land value differences across neighborhoods from differences in housing quality. Our calculations suggest that the local gains in land value from de novo were, at least in Dar es Salaam, no less than \$75-100 per square meter of plot (in 2017 prices). These gains far exceed the costs of the project, which amounted to no more than $\$ 8-13$.

In our empirical analysis we also use census micro data to characterize the sorting of residents across neighborhoods. We find that as of 2012, de novo neighborhoods attracted better educated residents, who likely had higher incomes to pay for better amenities. The sorting on education across neighborhoods is, however, only partial: about 45 percent of the adults in de novo areas had no more than a primary school education. Furthermore, even less educated people who initially owned de novo plots and eventually sold them likely gained from some of the land value appreciation. ${ }^{5}$

In contrast to our findings on de novo areas and in line with our model, our descriptive analysis of upgrading areas suggests that their housing quality is either similar to that of nearby areas or non-upgraded slums, or in some cases even worse. Our findings also suggest that upgrading areas do not enjoy better access to water mains or roads than the control areas, so the Sites and Services investments in these areas likely deteriorated. These results should be interpreted cautiously, however, since it is harder to find a clean counterfactual for upgrading areas (which were populated to begin with) than for de novo areas.

The economic evaluation of de novo Sites and Services areas is thus the focal point of our paper. Previous studies of Sites and Services around the world include surveys (e.g. Laquian 1983) and critical discussions (e.g. Mayo and Gross 1987 and Buckley and Kalarickal 2006). In the Tanzanian context, there are descriptive studies of Sites and Services in Dar es Salaam (Kironde 1991 and 1992 and Owens 2012). Other work on Dar es Salaam studies different interventions, including the shortterm impact of more recent slum upgrading projects on health, schooling, and income (Coville and Su 2014); descriptive analyses of a more recent episode of serviced plot provision, known as the "20,000 plots" project, which suggests sizeable short-run gains in land values (Tiba et al. 2005 and Kironde 2015); and willingness to pay for land titling in poor neighborhoods (Ali et al. 2016 and Manara and Regan 2019). But as far as we are aware, ours is the first long run econometric evaluation of de novo Sites and Services areas.

Our study is related to research on the role of coordinating land institutions (Libecap and Lueck 2011) - in our case formal plots - in underpinning economic development. It is also related to studies of housing externalities in cities (Hornbeck and Keniston 2017 and Rossi-Hansberg et al. 2010). Another recent and related paper - on Indonesia rather than Tanzania - is Harari and Wong (2017). They, like us, find that upgraded slums do not perform well economically in the long run. Our paper, however, differs from theirs since we focus on de novo neighborhoods, which are not part of the

\footnotetext{
${ }^{5}$ As we discuss below, a few years after Sites and Services were implemented, most of the residents in de novo neighborhoods in Dar es Salaam were still those targeted by the policy, many of whom were poor.
} 
context they study.

Our paper is also related to the literature on the economics of African cities (Freire et al. 2014). Like Gollin et al. (2016) we study not only the largest African cities (such as Dar es Salaam in Tanzania), but also secondary cities. Our contribution to this literature comes from studying these cities at a fine spatial scale, examining individual neighborhoods and buildings, using a combination of very high resolution daylight satellite images, building-level survey data, and precisely georeferenced census data.

A few recent papers study outcomes not only across African cities but within them (see for example Henderson et al. 2016). Our study differs not only in our focus on secondary African cities, but also in the longer time horizon we cover. We use historical satellite images and highly detailed maps going back over 50 years, which allow us to evaluate long run changes on historically undeveloped land in response to specific infrastructure investments. By combining these with data on individuals, we also provide more evidence about the sorting across neighborhoods.

Also related to our paper is a broader literature on the economics of slums (e.g. Castells-Quintana 2017 and Marx et al. 2019). Our contribution to this literature is to illustrate conditions under which housing of better quality forms and persists, and the limitations of upgrading existing slums. Poor neighborhoods have also been studied in other settings, especially in Latin America and South Asia. For example, Field (2005) and Galiani and Schargrodsky (2010) find that providing more secure property rights to slum dwellers in Latin America increases their investments in residential quality. ${ }^{6}$ Our paper differs in its setting (Tanzania is considerably poorer than Latin America) and its focus on early infrastructure provision.

While our paper's focus is on new neighborhoods rather than new cities, it is also related to Romer (2010), who investigates the potential for new Charter Cities as pathways for urban development in poor countries. Our work is also related to the position advocated by Shlomo Angel, that Sites and Services may be a relevant model for residential development in some circumstances. ${ }^{7}$

Methodologically, we contribute to the nascent literature using very high resolution daylight images (e.g. Jean et al. 2016). Like Marx et al. (2019) we study roof quality as a measure of residential quality. Our measure of quality differs, however; instead of measuring luminosity, we assess whether roofs are painted, since paint protects the roofs from rust. We also use the imagery data to develop a set of measures of residential quality, including building size, access to roads, and a measure of regularity of neighborhood layout, which we combine with survey data on building quality.

The remainder of our paper is organized as follows. Section 2 discusses the institutional background and data we use; Section 3 presents the research design and our empirical findings; Section 4 contains a model of investments in infrastructure and housing in different neighborhoods; and Section 5 concludes.

\footnotetext{
${ }^{6}$ In another paper, Galiani et al. (2013) study an intervention that provides pre-fabricated homes costing around US\$1,000 each in Latin America, but come without any infrastructure.

${ }^{7}$ See for example this interview with Angel, which discusses this idea:

http:/ / www.smartcitiesdive.com/ex/sustainablecitiescollective/conversation-dr-shlomo-angel/216636/
} 


\section{Institutional Background and Data}

\subsection{Institutional Background}

\section{What were Sites and Services projects?}

This paper studies the long term consequences of ambitious projects that were designed to improve the quality of residential neighborhoods in Tanzania. These projects, called "Sites and Services", formed an important part of the World Bank's urban development strategy during the 1970s and 1980s. Sites and Services projects were implemented not only in Tanzania, but also in other countries such as Senegal, Jamaica, Zambia, El Salvador, Peru, Thailand, and Brazil (Cohen et al. 1983). Of the World Bank's total Shelter Lending of \$4.4 billion (2001 US\$) from 1972-1986, Sites and Services accounted for almost 50 percent, and separate slum upgrading accounted for over 20 percent.

In Tanzania, Sites and Services were implemented in two rounds - the first began in the 1970s (World Bank 1974b and 1984) and the second in the 1980s (World Bank 1977b and 1987). These projects were co-financed by the World Bank and the Tanzanian government (World Bank 1974a and 1977a).

Sites and Services projects in Tanzania fell into two broad classes. The first involved de novo development of previously unpopulated areas. The second involved upgrading of pre-existing squatter settlements (sometimes referred to as "slum upgrading"). In total across both rounds, the program laid the groundwork for 12 de novo neighborhoods and 12 upgrading neighborhoods spread across seven cities (World Bank 1974b, 1977b, 1984, and 1987).

The overall cost of the Sites and Services projects in Tanzania was approximately \$130 million (in US\$2017), of which $\$ 83$ million were direct costs, covering for infrastructure, land compensation, equipment and consultancy (World Bank 1974b, 1977b, 1984 and 1987). ${ }^{8}$ The direct costs per square meter in the first round in de novo (\$2.20) and upgrading (\$2.37) were similar (World Bank 1974b, 1977b, 1984 and 1987). To compare these costs to present-day land values (see below), we focus on costs per square meter of plot, excluding public areas. As we explain in the Data Appendix, we estimate that the direct costs per square meter of plot were no more than $\$ 8$, and the total costs were no more than $\$ 13$ per square meter.

\section{What were the treatment and counterfactual?}

Our main empirical analysis compares de novo (our main treatment) to nearby control areas (our counterfactual). As we explain in Section 3, we implement a spatial regression discontinuity design, focusing on the difference in outcomes close to the boundary of de novo areas and adjacent control areas, which were (like de novo) unbuilt before the Sites and Services projects began. In Section 3 we also discuss and address potential threats to our identification strategy. Here we explain why we focus on the comparison between de novo and control areas and what we learn from it.

\footnotetext{
${ }^{8}$ The remainder of the costs covered a loan scheme and community buildings.
} 
De novo areas received roads, which were mostly unpaved, and water mains, as well as formal plots. ${ }^{9}$ The combination of these three infrastructure elements (formal plots, roads, and water mains) constitutes the main treatment for de novo areas. ${ }^{10}$ Roads reduce travel costs for both work and leisure for residents, customers and visitors. Water mains may improve the quality and reliability of water consumed, and reduce the transaction costs of purchasing water (e.g. from water trucks). They may also improve the residents' health and help them grow food. Formal plots reduce the risk of full expropriation, and of infringements onto parts of owners' plots and public spaces (such as roads and areas required to maintain water mains). They may also reduce conflicts over ownership, and the need to engage in costly defensive actions (such as building fences or walls). Moreover, the formal and regular plots may mitigate coordination problems, lead to easier access and better use of space, and make plots more easily tradeable, increasing the incentives to invest in them. Long-term gains in land values from a regular grid of plots (compared to a decentralized and irregular system) have been documented in the US context (Libecap and Lueck 2011). ${ }^{11}$

In addition to the main treatment components, both de novo and upgrading areas received a small number of public buildings, which were designated as schools, health clinics, and markets. ${ }^{12}$ While these could have had an impact, we think that they matter less than the plots, the roads and the water mains. First, the total cost of the public buildings was lower than either the roads or the water mains; and second, even if Sites and Services areas received more buildings than other areas (which we don't know), there is no evidence that access to them ends discontinuously at the project boundaries. In addition to the infrastructure investments, some Sites and Services residents were offered loans, which were not fully repaid. We think of these loans as relaxing some owners' budget constraints, and below we explain our strategy for studying the implications of differences across neighborhoods in owners' credit constraints.

As we discuss in more detail in the Data Appendix, control areas appear to have received significantly less infrastructure investments, although our data do suggest that they have some roads and connections to water mains.

For upgrading areas we do not have a clean counterfactual, because those areas were built on by squatters before Sites and Services began. Thus any present-day differences between them and other areas may reflect a combination of preexisting differences and the treatment effect of upgrading. In Section 3 we explain what we can nevertheless learn about those areas, at least descriptively, by comparing them to nearby areas or to other preexisting squatted areas that were not treated by Sites

\footnotetext{
${ }^{9}$ Formal plots are delineations of land, which meet local surveying and town planning standards. They increase tenure security, and are a prerequisite in any application for a Certificate of Right of Occupancy (the highest land tenure document in Tanzania).

${ }^{10}$ Upgrading areas also received roads and water mains, but no formal plots. The Data Appendix contains more information about the precise timing and more details the investments cost breakdown. The second round investments were generally lower - in some cases they may have excluded water mains, and for one of the de novo areas (the one in Tanga), we have some uncertainty as to the extent of infrastructure that was actually provided (World Bank 1987). Most of the de novo plots were, however, laid out in the first round.

${ }^{11}$ Hornbeck and Keniston (2017) similarly emphasize that starting afresh can lead to higher local land values in an urban setting.

${ }^{12}$ The first round buildings public buildings were also surrounded by street lighting
} 
and Services.

\section{How were treatment areas selected?}

While our regression discontinuity design helps to mitigate concerns about selection of areas, it is nonetheless important to explain how the locations of the treatment and control areas were selected. For de novo neighborhoods, the planners intended to purchase mostly empty (greenfield) land parcels measuring at least 50 hectares each, although in practice this criterion appears to have been met only for seven of the twelve de novo areas. The planners also sought land suitable for construction (e.g. with natural drainage) with access to off-site water mains, trunk roads, and employment opportunities. For upgrading the planners looked for squatter settlements that were large, well-defined, hazard-safe, and suitable for infrastructure investments (World Bank 1974a, 1977b). In most but not all cities, de novo and upgrading areas were adjacent to each other. We discuss our selection of the control areas in more detail below. All the areas are depicted in Figure A1.

\section{Who took part in the program?}

Another important aspect of the Sites and Services projects was the characteristics of the population they targeted. The planners had intended for the plots to be allocated following a point system, which prioritized applicants who met certain criteria. Different sources do not agree precisely on the criteria used, although it seems that a preference was given to the poor - but not the poorest - urban residents (World Bank 1974 and World Bank 1977). Laquian (1983) explains that the de novo projects in Tanzania were intended for income groups between the 20th and 60th income percentile of a country. In similar vein, Kironde (1991) argues that eligibility for de novo sites in Dar es Salaam excluded the poorest and richest households, but targeted an intermediate range of earners which covered over $60 \%$ of all urban households. It seems that the opportunity to purchase de novo plots was initially given to low income households, including those displaced from upgrading areas, presumably as a result of building new infrastructure (World Bank 1984 and Kironde 1991). ${ }^{13}$

There is some disagreement as to how this process was implemented in practice. One report (World Bank 1984) argues that there were irregularities in this process, which allowed some richer households to sort into de novo neighborhoods. But in discussing the de novo sites in Dar es Salaam in the late 1980s, Kironde (1991) argues that most plots were awarded to the targeted income groups, and as of the late 1980s: "The majority of the occupants (57.9 percent) are still the original inhabitants but there are many 'new' ones who were either given plots after the original awardees had failed to develop them, or who were given 'created' plots. A few, however, obtained plots through purchase or bequeathment". Taken together, the evidence suggests that de novo locations attracted some households with modest means, but gradually also richer ones. As our model below illustrates,

\footnotetext{
${ }^{13}$ The planners had intended for the plots to be allocated following a point system, which prioritized applicants who met certain criteria. But different sources (e.g. World Bank 1974, World Bank 1977, and Kironde 1991) differ in their accounts of what these precise criteria were.
} 
this type of sorting would likely have occurred even if the project had been administered flawlessly.

\section{How relevant are Sites and Services today?}

The difficulty of recouping Sites and Services costs, and criticism that they excluded the poorest urban population, appear to have motivated a shift away from them during the 1980s (World Bank 1987, Mayo and Gross 1987, and Buckley and Kalarickal 2006). As a result, the share of Sites and Services (including slum upgrading) in the World Bank's Shelter Lending fell from around 70\% from 1972-1986 to around 15\% from 1987-2005 (Buckley and Kalarickal 2006).

Nevertheless, Sites and Services projects deserve renewed attention for several reasons. First, as mentioned above, Africa's urban population is growing rapidly, and adding pressure to its congested cities. Second, Africa's GDP per capita has grown in recent decades, so more Africans can now afford better housing, and an important question is how to deliver this. Alternative solutions, such as government provision of public housing, are considerably more expensive than a de novo approach of the type we study. ${ }^{14}$ Third, cost recoupment and administration have since improved through increased use of digital record keeping, as evidenced by the Tanzanian Strategic Cities Project (TSCP - World Bank 2013). ${ }^{15}$ For example, the "20,000 Plots" project, a de novo program implemented in Tanzania in the early 2000s appears to have reduced the cost per plot by about half compared to the historical Sites and Services projects, even though the new plots were bigger (Tiba et al. 2005). Finally, land on the fringes of Tanzanian cities remains inexpensive (Tanzania Ministry of Lands 2012), so there are still opportunities for more de novo developments. ${ }^{16}$

To shed light on the motivations of urban planners in considering de novo projects, we turn to the above-mentioned "20,000 Plots" project. Among the concerns that lay in the background to this program were the ongoing expansion of unplanned squatter areas, which suffer from poor waste management, an inadequate supply of urban services and infrastructure, and transportation problems. These unplanned areas also hamper the government's ability to collect tax revenues (Tiba et al. 2005). It is in this context that the "20,000 Plots" project aimed to alleviate the shortage of surveyed and serviced plots and to reduce the rapid increase of informal settlements, as well as to restrict land speculation and corruption (Tiba et al. 2005). At the same time, distributional concerns regarding de novo projects remain relevant (Kironde 2015), and we revisit those in Section 5.

\subsection{Data Description}

This section outlines how we construct the datasets that we use in our empirical analysis, leaving further details to the Data Appendix. First, we explain how we measure the treatment and control

\footnotetext{
${ }^{14}$ According to correspondence with Simon Franklin, from the experience of housing programs in cities such as AddisAbaba, four room apartments (with a bathroom) in five-story buildings entail construction cost of around $\$ 10,000$, plus a further \$3,000-4,000 for infrastructure and administration. This figure excludes land costs.

${ }^{15}$ The TSCP was approved by the World Bank in May 2010 (see http://projects.worldbank.org/P111153/tanzaniastrategic-cities-project?lang=en).

${ }^{16}$ Even cheap land on the city fringes is likely to have some residents, however, and ensuring that de novo programs treat them inclusively is an important issue, which we revisit in the conclusions.
} 
areas. Second, we explain our choice of units of analysis. Third, we explain how we construct the variables that we use in our analysis. Lastly, we discuss summary statistics for key outcomes.

\section{How do we measure treatment and control areas?}

For five of the seven Sites and Services cities (Dar es Salaam, Iringa, Tabora, Tanga, and Morogoro) we have maps showing the program area boundaries (World Bank 1974a,b, 1977a,b, 1984, 1987). For the two remaining cities we use information from local experts (for Mbeya) and other historical maps (for Mwanza), as we explain in the Data Appendix. Tables A1 and A2 list all 24 areas (12 de novo and 12 upgrading) with some information on the data we have on each.

Having defined the treated areas, we now explain how we construct our control areas. In much of our analysis, we use all initially unbuilt (greenfield) land within 500 meters of the boundary of de novo, as control areas. ${ }^{17}$ We exclude areas that were uninhabitable (e.g. off the coast), built up, or designated for non-residential use prior to the start of the Sites and Services projects. In order to infer what had been previously built up, we use historical maps and imagery collected as close as possible to the start of the Sites and Services project, and where possible before its start date, as discussed in the Data Appendix. ${ }^{18}$

To construct control areas for the upgrading areas we similarly use greenfield areas within 500 meters of upgrading; or alternatively 21 slums that were delineated in the 1979 Dar es Salaam Masterplan (Marshall, Macklin, Monaghan Ltd. 1979) and were not upgraded as part of Sites and Services. Comparisons across slums should be taken with caution, since in accordance with the planners' intention to target larger slums (see Section 2), the upgraded slums covered an average area about four times larger than the control slums. Both upgraded and non-upgraded slums, however, had similar initial population densities (195 people per hectare in the upgraded slums and 234 in non-upgraded slums in 1979). Figure A1 shows the de novo, upgrading, and control areas in all seven cities. ${ }^{19}$

Our empirical approach described below assumes that both the de novo and the control areas were unbuilt (greenfields) before the onset of Sites and Services. To provide evidence that this was indeed the case, we use a subsample of the TSCP survey data, which provides construction years for buildings in Mbeya and Mwanza (see Data Appendix). We report results from using these data cautiously, since they involve a fairly small sample and a variable (construction year), which is measured with noise, and only observed for surviving houses. With these caveats in mind, we note that only about 0.5 percent of the housing units in de novo areas and about 1.3 percent of the housing units in the nearby control areas were built before the start of Sites and Services, suggesting that the control and de novo areas were probably very sparsely populated.

\footnotetext{
${ }^{17}$ Note that throughout our paper the control areas always exclude de novo and upgrading areas.

${ }^{18}$ For some of the analysis we also study untreated areas further than 500 meters from the treatment areas, in which case we again excluded areas that were built up before Sites and Services began.

${ }^{19}$ To keep the maps on a fixed and legible scale, we do not show the locations of the non-upgraded slums in Dar es Salaam.
} 


\section{How do we construct the units of analysis?}

Our research design (discussed below) uses as its main units of analysis a grid of $50 \times 50$ meter "blocks", each of which is assigned to novo, upgrading, or control area depending on where its centroid falls. This creates a fine partition of our study area, which allows us to account for empty areas at the block level and within blocks. As we explain below, however, data constraints compel us to conduct some of the analysis at the level of individual housing units, or at the level of 2012 census enumeration areas (EAs) or subunits of EAs (Tanzania National Bureau of Statistics, 2014, 2017).

\section{What are the key variables we measure?}

To study the quality of housing across all 24 Sites and Services locations we use high resolution Worldview satellite images (DigitalGlobe 2016). ${ }^{20}$ We employed a company (Ramani Geosystems) to trace out the building footprints from these data for six of the seven cities. For the final city, Dar es Salaam, we used separate building outlines from a freely available source - Dar Ramani Huria (2016). For all seven cities we then assembled more information on outcomes and control variables, as we explain in the Data Appendix. Here we describe some of the key variables.

For the purpose of measuring private housing quality using imagery data, we think of slums as typically containing small and irregularly laid out buildings, made of low quality materials and with poor access to roads. We therefore define as positive outcomes the opposite of this image of slums: buildings with large footprints, which are regularly laid out, and have good roofs and access to roads. We use three outcomes which we think of as largely reflecting private complementary investments. First is the logarithm of building footprint size, derived directly from the processed imagery. Second, we use the color satellite imagery to assess whether each roof is likely painted, and therefore less prone to rust. Third, we calculate the orientation of each building using the main axis of the minimum bounding rectangle that contains it. We then calculate the difference in orientation between each building and its nearest neighboring building, modulo 90 degrees, with more similar orientations representing a more regular layout. ${ }^{21}$ Finally, we construct an indicator for buildings that are within no more than 10 meters from the nearest road. Unlike the three previous measures, we think of this measure of road access as largely representing persistence of Sites and Services infrastructure investments.

While the imagery and the outcomes we derive from it have the advantage of broad coverage, we complement them with detailed survey data on all the buildings in three of the Sites and Services cities, Mbeya (in southwest Tanzania), Tanga (in northeast Tanzania), and Mwanza (in northwest Tanzania). These data are derived from the TSCP survey, which was conducted from 2010-2013 (World Bank 2010). We use these data to build a more detailed picture of building quality in the

\footnotetext{
${ }^{20}$ The images' resolution is $50 \times 50$ centimeters for greyscale, and a little coarser for color.

${ }^{21}$ When we regress the log hedonic price index (discussed below) on the three imagery measures using a block-level regression, the coefficients on each of the three measures is positive and significant. This provides further support for our use of these measures of housing quality. Where applicable we standardize and pool the three quality measures together to construct a "family of outcomes" z-index (Kling et al. 2007; Banerjee et al. 2015).
} 
areas we study. The TSCP data allow us to identify outbuildings (e.g. sheds, garages, and animal pens), which are generally smaller, and which we exclude from the analysis. ${ }^{22}$ This leaves us with a sample of buildings that are used mostly for residential purposes, although a small fraction may also serve commercial or public uses.

We use the TSCP survey data to measure the logarithm of building footprint, and create indicators for buildings which have more than one story, good (durable) roof materials, connection to electricity, and at least basic sanitation. ${ }^{23}$ These measures likely reflect private investments, since they were not part of the Sites and Services investments. In addition, we measure connection to water mains and having road access as largely reflecting persistence of Sites and Services investments. The TSCP data also provide the full names of owners of housing units, which we use as explained below.

We also use separate TSCP (World Bank 2013) valuation data for Arusha, a city where Sites and Services were not implemented, to construct a hedonic measure of building quality, as we explain in the Data Appendix. ${ }^{24}$ Another separate data source (Tanzanian Ministry of Lands 2012) provides us information about land values in Dar es Salaam, although at a coarser level.

In addition to these variables we construct geographic variables (distance to the nearest shore; an indicator for rivers or streams; and a measure of ruggedness), and other variables, which we use in our analysis below. All these are again explained in the Data Appendix.

We complement all these measures of the physical environment, with some data on people, including indicators for owners (identified by their full name and the city), taken from the TSCP survey, and population density and measures of schooling and literacy, which we calculate from the 2002 and 2012 censuses at the level of enumeration areas. We sometimes split enumeration areas to allocate them across treatment and control areas, as we explain in the Data Appendix.

\section{How do the different areas compare using raw data?}

Table A3 summarizes information on the number of plots and the population density, as of 2002, in de novo and upgrading areas, and their respective control areas. As the table shows, de novo areas were more densely populated than nearby control areas. Upgrading areas were very densely populated, and again denser than control areas near them. As we shall see below, the higher density in upgrading areas did not correspond to more multistory buildings, but in fact the opposite.

Figure A2 shows visual examples of parts of a de novo area, a control area near de novo, and an upgrading area, all in the same district of Dar es Salaam. The differences between the most orderly location (de novo) area and the least orderly one (upgrading) are visibly clear, and the control area

\footnotetext{
${ }^{22}$ Outbuildings account for around $10-30 \%$ of buildings in the areas we consider, where the fraction varies by city. Their mean size is typically around one third that of the average regular building size.

${ }^{23}$ In the de novo, upgrading, and control areas we classify as "basic sanitation" having either a septic tank $(30 \%$ of buildings) or sewerage connection ( $0.5 \%$ of buildings). Not having basic sanitation usually means a pit latrine $(67 \%$ of buildings) or "other" or none. As before, we construct a "family of outcomes" measure based on non-missing observations for each variable.

${ }^{24}$ Our approach of using characteristics linearly in a hedonic regression follows Giglio et al. (2014). There is also some evidence that in the case of housing, using the imputed hedonic values as dependent variables does not lead to much bias in the inference (McMillen et al. 2010 and Diewert et al. 2015).
} 
lies somewhere in between.

The impression that de novo areas have higher quality housing is corroborated in the summary statistics table (Table A4). The imagery data shows that compared to the control areas, de novo areas have buildings with larger footprints, a higher fraction of painted roofs, more regularly laid out buildings, and better access to roads. The survey data shows that de novo areas are also more likely to have multiple stories, good roof materials, connection to electricity, basic sanitation, and connection to water mains, as well as a much higher hedonic value. On almost all these measures, including the fraction of buildings with multiple stories, upgrading areas look worse, and control areas are somewhere in between de novo and upgrading. The log hedonic price differences suggest that on average, de novo housing units are about 63 percent more valuable than those in control areas and about 92 percent more valuable than those in upgrading areas.

\section{Research design and empirical findings}

\subsection{Research design}

The differences in outcomes described in Table A4 suggest that housing quality in de novo areas is considerably better than in control areas. The higher quality of housing in de novo areas reflects both elements that Sites and Services invested in directly, such as roads and water, and elements that it did not, such as electricity. But in order to study whether the de novo investments did in fact crowd in private investments (and if so - how much), we need to move beyond the descriptive statistics, as this section explains.

Our identification strategy compares de novo areas to nearby control areas, which (like de novo areas) were largely empty before the onset of Sites and Services. In our main analysis, we follow Gelman and Imbens (2017), by implementing a semi-parametric regression discontinuity design:

$y_{i}=\beta_{0}+\beta_{1}$ Denovo $_{i}+\beta_{2}$ Dist $_{i}+\beta_{3}$ Dist $_{i} \times$ Denovo $_{i}+\boldsymbol{\beta}_{4}$ Nearest_Denovo $_{i}+\beta_{5}$ Dist_CBD $_{i}+\boldsymbol{\beta}_{6}$ Controls $_{i}+\epsilon_{i}$,

where $y_{i}$ measure various outcomes, as described in Section 2 and the Data Appendix; Denovo $i$ is the main regressor of interest, which indicates whether the centroid of $i$ is in de novo areas, where control areas are the omitted category; Dist $_{i}$ is the distance in kilometers to the boundary between de novo and control areas; Nearest_Denovo $i$ is a vector of fixed effects for the nearest de novo areas; Dist_CBD $D_{i}$ measures the distance in kilometers of unit $i$ from the Central Business District (CBD) of the city in which it is located; Controls ${ }_{i}$ is a vector of additional controls, which we discuss below; and $\epsilon_{i}$ denotes the error term. The role of distance to the central business district is emphasized in many urban economics models (see Duranton and Puga 2015 for an overview), and adding Nearest_Denovo $i$ ensures that we only compare control areas to their nearest de novo area. In our baseline specification, each observation is a 50 x 50 meter block, but later on, as we explain, we also use housing units within buildings and enumeration areas as units of analysis. 
Our baseline analysis uses data from within 500 meters of the boundary between de novo and control areas. Using this fixed distance allows us to analyze all our outcomes across imagery and TSCP survey data (World Bank 2013) consistently. As we discuss further below, 500 meters also turns out to be fairly close to the optimal bandwidth we find for our key outcomes using the survey data. Finally, we also present below alternative specifications using more - and less - data.

In our baseline estimates we cluster the standard errors on $850 \times 850$ meter blocks, following the approach of Bester et al. (2011) and Bleakly and Lin (2012). The size of the blocks on which we cluster reflects the size of the Sites and Services neighborhoods. The median size of the 12 de novo neighborhoods was approximately 0.538 square kilometers, and the median size of all 24 neighborhoods was around 0.718 square kilometers. This last figure is just a little smaller than the area of a square whose sides are 850 meters, which we chose as a conservative benchmark for clustering. ${ }^{25}$

\section{Addressing threats to identification}

Our identification strategy assumes that conditional on the controls in specifications (1), the potential expected outcome functions are continuous at the discontinuity threshold. Our spatial regression discontinuity approach is similar to Dell (2010), and much of our analysis likewise applies a semiparametric RD, which combines both controls, as in equation (1), and a focus on areas that are close to (within 500 meters of) the boundary of de novo and control areas. ${ }^{26}$

One potential concern is that the areas selected for de novo differed in their "first nature" location fundamentals. But in our setting the geographic distances are much smaller than in most other settings, so we are less concerned with larger scale changes in geography, such as climate or soil fertility. Further, in our empirical analysis, we report balancing tests, which use specification (1) to compare the geographic variables as outcomes as we cross the de novo - control boundary. Some of the geographic variables - the land's ruggedness and the presence of rivers or streams - may be endogenous to housing development. Therefore below we report estimates both with and without the geographic controls.

Our identification strategy also assumes that both de novo and control areas were essentially empty (greenfields) before the start of Sites and Services. As we discuss in the Appendix, our classification of areas relies on historical aerial images and topographic maps, which allow us to detect pre-existing buildings. And in Section 2 we provide support for this assumption using a subsample of buildings for which we have construction dates.

Another relevant question is whether administrative boundaries correspond to some of the de novo - control boundaries, leading to different municipal policies on either side of the boundary. To

\footnotetext{
${ }^{25}$ In earlier versions of this paper we also reported specifications using Conley (1999) standard errors with a decay area equal to the size of the above-mentioned blocks, and the results were similar. To mitigate concerns about the variation in neighborhood size, we also experimented with modifying our baseline clustering blocks to treat each Sites and Services neighborhood as a separate clustering unit, with the remainder of the cluster units based on the grid (cut where necessary by the Sites and Services neighborhoods). Once again the estimated standard errors were quite similar.

${ }^{26}$ Since we have variation within several cities, we use functions of distance to the de novo boundary in our main specification, and functions of longitude and latitude only in our robustness checks, as we discuss below.
} 
address this question, we verified that in none of the cases do the boundaries between any treatment areas and the control areas coincide with the ward or district boundaries. ${ }^{27}$

A different type of concern is that there may be spillovers across neighborhoods. ${ }^{28}$ So, for example, it is possible that proximity to de novo areas improves nearby control areas, or that proximity to control areas worsens de novo areas; both would attenuate our estimates. To mitigate this concern we report "doughnut RD" specifications, which exclude bands of 100 meters around the boundary between de novo and control areas. To mitigate a related concern that upgrading areas may be affecting our estimates, we also report specifications, which exclude all blocks within 100 meters of upgrading areas. In a similar vein, since the TSCP data, but not the imagery data, cover entire cities, we also report specifications that use wider control areas, rather than only those near de novo areas. In those cases we use the same specification as in the baseline, but also report some results using second- and third-order polynomials in distance to the boundary. ${ }^{29}$

A related concern is that Sites and Services may have reshaped cities, and even affected the location of their CBD, and the distance to it. To address this concern we report robustness checks, which use distances to historically central locations - mostly railway stations, as discussed in Section 2 and the Data Appendix.

\section{Did Sites and Services create or displace value?}

Another question that we consider is whether Sites and Services created value or merely displaced it. Like many studies of place-based policies, it is difficult for us to answer this question definitively, since we do not have counterfactual cities of similar size, which were untreated by Sites and Services. And even if such cities had existed, one might still have worried about displacement of activity across cities. Nevertheless, our findings below suggest that de novo areas are relatively regularly laid out, and preserve good access to roads. It therefore seems likely that by solving coordination failures they created value and not merely displaced it. ${ }^{30}$

\section{Exploring mechanisms: sorting across neighborhoods and infrastructure persistence}

Our setting allows us to explore another important issue - the role of sorting of owners across neighborhoods. As we discuss above, initial ownership criteria in de novo areas excluded the poorest, and program loans may have further alleviated credit constraints for some of these owners (as well as for some of the owners in upgrading areas). The model characterizes sufficient conditions under which

\footnotetext{
${ }^{27}$ The closest case is Mwanza in 2012, where one district (Nyamangana) cuts into less than a quarter of the control area, while another (Ilemela) contains all of the treatment and most of the control area. However, this boundary was only observed in the 2012 census and not in the 2002 census, so it is almost certainly either unrelated to the Sites and Services project, or an indirect outcome of it. In the 2002 census, Ilemela district fully contained the Mwanza treatment and control areas.

${ }^{28}$ See related discussions in (Turner et al. 2014), Hornbeck and Keniston (2017) and Redding and Sturm (2016).

${ }^{29}$ The full city data also allow us to estimate regressions using an optimal bandwidth (Imbens and Kalyanaraman 2012), which we also report.

${ }^{30}$ As we also discuss below, our findings suggest that Sites and Services not only had positive effects on local land values, they may also have generated positive spillovers on nearby areas, an issue that we revisit in Section 3.
} 
including owner fixed effects overcomes the potential differences in credit constraints of owners who rent out multiple housing units. ${ }^{31}$ We note that renting is fairly common in our setting: as of 2007, renters accounted for a small majority of Dar es Salaam's residents, and over a third of the residents in other urban areas; back in 1992, the share of renters was even higher (Komu 2013).

To shed light on the sorting across neighborhoods of residents, we also use census data to characterize residents by measures of education, which are the best proxies we have for lifetime earnings.

Our model also highlights the role of persistently better infrastructure in de novo neighborhoods as a mechanism for crowding-in investments in housing quality. Empirically, we estimate regressions of the same form of as equation (1), using measures of water connection and access to roads as outcomes, since these closely relate to the investments made in the Sites and Services projects.

\section{Studying upgrading areas}

Finally, we repeat our analysis for upgrading areas, comparing them to proximate control areas, following the procedure outlined above. ${ }^{32}$ Finding appropriate counterfactuals for upgrading areas (which were populated before the program began) is harder than for de novo areas (which were essentially empty). To mitigate concerns about different starting conditions, we also report regressions that compare upgrading areas to 21 other slums that existed in Dar es Salaam in 1979, and which were not upgraded as part of Sites and Services. The slums that were not upgraded were on average smaller in area (see Section 2), but had similar, or even slightly higher, population density in 1979. The comparisons of upgrading areas to non-upgraded slums come with two caveats: first, this analysis is not a spatial RD, since the non-upgraded slums were not adjacent to the upgraded ones, although for consistency we still use specification (1); and these comparisons are only possible for the imagery data, since Dar es Salaam is not covered by the TSCP survey data.

\subsection{Empirical findings}

\section{Balancing tests}

We begin the discussion of our findings by reporting balancing tests on geographic characteristics. As Table A5 shows, when we compare geographic characteristics in de novo areas to nearby control areas, both distance to the shore and ruggedness differ in de novo areas (Panel A), but after including our baseline controls as in equation (1) (Panel B) de novo and control areas look balanced. We also report balancing tests using TSCP data, which also look balanced (with the exception of rivers and streams in the sample adjacent to the de novo areas). We note, however, that rivers and ruggedness may be endogenous to the de novo development, which may have flattened the soil and buried

\footnotetext{
${ }^{31}$ To be precise, we consider a full name as different if it appears in more than one city. In practice this does not seem to make much difference. Since this strategy uses variation within owners, it only employs part of the data, so in this case we need to use control areas from the rest of the city to ensure sufficient variation. We also acknowledge that some units may be owner-occupied, while others may be rented out, but we cannot separate the two with our data.

${ }^{32}$ In upgrading area regressions we measure distance to the upgrading (instead of de novo) - control boundary, and fixed effects for the nearest upgrading (instead of de novo) area.
} 
or diverted some streams. For completeness we report below estimates both with and without the geographic controls.

\section{Crowding in of private investments}

We now turn to our main results. In Table 1 we report estimates using specification (1) and our imagery sample. Panel A shows that de novo areas have footprints that are roughly 12 percent larger and have more regular layout, but their roof quality is not better. The z-index aggregating all three measures indicates that de novo areas have higher quality housing than nearby areas, and other estimates show that they have fewer empty blocks and a higher fraction of their area is built up. ${ }^{33}$ Panel $B$ reports robustness checks for the z-index using geographic controls, longitude and latitude polynomials, an alternative measure of CBDs that predates Sites and Services, and excluding blocks near upgrading areas - all are similar to our baseline estimate. When we use doughnut RD specifications to exclude areas near the boundary of de novo and control the estimates increase somewhat, suggesting that our baseline estimates may be a little attenuated due to spillovers (positive ones from de novo to controls, or negative ones from controls to de novo, or both). This finding also suggests that the higher quality housing in de novo areas may generate positive spillovers on neighboring areas (see Hornbeck and Keniston (2017) and Turner et al. (2014) for related discussions of local spillovers).

In sum, results for all seven cities using the satellite image data suggest that de novo areas have larger and more regularly oriented buildings. To get a more detailed picture of the differences in residential quality we turn to the TSCP survey data for Mbeya, Mwanza, and Tanga. In Panel A of Table 2 we report results again using specification (1). One advantage of the survey data is that unlike the imagery data they allow us to focus on residential buildings by excluding outbuildings, which we do. As Panel A shows, buildings in de novo areas have footprints that are about 50 percent (or $0.41 \log$ points) larger than the control areas. They are also about 23 percentage points (or 48 percent) more likely to be connected to electricity. The regressions also show economically large but statistically imprecise differences in favor of de novo areas in the share of buildings with multiple stories and with at least basic sanitation, but again almost no difference in roof quality.

We aggregate the measures of quality in the survey data in two ways: first using a z-index, and second using the predicted log hedonic value. Regressions using either as an outcome indicate significantly higher residential quality in de novo areas than in control areas. ${ }^{34}$ Specifically, the regressions suggest that the hedonic price is around 56 percent. This may understate the actual differences in house values, since the hedonics do not directly account for all housing characteristics, nor for the full impact of local neighborhoods' infrastructure. Noting this caveat, a result from the model in section 4.4 below suggests that land value differences in de novo (compared to control areas) are about 50 percent larger than house price differences. This result, combined with our hedonic estimates, suggests that land values in de novo areas are at least 86 percent higher than in control areas. To

\footnotetext{
${ }^{33}$ To visualize our results, Panel A of Figure A3 shows a regression discontinuity plot of binned values of the z-index.

${ }^{34}$ Panels B and C of Figure A3 show regression discontinuity plots for the Z-index and log hedonic prices.
} 
interpret this difference, we note that in Dar es Salaam, land values in de novo neighborhoods is in the range of $\$ 160-220$ per square meter (in 2017 prices). ${ }^{35}$ Combined with our estimates above, this suggest that de novo may have increased local land values by at least $\$ 75-100$ per square meter.

These values are high compared to the cost of investments per unit of treated plot area which we estimate above to be no more than $\$ 8$ per square meter of plot area, or no more than $\$ 13$ per square meter if we include indirect costs (in US\$2017). While these estimates should be interpreted with caution, they suggest that the gains from de novo investments were large, at least in Dar es Salaam. That said, we acknowledge that the gains in other cities, where prices are lower, may not be quite as high. ${ }^{36}$

In Panel B of Table 2 we report results from a series of robustness checks, focusing for brevity on the z-index and the log hedonic price. The estimates with geographic controls in column (1) are a little lower than the baseline; this could be either because the baseline regressions overstate the difference due to better geographic fundamentals in de novo location, or that the geographic controls are themselves outcomes and adding them understates the impact of de novo. Columns (2) and (3) show that controlling for the polynomial of longitude and latitude or using distance to historical (instead of contemporary) CBDs makes little difference compared to Panel A. The doughnut specification in column (4) is larger than the baseline, suggesting (as in Table 1) that the baseline estimates may be too small due to positive spillovers from de novo to controls (or negative ones going the other way). Column (5) excludes blocks near upgrading areas, and the results are similar to the baseline. Columns (6) uses control areas from the rest of the city, and the estimates are again larger, possibly because we are comparing de novo areas to a control group that is on average further away, and less affected by local spillovers. ${ }^{37}$ Finally, column (7) uses an optimal bandwidth, following Imbens and Kalyanaraman (2012), and the estimates is again quite similar to the baseline.

The results using hedonic values as outcomes in Panel $\mathrm{C}$ follow a similar pattern, where adding geographic controls reduces the estimate a little, and excluding areas near the boundary increases them a little. The main message, however, is that our baseline estimates are robust to using different specifications.

\section{The role of sorting}

The results discussed so far are silent on the respective role of the de novo treatment and the endogenous sorting across neighborhoods of owners with different levels of credit constraints. As our model below (in Section 4) shows, we can account for differences across areas in owners' credit constraints by adding owner fixed effects, which allow us to isolate the impact of de novo areas compared to control areas for owners with multiple housing units. The units of analysis used in these regressions are individual housing units, since this is the level at which ownership is defined. The housing units

\footnotetext{
${ }^{35}$ The coarse data we have on land values do not separately identify the control areas near de novo.

${ }^{36}$ Unfortunately, our land value data for other cities are either missing or not detailed enough to give a credible picture.

${ }^{37}$ The estimates are robust to using second- and third order polynomials, although in the latter case they are smaller.
} 
we focus on are those owned by owners of multiple units, which account for about 13 percent of all housing units. To ensure a sufficiently large sample, we reestimate specifications as in (1) for the full city TSCP sample, but now focusing on housing units whose owners have more than one unit. Table 3 reports estimates of these regressions with owner fixed effects (Panel A) and without them (Panel B). The estimates show that in this sample, housing units in de novo areas are considerably larger, and much more likely to have electricity and basic sanitation. Without owner fixed effects they also are more likely to be in multistory buildings, although this difference vanishes once we control for owner fixed effects. As reported previously, de novo housing units do not have better roof materials. The difference in quality between de novo and control areas, as reflected in the z-index and the hedonic value, suggests that de novo areas may be about $60 \log$ points (or about 83 percent) more valuable; as discussed above, this may understate the actual differences since it is unlikely to reflect all the amenity differences. Panels $C$ and $D$ of the table report robustness checks for the specifications with and without fixed effects, using the z-index as an outcome. Across a range of specifications reported in Table 3, roughly a third of the quality advantage of de novo areas is accounted for by the different ownership, and the rest likely reflects the impact of de novo on quality for owners who are relatively unconstrained in terms of investment. ${ }^{38}$

The characteristics of residents in de novo areas, compared to control areas, likely reflect their willingness to pay for higher quality housing. In Table A6 we report regressions using 2012 census data with "cut" enumeration areas as units of analysis (see Section 2 and Data Appendix for details). ${ }^{39}$ Consistent with the results discussed above, residents in de novo areas are better educated and more likely to be literate in English. The higher schooling of de novo residents is consistent with sorting across neighborhoods and a higher willingness of the more educated to pay for better housing quality, although it is also possible that some of it is the result of better access to schooling of existing residents. Still, as Table A6 shows, only about 55 percent of adults in de novo areas had more than primary school education, so the other 45 percent had no more than primary school education. This means that many less educated Tanzanians are still benefitting from de novo amenities.

\section{The persistence infrastructure}

To conclude our empirical analysis of the de novo areas, we explore whether their better housing quality corresponds to persistently better infrastructure. Here we focus on two of the main investments in Sites and Services, roads and water mains, and we again use specification (1). As Panel A of Table 4 shows, across both our imagery and TSCP data, de novo areas enjoy better access to roads, and the TSCP data also show that they are more likely to be connected to water mains. ${ }^{40}$ Panels B-D report robustness checks using the same specifications as in Table 2. Again the estimates are a little

\footnotetext{
${ }^{38}$ When we use the hedonic measure as an outcome, the regressions estimates with and without owner fixed effects are more similar to each other (results available on request).

${ }^{39}$ In this case number of units of analysis is small and they are uneven (some are whole EAs and some are cut), which makes it difficult to get a good measure of distance to the boundary. Therefore in these specifications we use nonparametric regression discontinuity, without controls for distance to the boundary.

${ }^{40}$ This last result is robust to excluding Tanga, where we have some uncertainty about the nature of de novo investments.
} 
smaller when we control for geographic covariates, and a little larger when we focus on control areas that are further from de novo, with our main estimates in between. And all the estimates are positive and statistically significant, showing that de novo investments translated into better infrastructure in the long run.

\section{Upgrading areas}

Having discussed the de novo areas, we now briefly discuss what we can learn from similar regressions for upgrading areas. As Table A7 suggests, upgrading areas look fairly similar to nearby control areas in terms of the geographic controls, except that in most specifications they are less likely to have rivers or streams. When compared to the non-upgraded slums, and conditional on our baseline controls, the upgrading areas are closer to the shore but not significantly different in the other two geographic controls (results available on request).

Table A8 reports estimates using imagery data for all seven cities. Panel A suggests that housing quality in upgrading areas is similar to that of nearby control areas. The only significant differences are that upgrading areas have fewer empty areas and are more densely built up. Panel B shows that this conclusion is robust to a range of different specifications.

In Panels C and D we compare upgrading areas in Dar es Salaam only to the preexisting ("old") slums that were not upgraded as part of Sites and Services. Once again the results suggest that upgrading areas are no different, except perhaps in a slightly more regular orientation of buildings than their control areas. Upgrading areas also seem to have fewer empty blocks and a larger fraction of built up area.

Next, in Table A9, we use TSCP survey data outcomes. Here the upgrading areas look somewhat worse than nearby control areas: they have fewer multistory buildings, worse roofs, and possibly worse sanitation, and their overall quality seems lower. This conclusion is reinforced in most of the robustness checks in Panels B and C, although not all the estimates are precise.

In Table A10 we examine the role of ownership in accounting for the worse quality in upgrading areas. The results suggest that ownership differences may partially explain the worse housing quality in upgrading areas, since controlling for owner fixed effects results in estimates that are small and in most cases imprecise.

A comparison of infrastructure persistence measures in upgrading areas may also help to explain why their housing is no better than that of nearby control areas. As Table A11 shows, upgrading areas look similar to nearby areas in their access to roads and water; the coefficients on upgrading areas are small, imprecise, and mostly negative. Adding the coefficients and the control means and comparing them to the estimates in de novo areas (Table 4) suggest that upgrading areas have worse infrastructure than de novo areas. As we discussed in Section 2, upgrading areas did receive roads and water mains, and investments measured in dollars per square meter were similar to those of de novo areas. A likely explanation for the poor state of upgrading areas' infrastructure today is that those areas' infrastructure deteriorated more than that of de novo areas. Kironde (1994, page 
464) and Theodory and Malipula (2012) discuss evidence that infrastructure did in fact deteriorate in upgrading slums in Dar es Salaam. Kironde (1994) mentions, for example, the deterioration of roadside drainage due to lack of maintenance; private construction on land that was intended for public use; and the degradation of water provision infrastructure.

Finally, Table A12 shows that residents of upgrading areas are less educated than those of nearby areas, consistent with the lower housing quality in these neighborhoods.

\section{Model}

\subsection{Assumptions and their relationship to the institutional setting}

To frame our empirical analysis we present a model, which characterizes conditions under which investment in infrastructure (as defined below) incentivizes owners to build higher quality housing. The model captures key aspects to our description of the Sites and Services projects in Section 2. It also connects to our econometric analysis in Section 3, by relating gains in house values to gains in land values, and motivating our use of owner fixed effects to account for owner sorting across neighborhoods. ${ }^{41}$

We consider a population of infinitely lived, profit maximizing owners, with formal or informal rights to build on their plot(s), which are organized into neighborhoods (areas). In each plot, the owner can build a house and rent it out. ${ }^{42}$ The model is in discrete time, and in each period $t \geq 1$, owners maximize their expected present discounted stream of rents, net of house construction costs, on each plot they own:

$$
E\left[\sum_{s=t}^{\infty} \delta^{t}\left[r\left(q_{t}, I_{t}\right)-B_{t} c\left(q\left(I_{t}\right)\right)\right]\right], \text { s.t. } \operatorname{Pr}\left(q_{t+1}=q_{t}\right)=1-d, \operatorname{Pr}\left(q_{t+1}=0\right)=d .
$$

The expectations are defined over the exogenous destruction probability of houses in each period, as discussed below. Owners are assumed to have a time preference $\delta \in(0,1)$. The rent that each owner receives on each house in each period is $r(q, I)=q^{\alpha} I^{1-\alpha}$, where $q$ and $I$ denote the quality of the house and the neighborhood infrastructure, and $\alpha \in(0,1)$. $B_{t}$ is an indicator equal to one if a house is built in period $t$ and zero otherwise. The construction costs of a house of quality $q$ are: $c(q)=c q^{\gamma}$, where $c>0, \gamma>1$. This convex cost function generalizes Hornbeck and Keniston (2017), who assume $\gamma=2$. In a different context, Combes, Duranton and Gobillon (2016) finds that the production function for housing can be approximated by a constant returns to scale Cobb-Douglas

\footnotetext{
${ }^{41}$ Our model builds on Hornbeck and Keniston (2017), but differs from theirs in several ways. We add to the model infrastructure and variation across owners in credit constraints, and we derive new analytical results. We also model spillovers across houses differently, and for simplicity we exclude the exogenous time trends.

${ }^{42} \mathrm{~A}$ "house" in the model denotes is a shorthand for a housing unit that we consider in the empirical analysis. Unlike Bayer et al. (2007), our model does not account for renter heterogeneity, because we have no data on the rents paid and have little information on the residents. Knowing more about renters would have allowed to build a better picture of the welfare gains from de novo areas.
} 
function using land and other inputs, where the coefficient on non-land inputs is approximately 0.65 . Holding land constant, this production function is consistent with a cost function $c(q)=c q^{\gamma}=$ $c q^{1 / 0.65}$, or $\gamma \simeq 1.54$.

Infrastructure captures a broad set of neighborhood characteristics, including formal and regularly laid out plots, which reduce coordination failures and protect owners' property rights; roads, which reduce the cost of travel and trade; and water mains, which contribute to living standards and health. ${ }^{43}$ Infrastructure also reflects other neighborhood level effects. ${ }^{44}$ For tractability, we consider three types of infrastructure: high quality $\left(I_{H}\right)$, medium quality $\left(I_{M}\right)$, and low quality $\left(I_{L}\right)$, where $I_{H}>I_{M}>I_{L}>0$. High quality describes the bundle that Sites and Services offered - mostly formal plots, roads, and water mains. We assume that high quality infrastructure deteriorates to medium quality unless the fraction of high quality housing is larger than a constant $\phi>0 .{ }^{45}$ Medium quality infrastructure is basic and unmaintained (e.g. bumpy dirt roads). It may be either high quality infrastructure that has deteriorated or it may start out as medium quality. We assume that medium quality infrastructure does not deteriorate. ${ }^{46}$ Low quality infrastructure corresponds to the level that prevails without any infrastructure investments in the neighborhood.

There are two types of owners in the model. Unconstrained owners may each own any finite number of plots and afford any level of investment in each plot, while Constrained owners may own no more than a single plot, and may afford to build at most low quality housing $q_{L}=q\left(I_{L}\right)$, as defined below. ${ }^{47}$ Consistent with our setting, we assume that no single owner has a sufficiently large number of plots to exert market power or to solve coordination problems that arise from neighborhood-level externalities. ${ }^{48}$

We consider three types of areas (neighborhoods), each with a continuum of plots. ${ }^{49}$ De novo areas start with empty plots $(q=0)$ and high quality infrastructure $\left(I_{H}\right)$; control areas start with

\footnotetext{
${ }^{43}$ Property rights protection may reduce the risk of outright expropriation, as we discuss below, as well as the risk of partial expropriation, when part of an owner's plot is built without authorization, which we do not model explicitly.

${ }^{44}$ In practice, other types of neighborhood effects may also matter. For example, the absence of proper sewerage may increase the risk of contagious diseases. Consistent with this, Jaupart et al. (2016) show that cholera outbreaks in Dar es Salaam were much more severe in slum areas with poor infrastructure. Another possibility is that neighborhoods with poor electrification and lighting (Painter and Farrington 1997) and high population density (Gollin et al. 2017) may attract crime. While we think that both of these channels could amplify the land value differentials between neighborhoods, we do not have the data to study them in our context.

${ }^{45}$ High quality housing is $q_{H}=q\left(I_{H}\right)$, as defined below. The potential for infrastructure deterioration means that owners' housing quality can be indirectly affected by those of their neighbors, through the effect on infrastructure. This mechanism is different from the direct impact of neighbors' housing quality in Hornbeck and Keniston (2017).

${ }^{46}$ Our assumption that medium infrastructure and deteriorated infrastructure are equal in quality is a simplifying assumption, motivated by our empirical finding that upgrading areas are no better than nearby control areas in terms of access to roads and water. Adding further parameters for deteriorated high quality and deteriorated medium quality infrastructure would not add much insight to the model.

${ }^{47}$ The distinction between two types of owners allows us to analyze owner sorting in a simple way. The results would have been similar if we had assumed that constrained owners could build up to any quality that is strictly lower than $q\left(I_{M}\right)$, as defined below.

${ }^{48}$ Our TSCP data indicate that only a small share of housing units are owned by those with more than a handful of plots. It is true that in principle a rich individual or a firm could buy up an entire neighborhood and internalize the externalities involved. But until recent years the Tanzanian government exerted strict control that prevented the concentration of neighborhood ownership.

${ }^{49}$ Our model does not account for other types of neighborhoods, such as former colonial areas (which typically constitute a small and wealthy part of cities), nor do we consider movements between different neighborhoods within the city.
} 
empty plots and medium quality infrastructure $\left(I_{M}\right)$; and upgrading areas start out with low quality housing $\left(q_{L}\right)$ and high quality infrastructure. ${ }^{50}$ This reflects the situation at the time when Sites and Services was implemented. ${ }^{51}$

The initial fractions of unconstrained owners are: $\theta_{D}$ in de novo areas, $\theta_{C}$ in control areas, and $\theta_{U}$ in upgrading areas. We assume that (as in the real world) upgrading areas are targeted for their relatively poor population, so they have few unconstrained owners, and therefore $\theta_{U}<\phi$.

In every period, the following sequence of events takes place. First, each owner decides whether to build (or rebuild) a house on each plot they own. ${ }^{52}$ Second, if the neighborhood's housing quality is insufficiently high, infrastructure quality deteriorates, as we discuss below. Third, each owner collects the rent on each house they own. Finally, there is an exogenous probability $d>0$ that each house is destroyed, resetting housing quality to zero. ${ }^{53}$

We assume that the risk that houses are destroyed and the fraction of owners of each type in each neighborhood are common knowledge, as is the understanding that all unconstrained owners will build high quality housing if the share of unconstrained owners is at least $\phi$. In Nash Equilibrium, each owner solves her maximization problem in each period, assuming that all other owners do the same.

\subsection{Solving the model}

This section characterizes the optimal level of investment by owners, beginning with unconstrained owners and then by constrained owners.

Unconstrained owners maximize profits on each plot they own by solving the following Bellman equation:

$$
V(q, I)=\operatorname{Max}\left\{\begin{array}{c}
r(q, I)+\delta E[V(q, I)] \\
r(q(I), I)+\delta E[V(q(I), I)]-c(q(I)),
\end{array}\right.
$$

where $r$ is return on house (e.g. rent), $q \geq 0$ is the house quality; $I \geq 0$ is the infrastructure quality which is expected when rents are collected and from that point onward; $q(I)$ is the optimal house quality; and $c(q(I))$ is the cost of building a house of quality $q(I) .{ }^{54}$

\footnotetext{
${ }^{50}$ In Section 2 we discuss the investments that were made as part of the Sites and Services projects. These suggest that though the investment per total land area in de novo and upgrading were similar.

${ }^{51}$ We also note that while the control areas we use were by definition empty to begin with, other areas looked like control areas but had a stock of low quality housing by the time they received infrastructure $I_{M}$.

${ }^{52}$ Following Hornbeck and Keniston (2017) and Henderson et al. (2017), we assume that owners cannot renovate incrementally, and that houses do not depreciate. The assumption that rebuilding a higher quality house requires a fresh start is particularly relevant for low quality housing that characterizes poorer neighborhoods in East African cities. It may be possible to make minor improvements to a house built of tin or mud walls. However, demolition and construction from scratch is required to make meaningful improvements such as adding brick walls, multiple stories, or plumbing. For simplicity, we maintain the assumption that no incremental improvement is possible. Relaxing this would reduce the benefit of early (de novo) investments.

${ }^{53}$ If a house is destroyed, the owner retains their plot. Given the paucity of construction dates in our data, it is difficult to assess $d$. But Henderson et al. (2017) estimate it at 3.2 percent per year using data from Tanzania's neighbor, Kenya.

${ }^{54}$ We could have included a probability $(1-\psi)$ that a plot is fully expropriated at the end of each period. If that were the case we would need to substitute $\psi \delta$ instead of $\delta$ throughout the analysis, but for simplicity we focus on the case without expropriation, namely $\psi=1$. Higher patience may reflect, at least in part, a lower risk of expropriation. Collin et al. (2015) elicit owners' perceived expropriation risk in Temeke, an informal area close to the CBD of Dar es Salaam, which implies
} 
The infrastructure quality which is anticipated when rents are collected and from that point onward is equal to the existing level, except where infrastructure of quality $I_{H}$ deteriorates to $I_{M}$. This deterioration happens when the fraction of high quality housing $\left(q_{H}=q\left(I_{H}\right)\right.$, as described below) is strictly lower than $\phi$.

The model reflects a tradeoff between keeping the current house quality $q$ and improving it to $q(I)$. But if an unconstrained owner's house is exogenously destroyed it is always rebuilt at the optimal quality $q(I)$. Starting from an empty plot, the optimal house quality for an unconstrained owner anticipating infrastructure $I$ at the time of rent collection is:

$$
q(I)=\left[\frac{\alpha I^{1-\alpha}}{\gamma c(1-\delta+d \delta)}\right]^{\frac{1}{\gamma-\alpha}}
$$

The quality of housing is characterized by the following comparative statics. First, $\frac{\partial q(I)}{\partial \delta}>0$, so more patient people invest more. Second, $\frac{\partial q(I)}{\partial d}<0$, so a higher probability of house destruction leads to lower quality housing. And finally, $\frac{\partial q(I)}{\partial c}<0$, so a higher construction cost reduces housing quality.

If an unconstrained owner starts with housing $q_{1} \equiv q\left(I_{1}\right)$ but with infrastructure $I_{2}$ (where $I_{2}>$ $I_{1}$ ), they choose between two options. ${ }^{55}$ They can replace their house with a higher quality house, in which case their expected payoff is equal to the expected value of an unbuilt a plot of land:

$$
\pi\left(0, I_{2}\right)=\frac{q_{2}^{\alpha} I_{2}^{1-\alpha}-c d q_{2}^{\gamma}}{1-\delta}-(1-d) c q_{2}^{\gamma}
$$

where $\pi(q, I)$ is the maximized expected payoff from an existing house of quality $q$ and infrastructure quality $I$. Alternatively, they can keep the current quality $q_{1}$ and only build a better house when their house needs rebuilding. In this case their expected payoff is:

$$
\pi\left(q_{1}, I_{2}\right)=q_{1}^{\alpha} I_{2}^{1-\alpha}+\delta\left[(1-d) \pi\left(q_{1}, I_{2}\right)+d \pi\left(0, I_{2}\right)\right]
$$

Solving this expression we get:

$$
\pi\left(q_{1}, I_{2}\right)=\frac{q_{1}^{\alpha} I_{2}^{1-\alpha}+d \delta \pi\left(0, I_{2}\right)}{1-\delta+d \delta}
$$

Proposition 1 For each level of infrastructure $I_{1}>0$, there exists a unique value $I_{1}^{\text {crit }}=\left(\frac{\gamma}{\gamma-\alpha}\right)^{\frac{\gamma-\alpha}{\alpha(\alpha-1)}} I_{1}$, such that unconstrained owners starting with $q_{1}=q\left(I_{1}\right)$ and infrastructure $I_{2}=I_{1}^{\text {crit }}$ are indifferent between rebuilding and not rebuilding, and owners rebuild if and only if $I_{2}>I_{1}^{\text {crit }}$.

Proof. To obtain $I_{2}=I_{1}^{\text {crit }}$, combine the condition $\pi\left(q_{1}, I_{1}^{\text {crit }}\right)=\pi\left(0, I_{1}^{\text {crit }}\right)$ with (5) and (6), where housing quality $q_{2}=q\left(I_{2}\right)$ comes from (4). To show that owners rebuild if and only if $I_{2}>I_{1}^{\text {crit }}$, note that $\frac{\partial}{\partial I_{2}}\left(\pi_{I_{2}}-\pi_{q_{1}, I_{2}}\right)>0$.

a risk of around $8 \%$ per year. Given the setting, this is likely an upper bound to the perceived expropriation risk in the locations we study.

${ }^{55} \mathrm{We}$ assume that if owners are indifferent they do not improve their houses. 
This result implies that unconstrained owners face what we refer to as an "inaction zone", $\left(I_{1}, I_{1}^{\text {crit }}\right]$. If infrastructure is upgraded from $I_{1}$ to a level in the inaction zone, owners will not improve their house right away, but only when it is exogenously destroyed. But if the infrastructure upgrade is to $I_{2}>I_{1}^{\text {crit }}$, unconstrained owners will rebuild at a higher quality $q_{2}$ right away.

The investment problem for constrained owners is similar to that of unconstrained owners, except that the maximum quality they can build is $q_{L}$. As a result, in equilibrium they build $q_{L}$ if their plot is empty, and otherwise they do not rebuild.

\subsection{Neighborhood development}

\subsubsection{De novo areas}

De novo areas begin empty with infrastructure $\left(I_{H}\right)$. Constrained owners build $q_{L}$, so that the share of low quality houses is $1-\theta_{D}$. If $\theta_{D} \geq \phi$ then there is no deterioration in equilibrium, anticipated infrastructure is $I_{H}$, and the unconstrained owners build $q_{H}$. If $\theta_{D}<\phi$ then there is deterioration in equilibrium, anticipated infrastructure is $I_{M}$, and unconstrained owners build $q_{M}=q\left(I_{M}\right)$. In practice it seems that de novo areas' infrastructure is better than other areas' (Table 4), suggesting that at least some higher quality infrastructure survived.

\subsubsection{Control areas}

Control areas begin empty and with medium quality infrastructure $\left(I_{M}\right)$. Unconstrained owners build housing quality $q_{M}$, while constrained owners build $q_{L}$.

As discussed above, Tanzanian cities also contained areas (which are not part of our main analysis), which are similar to control areas but had a stock of low quality housing by the time they received infrastructure $I_{M}$. In those areas the constrained owners keep $q_{L}$, while the unconstrained owners either build $q_{M}$ right away (if $I_{M}>I_{L}^{\text {crit }}$ ) or otherwise build $q_{M}$ only when their house is destroyed.

\subsubsection{Upgrading areas}

Upgrading areas begin with housing quality $q_{L}$ and infrastructure $I_{H}$, and we consider four different cases. In the first case $I_{L}^{c r i t}>I_{H}$, so the upgrading is minimal and all owners initially keep $q_{L}$, and infrastructure deteriorates to $I_{M}$; in later periods, as houses are exogenously destroyed, unconstrained owners build to $q_{M}$. In the second case $I_{H} \geq I_{L}^{\text {crit }}>I_{M}$ and $\theta_{U}<\phi$, in which case everyone initially keeps $q_{L}$, infrastructure deteriorates to $I_{M}$; and unconstrained owners improve their houses to $q_{M}$ when they are destroyed. In the third case $I_{M} \geq I_{L}^{c r i t}$ and $\theta_{U}<\phi$, in which case unconstrained owners build $q_{M}$ right away while constrained owners keep $q_{L}$, and infrastructure deteriorates to $I_{M}$. In the final case $I_{H} \geq I_{L}^{c r i t}$ and $\theta_{U} \geq \phi$, so unconstrained owners build $q_{H}$ and infrastructure remains $I_{H}$, while constrained owners keep $q_{L}$. But in practice this final case is unlikely to be relevant, because upgrading areas were targeted as poor. 


\subsection{Relating the model to the empirical analysis}

The model demonstrates the role of differing infrastructure investment and owner sorting in accounting for neighborhood quality. For example, consider the following scenario. De novo areas had enough unconstrained owners to ensure that their higher quality infrastructure $\left(I_{H}\right)$ survived. In this case, the difference in the logarithm of mean housing quality between de novo and control areas is:

$$
\ln \left(\theta_{D} q_{H}+\left(1-\theta_{D}\right) q_{L}\right)-\ln \left(\theta_{C} q_{M}+\left(1-\theta_{C}\right) q_{L}\right)
$$

This quality difference reflects both the effect of the higher infrastructure quality in de novo areas and the different composition of owners in those areas. But controlling for owner fixed effects allows us to focus on houses owned by unconstrained owners, for whom the difference in log mean housing quality between de novo and control areas is:

$$
\ln \left(q\left(I_{H}\right)\right)-\ln \left(q\left(I_{M}\right)\right)
$$

In other words, under the model's assumptions, adding owner fixed effects allows us to identify the effect of de novo investments on housing quality for unconstrained owners. We acknowledge that in practice adding owner fixed effects may not solve all the potential problems, if for example some owners are constrained in investing in a second house (but not in the first), or have some different preferences for investing across areas. Nevertheless, the model shows that adding owner fixed effects is useful in the context of Sites and Services, where owners in different areas may have had different levels of wealth, due both to sorting and to the program's loans scheme.

The model also allows us to relate differences in infrastructure and housing quality, which we cannot measure directly, to the estimated differences in the value of housing, which are approximated by the hedonic regressions, subject to the limitations discussed in Section 2. Specifically, our model predicts the following:

Proposition 2 For unconstrained owners who face no risk of exogenous house destruction $(d=0)$

$$
\ln \left(I_{H}\right)-\ln \left(I_{M}\right)=\frac{\gamma-\alpha}{\gamma-\alpha \gamma}\left(\operatorname { l n } \left(\pi\left(q\left(I_{H}\right), I_{H}\right)-\ln \left(\pi\left(q\left(I_{M}\right), I_{M}\right)\right),\right.\right.
$$

and

$$
\ln \left(q\left(I_{H}\right)\right)-\ln \left(q\left(I_{M}\right)\right)=\frac{1}{\gamma}\left(\operatorname { l n } \left(\pi\left(q\left(I_{H}\right), I_{H}\right)-\ln \left(\pi\left(q\left(I_{M}\right), I_{M}\right)\right)\right.\right.
$$

Proof. To derive the expression for $\ln \left(I_{H}\right)-\ln \left(I_{M}\right)$, use (5) and the fact that $\pi\left(q_{2}, I_{2}\right)=\pi\left(0, I_{2}\right)+$ $c\left(q_{2}\right)$, and plug in $d=0$ to obtain $\ln \left(\pi\left(q_{2}, I_{2}\right)\right)=\ln \left(q_{2}^{\alpha} I_{2}^{1-\alpha}\right)-\ln (1-\delta)$. Next apply a similar calculation for $\ln \left(\pi\left(q_{1}, I_{1}\right)\right)$ and plug in (4) to calculate $\ln \pi\left(q_{2}, I_{2}\right)-\ln \left(\pi\left(q_{1}, I_{1}\right)\right.$. Now combine the expression for $\ln \left(I_{H}\right)-\ln \left(I_{M}\right)$ with (4) to derive the expression for $\ln \left(q\left(I_{H}\right)\right)-\ln \left(q\left(I_{M}\right)\right)$.

This result indicates that the difference across areas in log housing quality are smaller than the differences in log values. Taking the above-mentioned estimate of $\gamma$ suggests that the quality differ- 
ences across neighborhoods are about $\frac{1}{\gamma}=0.65$ times the value differences for unconstrained owners, for low values of $d$, which seem empirically relevant. Our baseline estimate of the hedonic log value differences between de novo and control areas, with owner fixed effects, are around 0.5, suggesting $\log$ quality differences of around one third. ${ }^{56}$

The model also allows us to consider differences between upgrading and control areas. As discussed in Section 3, upgrading areas look similar, or in some cases worse than control areas. Table A10 suggests that the worse housing in upgrading areas may in part be explained by owner fixed effects. In the context of the model, this may reflect persistence in upgrading areas of some of the initial owners (or their descendants), who were targeted by the program, and may have been poorer than their counterparts in control areas $\left(\theta_{U}<\theta_{C}\right)$.

Finally, the similarity of housing quality in upgraded and non-upgraded slums is also consistent with the model, if we think of the non-upgraded slums as control areas with constrained owners.

\subsection{Implications of the model}

The model offers several implications for thinking about infrastructure investments for housing. First, an important theme of the paper is that infrastructure investment may crowd in private investments. The model helps us to think about the conditions under which this takes place. In the model, infrastructure investments crowd in more private investments when its quality is sufficiently high and owners can afford to invest in housing quality. In these cases, private investment in housing quality takes place when there is a sufficient fraction of unconstrained owners, either due to their own wealth or through loans that allow them to invest. This also suggests a note of caution: if de novo investments were expanded widely, poor and credit constrained residents may be unable to make full use of them, since infrastructure may deteriorate without sufficient complementary private investment.

Second, the model helps us think about the benefits of early infrastructure investments compared to ex-post infrastructure upgrading. Upgrading areas do not always fully benefit from high levels of infrastructure investments, since in those settings infrastructure either deteriorates or leads to the scrapping of existing houses. ${ }^{57}$

Finally, turning back to our empirical findings, the model can help explain why infrastructure survived better in de novo areas, but not in upgrading areas. The model highlights the importance of feedback from owner investments to infrastructure, which can be seen as a neighborhood externality, and is sometimes overlooked when infrastructure investments are made.

\footnotetext{
${ }^{56}$ As discussed in Section 2, the log value differences in the hedonic regressions may understate the actual value differences.

${ }^{57}$ In reality there are other costs of delivering infrastructure in a dense settlement that has developed organically, because it is difficult to resolve coordination failures and negative externalities once they have been put in place. In Sites and Services, for example, the cost per square meter was similar in de novo and upgrading areas, even though de novo areas received formal plots, which upgrading areas did not.
} 


\section{Concluding Remarks}

This paper examines the consequences of different strategies for developing basic infrastructure for residential neighborhoods. Specifically, we study the Sites and Services projects implemented in seven Tanzanian cities during the 1970s and 1980s. These projects provided basic infrastructure, leaving it to the residents to build their own houses. We examine the long run development of these neighborhoods, emphasizing the comparison between de novo neighborhoods and other nearby areas that were greenfields when the Sites and Services program started. We also provide descriptive evidence on the development of neighborhoods whose infrastructure was upgraded.

We use high-resolution imagery and building level survey data to study housing quality and infrastructure in the de novo neighborhoods and other areas in their vicinity that were also greenfields to begin with. We find that the de novo neighborhoods developed significantly higher quality housing than other initially unbuilt areas. Our findings reflect complementary private investments that were made in response to the Sites and Services programs. We also present evidence that the initial infrastructure investments in roads and water mains were more likely to persist in de novo areas. For three cities where we have survey data, we find sizeable gains in quality from de novo even when we control for owner fixed effects, although these fixed effects account for up to a third of the average housing quality. Our findings suggest that de novo areas increased local land values by at least 75-100 USD per square meter, compared to total costs of no more than 8-13 USD per square meter (all in 2017 prices).

We also report evidence that de novo neighborhoods attract more educated residents, who can afford to pay for the higher quality on offer. But as of 2012 almost half of the adults in de novo areas still had no more than primary school education, suggesting that some people with lower lifetime incomes also benefitted from the de novo investments. But we also note that de novo areas were unaffordable to the poorest of the urban poor, a consideration that future projects may want to take into account, perhaps by creating some smaller and more affordable plots. Such plots may also benefit the few people who may be displaced by such projects, even when they target largely empty areas.

Our paper also reports descriptive evidence on upgrading areas, comparing them to nearby control areas, or where the data permit to slums that were not upgraded. The results suggest that upgrading areas now have either similar, or worse, housing quality, and the program's investments in roads and water mains did not survive well in upgrading areas. While we should be cautious in interpreting these results, they suggest that upgrading, at least as implemented in Sites and Services, was not a panacea for pre-existing squatter areas. We cannot rule out that other upgrading efforts may be prove more successful, but in order to provide long lasting benefits, upgrading programs should aim to address the risk of infrastructure deterioration.

Taken together, our findings suggest that de novo investments are a policy tool worthy of consideration for growing African cities. They are considerably cheaper than building public housing, and 
therefore more affordable for poor countries. They also offer important advantages to residents, who can invest in higher quality housing. Our findings also suggest that it is important to ensure that the infrastructure investments do not deteriorate as a result of poor private investments. While the implementation of Sites and Services projects in Tanzania in the 1970s and 1980s was not flawless, it has taught us important lessons. We hope that these lessons can inform future planning and investment decisions in a continent that is growing in both population and income per capita, but where many poor people still live in poor quality buildings and neighborhoods.

\section{References}

Ali, Daniel Ayalew, Matthew Collin, Klaus Deininger, Stefan Dercon, Justin Sandefur, and Andrew Zeitlin. 2016. "Small Price Incentives Increase Women's Access to Land Titles in Tanzania." Journal of Development Economics, 123: 107-122.

Angel, Shlomo. 2012. Planet of Cities. Lincoln Institute of Land Policy

Ali, Daniel Ayalew, Matthew Collin, Klaus Deininger, Stefan Dercon, Justin Sandefur, and Andrew Zeitlin. 2016. "Small Price Incentives Increase Women's Access to Land Titles in Tanzania." Journal of Development Economics, 123: 107-122.

Banerjee, Abhijit, Esther Duflo, Rachel Glennerster, and Cynthia Kinnan. 2015. "The Miracle of Microfinance? Evidence from a Randomized Evaluation." American Economic Journal: Applied Economics, 7(1): 22-53.

Bayer, Patrick, Fernando Ferreira, and Robert McMillan. 2007. "A Unified Framework for Measuring Preferences for Schools and Neighborhoods", Journal of Political Economy, 115(4): 588-638

Bester, C Alan, Timothy G Conley, and Christian B Hansen. 2011. "Inference with Dependent Data Using Cluster Covariance Estimators." Journal of Econometrics, 165(2): 137-151.

Bleakley, Hoyt, and Jeffrey Lin. 2012. "Portage and Path Dependence." The Quarterly Journal of Economics, 127(2): 587-644.

Brinkhoff, Thomas. 2017. "City Population." https://www.citypopulation.de (accessed May 25, 2017).

Buckley, Robert M, and Jerry Kalarickal. 2006. Thirty Years of World Bank Shelter Lending: What Have We Learned? Washington, DC:World Bank Publications.

Castells-Quintana, David. 2017. "Malthus Living in a Slum: Urban Concentration, Infrastructure and Economic Growth." Journal of Urban Economics, 98: 158-173.

Cohen, Michael, Callisto E. Madavo, and Harold Dunkerley. 1983. "Learning by Doing: World Bank Lending for Urban Development 1972-82."

Collin, Matthew, Justin Sandefur, and Andrew Zeitlin. 2015. "Falling off the Map: The Impact of Formalizing (Some) Informal Settlements in Tanzania." Centre for the Study of African Economies Working Paper, University of Oxford. 
Combes, Pierre-Philippe, Gilles Duranton, and Laurent Gobillon (2016), “The Production Function for Housing: Evidence from France", IZA discussion Paper No.1037

Conley, Timothy G. 1999. "GMM Estimation with Cross Sectional Dependence." Journal of Econometrics, 92(1): 1-45.

Coville, Aidan, and Yu-hsuan Su. 2014. "From the Ground Up: An Impact Evaluation of the Community Infrastructure Upgrading Programme in Dar-es-Salaam." World Bank, mimeo.

Dar Ramani Huria. 2016. "Community-Based Mapping Project in Dar-es-Salaam."

http:/ / ramanihuria.org/data/ (accessed May 25, 2017).

Dell, Melissa. 2010. "The persistent effects of Peru's mining mita." Econometrica 78(6): 1863-1903.

Diewert, W. Erwin, Jan de Haan, and Rens Hendriks. 2015. "Hedonic regressions and the decomposition of a house price index into land and structure components." Econometric Reviews 34(1-2): 106-126.

DigitalGlobe. 2016. "Worldview Satellite Imagery."

Directorate of Overseas Surveys. 2015. "Aerial Imagery and Topographic maps from 1:2,500 to 1:50,000."

Duranton, Gilles and Diego Puga. 2015. "Urban Land Use", Chapter 8 in Handbook of Regional and Urban Economics, Volume 5, 467-560

Duranton, Gilles and Anthony J. Venables. 2020. "Place-based Policies foe Development." in Handbook of Regional Science, Manfred Fisher and Peter Nijkamp (eds) Springer-Verlag, Berlin.

Epple, Dennis, Brett Gordon, and Holger Sieg. 2010. “Drs. Muth and Mills Meet Dr. Tiebout: Integrating Location-Specific Amenities into Multi-Community Equilibrium Models", Journal of Regional Science, 50(1): 381-400

Field, Erica. 2005. "Property Rights and Investment in Urban Slums." Journal of the European Economic Association, 3(2-3): 279-290.

Franklin, Simon. 2020. "Enabled to Work: The Impact of Government Housing on Slum Dwellers in South Africa." Journal of Urban Economics, forthcoming

Freire, Maria E, Somik Lall, and Danny Leipziger. 2014. "Africa's Urbanization: Challenges and Opportunities." The Growth Dialogue, 1-30.

Galiani, Sebastian, Paul J. Gertler, Raimundo Undurraga, Ryan Cooper, Sebastian Martinez, and Adam Ross. 2016. "Publisher's note on Shelter from the storm: Upgrading housing infrastructure in Latin American slums." Journal of Urban Economics, 96: 166-194.

Galiani, Sebastian, and Ernesto Schargrodsky. 2010. "Property Rights for the Poor: Effects of Land Titling." Journal of Public Economics, 94(9): 700-729.

Gelman, A and G Imbens. 2017. "Why High-Order Polynomials Should Not Be Used in Regression Discontinuity Designs" Journal of Business and Economic Statistics 37(4): 447-456.

Giglio, Stefano, Matteo Maggiori, and Johannes Stroebel. 2014. "Very long-run discount rates." Quarterly Journal of Economics 130(1): 1-53. 
Gollin, Douglas, Martina Kirchberger, and David Lagakos. 2017. "In Search of a Spatial Equilibrium in the developing world," NBER Working Paper \#23916.

Gollin, Douglas, Remi Jedwab, and Dietrich Vollrath. 2016. "Urbanization with and without Industrialization." Journal of Economic Growth, 21(1): 35-70.

Harari, Mariaflavia, Maisy Wong. 2017. "Long-term Impacts of Slum Upgrading: Evidence from the Kampung Improvement Program in Indonesia." Mimeo.

Henderson, J Vernon, Anthony J Venables, Tanner Regan, and Ilia Samsonov. 2016. "Building Functional Cities." Science, 352(6288): 946-947.

Henderson, J Vernon, Tanner Regan, and Anthony J Venables. 2017. "Building the City: Urban Transition and Institutional Frictions." Centre for Economic Policy Research Discussion Paper 11211.

Hornbeck, Richard, and Daniel Keniston. 2017. "Creative Destruction: Barriers to Urban Growth and the Great Boston Fire of 1872". American Economic Review 107(6): 1365-1398.

Imbens, Guido, and Karthik Kalyanaraman. 2012. "Optimal bandwidth choice for the regression discontinuity estimator." Review of Economic Studies 79(3): 933-959.

IPUMS International. 2017. “Tanzania Population Census 2012"

https:/ /international.ipums.org/international/ (accessed June 20, 2017)

Jaupart, Pascal, Ying Chen, and Nathalie Picarelli. 2017. "Cholera in times of floods. Weather shocks \& health impacts in Dar es Salaam". Manuscript

Jean, Neal, Marshall Burke, Michael Xie, W Matthew Davis, David B Lobell, and Stefano Ermon. 2016. "Combining Satellite Imagery and Machine Learning to Predict Poverty." Science, 353(6301): 790-794.

Kironde, J M Lusugga. 1991. "Sites-and-Services in Tanzania: The Case of Sinza, Kijitonyama and Mikocheni Areas in Dar-es-Salaam." Habitat International, 15(1-2): 27-38.

Kironde, J M Lusugga. 1992. "Creations in Dar-es-Salaam and Extensions in Nairobi: The Defiance of Inappropriate Planning Standards." Cities, 9(3): 220-231.

Kironde, J M Lusugga. 1994. "The Evolution of the Land Use Structure of Dar es Salaam 18901990: A Study in the Effects of Land Policy." PhD dissertation, University of Nairobi.

Kironde, J M Lusugga. 2015. "Good Governance, Efficiency and the Provision of Planned Land for Orderly Development in African Cities: The Case of the 20,000 Planned Land Plots Project in Dar es Salaam, Tanzania." Current Urban Studies, 3: 348-367.

Kling, Jeffrey R, Jeffrey B Liebman, and Lawrence F Katz. 2007. "Experimental Analysis of Neighborhood Effects." Econometrica, 75(1): 83-119.

Komu, Felician. 2013. "Rental Housing in Tanzania: Power and Dialects of Misidentification." Journal of Building and Land Development, ppecial issue: 29-41.

Laquian, Aprodicio A. 1983. "Sites, Services and Shelter - an Evaluation." Habitat International, 7(5-6): 211-225.

Libecap, Gary D. and Dean Lueck. 2011. "The Demarcation of Land and the Role of Coordinating Property Institutions." Journal of Political Economy, 119(3): 426-467 
Lupala, J, J Malombe, and A Könye. 1997. "Evaluation of Hanna Nassif Community-Based Urban Upgrading Project Phase I." Government of Tanzania/UNDP/NIGP/Ford Foundation/ILO Evaluation Mission Team Report, Dar-es-Salaam.

Manara, Martina and Tanner Regan. 2019. "Eliciting demand for title deeds: Lab-in-the-field evidence from urban Tanzania"

Marshall, Macklin, Monaghan Ltd. 1979. The Dar-es-Salaam Master Plan: Main Report - Five Year Development Programme. Toronto, Canada.

McMillen, Daniel P., and Christian L. Redfearn. 2010. "Estimation and hypothesis testing for nonparametric hedonic house price functions." Journal of Regional Science 50(3): 712-733.

Marx, Benjamin, Thomas M Stoker, and Tavneet Suri. 2019. "There is no Free House: Ethnic Patronage in a Kenyan Slum." American Economic Journal: Applied Economics 11, no. 4 (2019): 36-70.

Marx, Benjamin, Thomas Stoker, and Tavneet Suri. 2013. "The Economics of Slums in the Developing World." The Journal of Economic Perspectives, 27(4): 187-210.

Mayo, Stephen K, and David J Gross. 1987. "Sites and Services and Subsidies: The Economics of Low-Cost Housing in Developing Countries." The World Bank Economic Review, 1(2): 301-335.

Mwanza City Municipality. 1973. "Mwanza Cadastral Maps".

Minnesota Population Center. 2017. "Integrated Public Use Microdata Series, International: Version 6.5 [dataset]." Minneapolis: University of Minnesota.

Montenegro, Claudio E. and Harry Anthony Patrino. 2014. Comparable Estimates of Returns to Schooling Around the World. World Bank Policy Research Working Paper 7020

National Oceanic and Atmospheric Administration. National Geophysical Data Center. 2012. "Version 4 DMSP-OLS Nighttime Lights Time Series."

https://ngdc.noaa.gov/eog/dmsp/downloadV4composites.html (accessed May 22, 2017).

OpenStreetMap 2017. https: / / www.openstreetmap.org/

Owens, Kathryn. 2012. "Enabling Sustainable Markets? The Redevelopment of Dar-es-Salaam." Unipublished.

Painter, K., \& Farrington, D. P. 1997. "The crime reducing effect of improved street lighting: The Dudley project." Situational crime prevention: Successful case studies, 2, 209-226.

Redding, Stephen J, and Daniel M Sturm. 2016. "Estimating Neighborhood Effects: Evidence from War-time Destruction in London." Princeton University, mimeograph.

Romer, Paul. 2010. "Technologies, Rules, and Progress: The Case for Charter Cities." Center for Global Development Essay.

Romer, Paul. 2012. "Urbanization as Opportunity", unpublished, http:/ / www.oecd.org/cfe/regionalpolicy/Urbanization\%20as\%20Opportunity\%20-\%20Paul\%20Romer.pdf

Rossi-Hansberg, Esteban, Pierre-Daniel Sarte, and Raymond Owens III. 2010 "Housing externalities." Journal of Political Economy 118(3): 485-535.

United States Geological Survey. 2015. "Declassified Satellite Imagery from 1960-1972." United States Geological Survey, Reston, VA. 
Tanzania Ministry of Lands. 2012. "Rates Land Value Mikoa (Regions) 10 2012."

Tanzania National Bureau of Statistics. 2011. "Tanzania Population and Housing Census 2002."

Tanzania National Bureau of Statistics. 2014. "Tanzania Population and Housing Census 2012."

Tanzania National Bureau of Statistics. 2017. “2012 Census Shapefiles (machine readable data files)"

Theodory, T. F., \& Malipula, M. M. (2012). Supplying Domestic Water Services to Informal Settlements in Manzese, Dar es Salaam: Challenges and Way Forward.

Tiba , A. D., G. Mwarabu, W.H. Sikamkono, H. Kenekeza, S.R. Sarehe, V. Mwakalinga, and V. Fyito .2005. The Implication of 20,000 Plots Project on the Emerging form of Dar es Salaam City. MSc Semester Project, Dar es Salaam: Department of Urban Planning and Management, UCLAS, UDSM.

Turner, Matthew A., Andrew Haughwout, and Wilbert Van Der Klaauw. 2014. "Land use regulation and welfare." Econometrica 82(4): 1341-1403.

UN Habitat. 2012. State of the World's Cities 2012/2013: Prosperity of cities.

United Nations, Economic and Social Affairs, Population Division. 2015. "World Population Prospects."

World Bank. 1974a. "Appraisal of National Sites and Services Project." Report No. 337a-TA, Washington, DC: Urban Projects Department.

World Bank. 1974b. "Development Credit Agreement between United Republic of Tanzania and International Development Association (Conformed Copy)." Credit No. 495 TA, Washington, DC.

World Bank. 1977a. "Development Credit Agreement between United Republic of Tanzania and International Development Association (Conformed Copy)." Credit No. 732 TA, Washington, DC.

World Bank. 1977b. "Tanzania: The Second National Sites and Project." Report No. 1518a-TA, Washington, DC: Urban Projects Department.

World Bank. 1984. "Completion Report: Tanzania - First National Sites and Services Project." Report No. 4941, Washington, DC: Eastern Africa Regional Office.

World Bank. 1987. "Tanzania: The Second National Sites and Project." Report No. 6828, Washington, DC: Operations Evaluation Department.

World Bank. 2010. "Project Appraisal Document for a Tanzania Strategic Cities Project." Report No. 51881-TZ, Washington, DC: Urban and Water Department.

World Bank. 2013. "Tanzania Strategic Cities Project Housing Survey". Produced by President's Office - Regional Administration and Local Government. 
Main Tables

Table 1: De novo Regressions using Imagery Data for all Seven Cities

\begin{tabular}{|c|c|c|c|c|c|c|}
\hline & (1) & (2) & (3) & (4) & (5) & (6) \\
\hline & $\begin{array}{c}\text { Mean } \\
\text { log } \\
\text { building } \\
\text { footprint } \\
\text { area }\end{array}$ & $\begin{array}{l}\text { Share of } \\
\text { buildings } \\
\text { with } \\
\text { painted } \\
\text { roof }\end{array}$ & $\begin{array}{c}\text { Mean } \\
\text { similarity } \\
\text { of } \\
\text { building } \\
\text { orien- } \\
\text { tation }\end{array}$ & $\begin{array}{c}\text { Mean } \\
\text { z-index }\end{array}$ & $\begin{array}{c}\text { Share of } \\
\text { empty } \\
\text { blocks }\end{array}$ & $\begin{array}{c}\text { Share of } \\
\text { area } \\
\text { built up }\end{array}$ \\
\hline \multicolumn{7}{|c|}{ Panel A: 500m bandwidth } \\
\hline De novo & $\begin{array}{c}0.114 \\
(0.051)\end{array}$ & $\begin{array}{l}-0.013 \\
(0.012)\end{array}$ & $\begin{array}{c}2.821 \\
(0.722)\end{array}$ & $\begin{array}{c}0.168 \\
(0.057)\end{array}$ & $\begin{array}{l}-0.152 \\
(0.037)\end{array}$ & $\begin{array}{c}0.094 \\
(0.013)\end{array}$ \\
\hline Observations & 6,562 & 6,500 & 6,562 & 6,562 & 8,440 & 8,440 \\
\hline \multirow[t]{2}{*}{ Mean (control) } & 4.457 & 0.184 & -8.669 & 0.042 & 0.306 & 0.155 \\
\hline & Geography & $\begin{array}{l}\text { Lat-Long } \\
2^{\text {nd }} \text { Poly. }\end{array}$ & $\begin{array}{l}\text { Historical } \\
\text { CBD }\end{array}$ & $\begin{array}{l}\text { Doughnut } \\
100 \mathrm{~m}\end{array}$ & $\begin{array}{l}\text { Exclude } 100 \mathrm{~m} \\
\text { to Upgrade }\end{array}$ & \\
\hline \multicolumn{7}{|c|}{ Panel B: robustness (mean z-index only as outcome) } \\
\hline De novo & $\begin{array}{c}0.143 \\
(0.053)\end{array}$ & $\begin{array}{c}0.156 \\
(0.057)\end{array}$ & $\begin{array}{c}0.168 \\
(0.057)\end{array}$ & $\begin{array}{c}0.241 \\
(0.100)\end{array}$ & $\begin{array}{c}0.175 \\
(0.059)\end{array}$ & \\
\hline Observations & 6,562 & 6,562 & 6,562 & 4,568 & 6,158 & \\
\hline Mean (control) & 0.042 & 0.042 & 0.042 & 0.015 & 0.047 & \\
\hline
\end{tabular}

Notes: This table reports estimates from regressions using specification (1) and block level observations with outcomes derived from imagery for all seven Sites and Services cities. The sample includes the de novo areas and control areas within 500 meters of their boundary. The outcomes are measures of housing quality that do not reflect direct investments in de novo areas. Each observation is a block based on an arbitrary grid of 50x50 meter blocks. Blocks are assigned to de novo or control areas based on where their centroid falls. Outcomes are derived from the set of buildings with a centroid in the block (see Data Appendix for further details). In Panel A the outcomes vary, while in Panel B the dependent variable in all columns is the z-index (composed of all outcomes in columns (1)-(3) in Panel A). In each specification the regressor of interest is de novo, and the control variables include a linear control in distance to the de novo-control area boundary interacted with the de novo indicator, fixed effects for the nearest de novo area, and distance to the Central Business District (CBD) of each city. In addition, in Panel B, column (1) includes geographic controls, column (2) includes a second order polynomial in longitude and latitude, column (3) uses distance to historical (instead of contemporary) CBDs, column (4) excludes areas within 100 meters of the boundary between de novo and control areas, and column (5) excludes areas within 100 meters of the boundary between upgrade and control areas. Standard errors, in parentheses, are clustered by arbitrary $850 \times 850$ meter grid squares, corresponding to the median size of Sites and Services areas. There are 90 clusters, except in columns (5) and (6) of Panel A, which have 92 clusters, and column (4) of Panel B, which has 89 clusters, and column (5) of Panel B, which has 88 clusters. 
Table 2: De novo Regressions using TSCP Survey Data for Mbeya, Mwanza, and Tanga

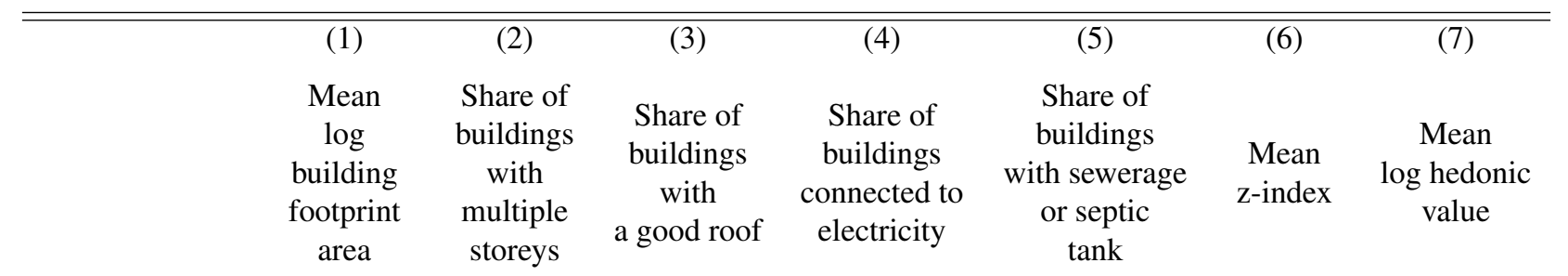

Panel A: 500m bandwidth

\begin{tabular}{|c|c|c|c|c|c|c|c|}
\hline De novo & $\begin{array}{c}0.405 \\
(0.070)\end{array}$ & $\begin{array}{c}0.081 \\
(0.066)\end{array}$ & $\begin{array}{l}-0.010 \\
(0.008)\end{array}$ & $\begin{array}{c}0.226 \\
(0.039)\end{array}$ & $\begin{array}{c}0.142 \\
(0.091)\end{array}$ & $\begin{array}{c}0.342 \\
(0.091)\end{array}$ & $\begin{array}{c}0.446 \\
(0.081)\end{array}$ \\
\hline Observations & 2,009 & 1,975 & 2,009 & 2,009 & 2,008 & 2,009 & 2,009 \\
\hline \multirow[t]{2}{*}{ Mean (control) } & 4.739 & 0.096 & 0.984 & 0.466 & 0.381 & 0.033 & 17.234 \\
\hline & Geography & $\begin{array}{l}\text { Lat-Long } \\
2^{\text {nd }} \text { Poly. }\end{array}$ & $\begin{array}{l}\text { Historical } \\
\text { CBD }\end{array}$ & $\begin{array}{c}\text { Doughnut } \\
100 \mathrm{~m}\end{array}$ & $\begin{array}{l}\text { Exclude } 100 \mathrm{~m} \\
\text { to Upgrade }\end{array}$ & Full City & $\begin{array}{c}\text { Optimal } \\
\text { bandwidth }\end{array}$ \\
\hline \multicolumn{8}{|c|}{ Panel B: robustness (mean z-index only as outcome) } \\
\hline De novo & $\begin{array}{c}0.263 \\
(0.091)\end{array}$ & $\begin{array}{c}0.323 \\
(0.076)\end{array}$ & $\begin{array}{c}0.342 \\
(0.090)\end{array}$ & $\begin{array}{c}0.408 \\
(0.190)\end{array}$ & $\begin{array}{c}0.375 \\
(0.093)\end{array}$ & $\begin{array}{c}0.588 \\
(0.079)\end{array}$ & $\begin{array}{c}0.312 \\
(0.082)\end{array}$ \\
\hline Observations & 2,009 & 2,009 & 2,009 & 1,410 & 1,887 & 34,602 & 34,602 \\
\hline Mean (control) & 0.033 & 0.033 & 0.033 & 0.001 & 0.022 & -0.149 & 0.038 \\
\hline \multicolumn{8}{|c|}{ Panel C: robustness (mean log hedonic value only as outcome) } \\
\hline De novo & $\begin{array}{c}0.329 \\
(0.081)\end{array}$ & $\begin{array}{c}0.431 \\
(0.059)\end{array}$ & $\begin{array}{c}0.446 \\
(0.077)\end{array}$ & $\begin{array}{c}0.541 \\
(0.190)\end{array}$ & $\begin{array}{c}0.427 \\
(0.077)\end{array}$ & $\begin{array}{c}0.505 \\
(0.089)\end{array}$ & $\begin{array}{c}0.411 \\
(0.063)\end{array}$ \\
\hline Observations & 2,009 & 2,009 & 2,009 & 1,410 & 1,887 & 34,602 & 34,602 \\
\hline Mean (control) & 17.234 & 17.234 & 17.234 & 17.231 & 17.229 & 17.113 & 17.239 \\
\hline
\end{tabular}

Notes: This table reports estimates from regressions using specification (1) and block level observations with outcomes derived from TSCP survey data for the three cities where these data exist: Mbeya, Mwanza, and Tanga. The sample includes the de novo areas and control areas within 500 meters of their boundary. The outcomes are measures of housing quality that do not reflect direct investments in de novo areas. Each observation is a block based on an arbitrary grid of 50x50 meter blocks. Blocks are assigned to de novo or control areas based on where their centroid falls. Outcomes are derived from the set of buildings with a centroid in the block (see Data Appendix for further details). In Panel A the outcomes vary, while in Panel B the dependent variable in all columns is the z-index (composed of all outcomes in columns (1)-(5) in Panel A), and in Panel C the dependent variable is the predicted log value from hedonic regressions. In each specification the regressor of interest is de novo, and the control variables include a linear control in distance to the de novo-control area boundary interacted with the de novo indicator, fixed effects for the nearest de novo area, and distance to the Central Business District (CBD) of each city. In addition, in Panels B and C, column (1) includes geographic controls, column (2) includes a second order polynomial in longitude and latitude, column (3) uses distance to historical (instead of contemporary) CBDs, column (4) excludes areas within 100 meters of the boundary between de novo and control areas, column (5) excludes areas within 100 meters of the boundary between upgrade and control areas, column (6) changes the control area to the sample of blocks covering the whole city excluding de novo areas, and column (7) uses 2033 observations inside the optimal bandwith for panel B and 1882 observations inside the optimal bandwith for panel C based on Imbens and Kalyanaraman (2012). The 'Full City' in column (6) is robust to higher order polynomials in distance to boundary: In panel B: second order polynomial gives an estimate of 0.571 and standard error of 0.087 , and third order polynomial gives an estimate of 0.381 and standard error of 0.098. In panel C: second order polynomial gives an estimate of 0.498 and standard error of 0.104 , and third order polynomial gives an estimate of 0.296 and standard error of 0.117 . The control mean in column (7) reports the mean for the control areas inside the optimal bandwidth (Imbens and Kalyanaraman 2012). Standard errors, in parentheses, are clustered by arbitrary $850 \times 850$ meter grid squares, corresponding to the median size of Sites and Services areas. There are 29 clusters, except in column (5) of Panels B and C, which has 28 clusters, and column (6) of Panels B and C, which has 439 clusters. 
Table 3: De novo Regressions using TSCP Survey Data for Mbeya, Mwanza, and Tanga with Owner Name Fixed Effects

(1)

(3)

(4)

(5)

(6)

(7)

$\log$

building Multistorey Good

footprint building roof

area

Panel A: Full City, Owner FE

De novo

0.553
$(0.145)$

0.119

$-0.002$

0.417

(0.078)

$(0.062)$

Observations

20,177

16,605

0.164

20,054

20,139

0.968

0.404

Connected

to

electricity
Sewerage or septic tank
Z-index

Log hedonic value

Panel B: Full City, no Owner FE, same sample as A

\begin{tabular}{cccccccc}
\multicolumn{1}{c}{ De novo } & 0.594 & 0.514 & -0.010 & 0.405 & 0.122 & 0.642 & 0.612 \\
& $(0.177)$ & $(0.138)$ & $(0.015)$ & $(0.066)$ & $(0.069)$ & $(0.086)$ & $(0.185)$ \\
& & & & & & & \\
Observations & 20,177 & 16,605 & 20,054 & 20,139 & 19,595 & 20,177 & 20,177 \\
Mean (control) & 4.573 & 0.164 & 0.968 & 0.404 & 0.249 & -0.016 & 17.016
\end{tabular}

$\begin{array}{ccccccc} & \text { Lat-Long } & \text { Historical } & \text { Doughnut } & \text { Exclude } 100 \mathrm{~m} & \text { Second Order } & \text { Third Order } \\ \text { Geography } & 2^{\text {nd }} \text { Poly. } & \text { CBD } & 100 \mathrm{~m} & \text { to Upgrade } & \text { Polynomial } & \text { Polynomial }\end{array}$

Panel C: robustness owner FE (z-index only as outcome)

$\begin{array}{lccccccc}\text { De novo } & 0.422 & 0.411 & 0.434 & 0.336 & 0.471 & 0.431 & 0.372 \\ & (0.085) & (0.092) & (0.087) & (0.166) & (0.093) & (0.112) & (0.140) \\ & & & & & & & \\ \text { Observations } & 20,177 & 20,177 & 20,177 & 19,694 & 19,729 & 20,177 & 20,177 \\ \text { Mean (control) } & -0.016 & -0.016 & -0.016 & -0.019 & -0.018 & -0.016 & -0.016\end{array}$

Panel D: robustness, no owner FE, same sample as C (z-index only as outcome)

\begin{tabular}{lcccccccc}
\multicolumn{1}{c}{ De novo } & 0.616 & 0.648 & 0.631 & 0.654 & 0.675 & 0.674 & 0.627 \\
& $(0.086)$ & $(0.089)$ & $(0.084)$ & $(0.134)$ & $(0.102)$ & $(0.081)$ & $(0.092)$ \\
& & & & & & & \\
Observations & 20,177 & 20,177 & 20,177 & 19,694 & 19,729 & 20,177 & 20,177 \\
Mean (control) & -0.016 & -0.016 & -0.016 & -0.019 & -0.018 & -0.016 & -0.016 \\
\hline \hline
\end{tabular}

Notes: This table reports estimates from regressions using specification (1) and unit level observations with outcomes derived from TSCP survey data for the three cities where these data exist: Mbeya, Mwanza, and Tanga. The sample includes the de novo areas and the entire city as control areas. The outcomes are measures of housing quality that do not reflect direct investments in de novo areas. Each observation is a property unit in a building, and only multi-unit owners are used. Units are assigned to de novo or control areas based on where their building's centroid falls. Outcomes are measured at the building level (see Data Appendix for further details). In Panels A and B the outcomes vary, while in Panels C and D the dependent variable in all columns is the z-index (composed of all outcomes in columns (1)-(5) in Panel A). Panels A and C display results with unit owner last name fixed effects, including units inside de novo and control areas but restricting the sample by keeping only last name owners that appear more than once in the sample. Panel B (D) displays results with the same sample as in A (C) but without owner last name fixed effects. In each specification the regressor of interest is de novo, and the control variables include a linear control in distance to the de novo-control area boundary interacted with the de novo indicator, fixed effects for the nearest de novo area, and distance to the Central Business District (CBD) of each city. In addition, in Panels C and D, column (1) includes geographic controls, column (2) includes a second order polynomial in longitude and latitude, column (3) uses distance to historical (instead of contemporary) CBDs, column (4) excludes areas within 100 meters of the boundary between de novo and control areas, column (5) excludes areas within 100 meters of the boundary between upgrade and control areas, and columns (6) and (7) control for second and third order polynomials in distance to the boundary, respectively. Standard errors, in parentheses, are clustered by arbitrary $850 x 850$ meter grid squares, corresponding to the median size of Sites and Services areas. There are 342 clusters, except in column (2) of Panels A and B and in columns (4) and (5) of Panels C and D, which all have 341 clusters. 
Table 4: De novo Regressions on Persistence Measures using Imagery and TSCP Survey Data

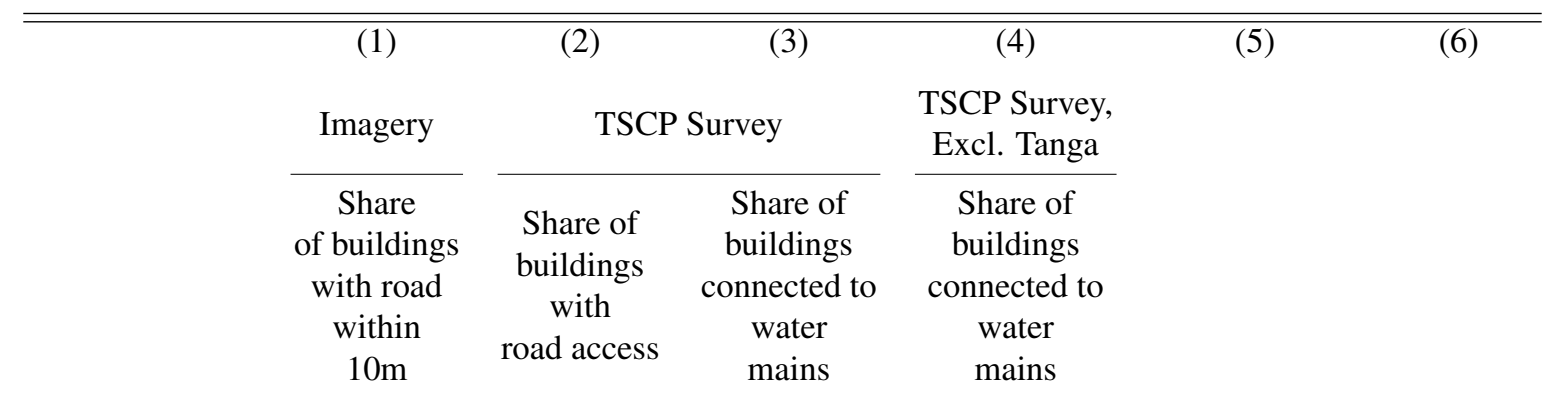

Panel A: 500m bandwidth

\begin{tabular}{lccccc}
\multicolumn{1}{c}{ De novo } & 0.141 & 0.197 & 0.211 & 0.233 & \\
& $(0.028)$ & $(0.050)$ & $(0.057)$ & $(0.060)$ & \\
Observations & 6,562 & 2,008 & 2,009 & 1,952 & \\
Mean (control) & 0.202 & 0.477 & 0.547 & 0.547 & \\
& & & & & \\
& & & & & \\
& Geography & Lat-Long & Historical & Doughnut & Exclude $100 \mathrm{~m}$ \\
& & $2^{\text {nd }}$ Poly. & CBD & $100 \mathrm{~m}$ & to Upgrade
\end{tabular}

Panel B: robustness for share of buildings with road within 10m (Imagery)

\begin{tabular}{cccccc}
\multicolumn{1}{c}{ De novo } & 0.129 & 0.142 & 0.142 & 0.185 & 0.150 \\
& $(0.025)$ & $(0.029)$ & $(0.028)$ & $(0.056)$ & $(0.029)$ \\
Observations & 6,562 & 6,562 & 6,562 & 4,568 & 6,158 \\
Mean (control) & 0.202 & 0.202 & 0.202 & 0.205 & 0.197
\end{tabular}

$\begin{array}{cccccc}\text { Geography } & \text { Lat-Long } & \text { Historical } & \text { Doughnut } & \begin{array}{c}\text { Exclude } 100 \mathrm{~m} \\ \text { to Upgrade }\end{array} & \text { Full City } \\ & 2^{\text {nd }} \text { Poly. } & \text { CBD } & 100 \mathrm{~m} & \text { to Upgon }\end{array}$

Panel C: robustness for share of buildings with road access (TSCP)

\begin{tabular}{ccccccc}
\multicolumn{1}{c}{ De novo } & 0.134 & 0.190 & 0.199 & 0.191 & 0.206 & 0.170 \\
& $(0.039)$ & $(0.049)$ & $(0.050)$ & $(0.159)$ & $(0.051)$ & $(0.056)$ \\
& & & & & & \\
Observations & 2,008 & 2,008 & 2,008 & 1,409 & 1,886 & 34,578 \\
Mean (control) & 0.477 & 0.477 & 0.477 & 0.485 & 0.449 & 0.573
\end{tabular}

Panel D: robustness for share of buildings connected to water mains (TSCP)

\begin{tabular}{lcccccc}
\multicolumn{1}{c}{ De novo } & 0.164 & 0.188 & 0.209 & 0.319 & 0.204 & 0.403 \\
& $(0.060)$ & $(0.051)$ & $(0.057)$ & $(0.128)$ & $(0.062)$ & $(0.042)$ \\
& & & & & & \\
Observations & 2,009 & 2,009 & 2,009 & 1,410 & 1,887 & 34,588 \\
Mean (control) & 0.547 & 0.547 & 0.547 & 0.535 & 0.534 & 0.433 \\
\hline \hline
\end{tabular}

Notes: This table reports estimates from regressions using specification (1) and block level observations with outcomes derived from imagery for all seven Sites and Services cities (road within 10m) and TSCP survey data for Mbeya, Mwanza, and Tanga (road access and connection to water mains). The sample includes the de novo areas and control areas within 500 meters of their boundary. The outcomes are measures of persistence of infrastructure treatment. Each observation is a block based on an arbitrary grid of 50x50 meter blocks. Blocks are assigned to de novo or control areas based on where their centroid falls. Outcomes are derived from the set of buildings with a centroid in the block (see Data Appendix for further details). In Panel A the outcomes vary, while in Panel B the dependent variable in all columns is the share of buildings with a road within 10 meters (from imagery data), in Panel C the dependent variable in all columns is the share of buildings with road access (from TSCP data), and in Panel D the dependent variable is the share of buildings connected to water mains (from TSCP data). In each specification the regressor of interest is de novo, and the control variables include a linear control in distance to the de novo-control area boundary interacted with the de novo indicator, fixed effects for the nearest de novo area, and distance to the Central Business District (CBD) of each city. In addition, in Panels B, C and D, column (1) includes geographic controls, column (2) includes a second order polynomial in longitude and latitude, column (3) uses distance to historical (instead of contemporary) CBDs, column (4) excludes areas within 100 meters of the boundary between de novo and control areas, and column (5) excludes areas within 100 meters of the boundary between upgrade and control areas. Moreover, in Panels C and D, column (6) changes the control area to the sample of blocks covering the whole city excluding upgrade areas. Standard errors, in parentheses, are clustered by arbitrary $850 x 850$ meter grid squares, corresponding to the median size of Sites and Services area. There are 29 clusters in TSCP data, except in column (5) of Panels C and D, which have 28 clusters, and in column (6) of Panels C and D, which have 439 clusters. There are 90 clusters in imagery data, except in column (4) of Panel B which has 88 clusters, and column (5) of Panel B which has 89 clusters. 


\title{
For Online Publication - Data Appendix for: Planning Ahead for Better Neighborhoods: Long Run Evidence from Tanzania
}

\author{
Guy Michaels (LSE) Dzhamilya Nigmatulina (LSE) Ferdinand Rauch (Oxford) \\ Tanner Regan (LSE) Neeraj Baruah (LSE) Amanda Dahlstrand (LSE)
}

This data appendix is organized as follows. We begin by describing the Sites and Services projects, the nature of the treatment, selection of the treated areas, and how the de novo plots were allocated. We then explain how we measure the treatment and control areas in the seven cities. We then describe the three main datasets: the first comes from imagery data; the second from the Tanzania Strategic Cities Project Survey (TSCP, World Bank 2013); and the third comes from 2012 Tanzanian census micro data. Finally, we discuss other auxiliary datasets, including: geographic variables; additional census data; land values data; data on project costs; and population data for 2002. Finally, we explain how we make currency conversions.

\section{Project Background and Treatment}

\section{Background}

The Sites and Services projects were implemented in seven Tanzanian cities. The projects treated 12 de novo areas (greenfield investments) and 12 slum upgrading areas (involving the upgrading of squatter settlements). The projects were rolled out in two rounds. The first round was implemented from 1974-1977, with infrastructure construction taking place in 1975-1976; and the second round was implemented from 1977-1984, with infrastructure construction taking place from 1980-1984. In the First Round, the World Bank treated the northwest of Dar es Salaam (Kinondoni district) and Mbeya with both de novo and upgrading and Mwanza with de novo investment only. In the Second Round the two types of treatment took place in the southeast of Dar es Salaam (Temeke district), Tanga, Tabora, Morogoro and Iringa. The number of de novo and upgrading plot surveyed in each round is reported in Table A3. ${ }^{58}$ Details of the projects are discussed in World Bank (1974a,b, 1977a,b, 1984, and 1987).

Sites and Services projects in Tanzania fell into two broad classes. The first involved de novo development of previously unpopulated areas. The second involved upgrading of pre-existing squatter settlements (sometimes referred to as "slum upgrading").

\footnotetext{
${ }^{58}$ An additional upgrade was planned for the area Hanna Nassif in Dar es Salaam, but it was not implemented as part of Sites and Services. This area was nevertheless upgraded later on in a separate intervention (Lupala et al. 1997), but it is excluded from our analysis. Two additional areas, Mbagala and Tabata, were considered for the Second Round of Sites and Services, but it appears that they were eventually excluded from the project (World Bank 1987 and Kironde 2017).
} 
We provide a more detailed breakdown of the project costs below, but we note that among the infrastructure costs, the two main components were roads and water mains, and the cost of surveying the plots formal de novo plots was also important. Other investments, which covered public buildings (schools, clinics, and markets) were minor parts of the overall scheme. ${ }^{59}$ It is also unlikely that access to these services ends discontinuously at the program boundaries, so our regression discontinuity design should mitigate any effect from such services. The indirect costs of the project mainly consisted of loans, which we discuss below. Taken together, it seems that roads, water mains, and plot surveys were the most relevant elements of the program. The roads and water mains were implemented in both de novo and upgrading, but the formal plots were only implemented in de novo areas. $^{60}$

In addition to the three elements discussed above, both de novo and upgrading areas received a small number of public buildings, which were designated as schools, health clinics, and markets. While these could have had an impact, we think that they matter less than the plots, the roads and the water. First, the total cost of the public buildings was lower than both the roads and the water mains (separately); and second, even if Sites and Services received more buildings than other areas, there is no evidence that access to those facilities ended discontinuously at the project boundaries, which is relevant for the empirical strategy that we explain below. And some Sites and Services residents were offered loans, which were not fully repaid. We think of these loans as relaxing some owners' budget constraints, so we explain in the main body of the paper our strategy for addressing this channel.

The control areas (see more details below) mostly developed in an informal way. We have traced back the history of the control areas near de novo using various reports, at least for Dar es Salaam, whose urban evolution seems better documented. For example, according to the 1968 Dar Masterplan (Project Planning Associates Ltd. 1968) the De-novo control areas appear to be "Vacant land and land used for agriculture", and according to the 1979 Dar Masterplan (Marshall, Macklin, Monaghan Ltd. 1979), the de-novo areas are not indicated as being squatted; by the late 1980s, however, it seems that all the control areas have some unplanned sections (Kironde 1994). Finally, the Transport Policy and System Development Master Plan (Dar es Salaam City Council 2008) in Dar indicates all de-novo, control and upgrading areas as "built up" by 1992. But we note that our data gives a more disaggregated picture on the extent of built up area, and it appears that at this more fine-grained resolution not all the control areas were built up.

For the six secondary cities in which Sites and Services projects were implemented, we have not found evidence that any parts of the control areas were made formal under any planning scheme. In Dar es Salaam, however, Kironde (1994) documents that one planning scheme (Mbezi Beach) took place after the Sites and Services project. While we do not have precise maps, looking at present-day neighborhood boundaries this planned area may overlap with around 10-15\% of our control area in

\footnotetext{
${ }^{59}$ The first round buildings public buildings were also surrounded by street lighting.

${ }^{60}$ The Second Round investments were generally lower, and for one of the de novo areas (the one in Tanga), we have some uncertainty as to the extent of infrastructure that was actually provided (World Bank 1987).
} 
Dar es Salaam. For the Mbezi scheme it seems that there was very little, if any, government provision of infrastructure, at least in the initial stages. As we discuss in the paper, however, eventually it seems that some investments in water mains and roads were made, but these were modest at best.

\section{Treatment and Control Areas}

We use a variety of historical maps and imagery from satellites and aerial photographs to define the exact boundaries of treatment and control areas. For Dar es Salaam, Iringa, Tabora, Tanga, and Morogoro, the World Bank Project Appraisals (World Bank, 1974a and World Bank, 1977b) provide maps with resolutions from 1:10,000 to 1:30,000 of the planned boundaries of the upgrading and de novo sites. In Dar, two maps were available, from 1974 and 1977, differing slightly for Mikocheni area. For all the areas except Tandika and Mtoni, we used the 1974 map, which appeared more precise. However, for Tandika and Mtoni we had to use the 1977 map, since these areas were not covered by the 1974 map.

For the two remaining cities, Mbeya and Mwanza, the maps from the project appraisal were unavailable. Therefore, for Mbeya we asked three experts to draw the boundaries of treatment. These experts were Anna Mtani and Shaoban Sheuya from Ardhi University, who both worked on the first round of Sites and Services project, and Amulike Mahenge from the Ministry of Land, who was the Municipal Director in Mbeya.

To delineate the treatment areas in Mwanza we obtained from the city municipality cadastral maps, dating back to 1973, at a resolution of 1:2,500. Since in Mwanza the treatment included only de novo plots, the cadastral map was sufficient to get the information for the intended treatment areas. We define the treatment area as covering the numbered plots that were of a size that (approximately) fitted the project descriptions (288 square meters); we also include public buildings into the treatment areas, to be consistent with the procedure in other cities. This procedure gives us a comprehensive picture of the twelve de novo and twelve upgrading neighborhoods across all seven cities.

To define our control areas, along with the historical World Bank maps from the Appraisal reports (World Bank, 1974a and World Bank, 1977b), we use historical topographic maps, and satellite and aerial images taken just before the dates of the treatment. We assign all undeveloped ("greenfield") land within 500 meters of any treatment border to our set of control areas. However, as we explain in more detail below, we exclude areas that were either designated for non-residential use, or that were developed prior to treatment, or that are uninhabitable. Our rationale for looking at greenfield areas as controls because we want a clear counterfactual for the de novo areas. We have no "natural" counterfactual for the upgraded squatter areas, because we do not observe untreated squatter areas in the vicinity. The 500 meter cut-off reduces the risk of substantial heterogeneity in locational fundamentals. As part of our analysis we also focus on areas that are even closer to the boundaries between areas.

In order to know what had been previously developed, we used historical maps or imagery as close in time to the treatment date as we could find. We used all planned treatment maps. These in- 
clude the 1974 and 1977 maps for Dar es Salaam and the 1977 maps for Morogoro, Iringa, Tanga and Tabora (World Bank 1987); the 1973 cadastral map of Mwanza (Mwanza City Municipality, 1973); satellite images from 1966 (United States Geological Survey 2015); aerial imagery from 1978 for Tabora and topographic maps from 1967, 1974, and 1978 for Tabora, Iringa and Morogoro (Directorate of Overseas Surveys 2015). ${ }^{61}$ All areas (with some minor exceptions described below) were covered by at least one source. Satellite images and maps also confirm that the areas designated as de novo were indeed unbuilt before the Sites and Services program was implemented.

We use all these data to determine which areas within 500 meter of Sites and Services areas to exclude from our baseline control group. Our rules for exclusion from the control areas are as follows. First, we exclude areas that were planned for non-residential use. These were indicated on the planned treatment map for industrial or governmental use. Second, we exclude areas that were developed before the Sites and Services projects began. These were either indicated as houses or industrial areas on topographic maps, or visibly built in the historical satellite images. Third, we exclude uninhabitable areas, for example, those off the coast. Finally, in the case of Mwanza (where we had to infer the treatment areas) we applied additional criteria for exclusion. In this case we exclude large numbered plots and all unnumbered plots, which do not seem to fit the description of de novo plots. We also exclude areas where the treatment areas are truncated at the edge, since we do not know where the exact boundary of treatment is. In this case we drew rectangles perpendicular to the map edge where the treatment area is truncated, and exclude the area within them. ${ }^{62}$ Further details on defining exclusion areas in each city are outlined in Table A13.

It is possible that some of the areas that were unbuilt in 1966 were built up from 1966 until the start of Sites and Services. But from partial evidence on construction dates in the TSCP data for two cities - Mbeya and Mwanza - it seems that only a very small share (about 1.3 percent) of the buildings with construction dates in control areas near de novo were built before 1974.

Our treatment maps (Figure A1) show upgrading, de novo and control areas, as well as excluded areas. Moreover, with these appropriately defined control areas net of excluded locations, we can analyze present day outcomes using boundaries between control areas and de novo areas, and between control areas and upgrading areas.

We also note that for some of the analysis using the TSCP survey data (more below) we also used data further than 500 meters from Sites and Services. For the three Sites and Services cities with TSCP data (Mbeya, Mwanza, and Tanga), we used imagery from 1966 to exclude areas that were built up at the time.

\footnotetext{
${ }^{61}$ The resolutions of these maps range from 1:2,500 to $1: 50,000$.

${ }^{62} \mathrm{We}$ include in the baseline control areas (minor) areas where there is no pre-treatment data, because they are very sparse and are located near other empty areas.
} 


\section{Allocation of de novo plots}

Plots were allocated to beneficiaries according whose i) houses were demolished in the upgrading areas ii) income was in the range of 400-1000 Tanzanian shilling (Tsh) a month. The income range was meant to target the 20th-60th percentiles of countrywide incomes (Kironde, 1991). According to project completion reports (World Bank 1984 and World Bank, 1987), between 50\% and 70\% of all project beneficiaries belonged to the target population. There was some evidence (World Bank, 1987) that a number of more affluent individuals obtained some of the plots after they had not been developed by initial beneficiaries.

\section{Outcome Variables Derived from Imagery Data}

A summary of the outcome variables we construct using the imagery data can be found in Table A14. Here we provide more detail on some of the key variables.

\section{Buildings}

To study the quality of housing we use Worldview satellite images (DigitalGlobe 2016), which provide greyscale data at resolution of approximately 0.5 meters along with multispectral data at a resolution of approximately 2.5 meters. ${ }^{63}$ We employed a company (Ramani Geosystems) to trace out the building footprints from these data for six of the seven cities. For the final city, Dar es Salaam, we used building outlines from a different, freely available, source - Dar Ramani Huria (2016). ${ }^{64}$

We derive the following indicators of building quality using the building outlines: the logarithm of building footprint, building orientation relative to its neighbors and, finally the distance to the nearest road using ArcGIS tools.

For block outcomes we average each measure and indicator to get averages and shares. To do that, we begin with an arbitrary grid of $50 \times 50$ meter blocks. If a block is divided between de novo, upgrading, and control areas, we attribute the block to the area where its centroid lies. Finally, we match into each block the buildings whose centroids fall within it. This allows us to additionally measure three variables: the share of built up area in the block, the count of buildings in a block and whether the block is empty.

\section{Roofs}

To study the quality of roofs, we use the same Worldview satellite images as we did for the building outcomes above. Our aim was to separate painted roofs (which are less prone to rust) from unpainted

\footnotetext{
${ }^{63}$ The images were taken at different dates: Iringa (2013), Mbeya (2014), Morogoro (2012), Mwanza (2014), Tabora (2011), Tanga (2012) and there are two separate images for two districts in Dar es Salaam: Kinondoni (2015) and Temeke(2014)

${ }^{64}$ We have checked a sample of buildings traced out from the imagery data to the buildings in the TSCP survey data. Incidence of splitting or merging of buildings are fairly rare, occurring around 10 percent of the time, and more so in slum areas. This may also be in part due to a gap of a few years between the datasets. Therefore splitting or merging of buildings does not seem like much of a problem, especially when we focus on de novo areas.
} 
tin roofs (rusted or not), in order to get a measure for roof quality that captures more variation than the TSCP survey indicator for good quality roofs. The cut-off between painted and unpainted roofs was chosen also because we had evidence from our initial field investigation that the painted roofs are considerably more expensive.

To this end, we create an algorithm through which ArcGIS and Python can separate painted from unpainted roofs for each satellite image of the seven Sites and Services cities. Before running the algorithm, we created unique color bins which would identify each type of roof material. These bins are three-dimensional sections of the red-green-blue space that correspond to different colors, which we think of as either painted roofs (e.g. painted red, green, or blue ${ }^{65}$ ) or unpainted ones (e.g. tin, rusted, and bright $\operatorname{tin}^{66}$ ). We defined the bins through a process of sampling pixels from each roof material type, identifying the color bins to which the pixels belong, and iteratively narrowing the bins for each roof type until they were mutually exclusive. Since each satellite image was slightly different in terms of sharpness, brightness and saturation, we sampled pixels from each image and created city-specific bands.

The algorithm is then applied to each city with its unique color bins. The algorithm works by reading the values of the color spectrum for red, green and blue of each pixel of a roof, and comparing these values to the above-mentioned unique bands of the color spectrum identifying painted, rusted and tin roofs. We assign to each roof the color bin that contains the plurality of pixels, and this indicates whether we classify it as a painted roof or not.

\section{Roads}

For all seven cities we used road data from Openstreetmap (2017). We had to clean these data in some locations using ArcGIS and Python, so that we only use roads that seem wide enough for a single car to pass through (we eliminated "roads" between buildings that were less than one meter apart). Following this automated procedure, we cleaned the road data manually to identify roads that appear passable to a single car.

\section{Tanzanian Strategic Cities Project Survey Data}

For three cities, Mbeya (in southwest Tanzania), Tanga (in northeast Tanzania), and Mwanza (in northwest Tanzania) we have detailed building-level data from the Tanzanian Strategic Cities Project (TSCP) which is a World Bank project implemented by the Prime Minister's Office of Regional Administration and Local Government (World Bank 2010). These surveys were carried out by the Tanzanian government from 2010-2013. We use these data to build a more detailed picture of building

\footnotetext{
${ }^{65}$ Apart from red, green and blue we also had a bin for brown painted roofs in Kinondoni, since only in that image we noticed a large number of painted roofs that had a brown color, either due to image particularities or geographically varying preferences for brown painted roofs.

${ }^{66}$ In Iringa and Mwanza we did not have the category bright tin since the particularities of the image or the conditions of the day when the image was taken resulted in other roofs than tin also being very bright in these cities.
} 
quality in the areas we study. Table A15 summarizes the key outcome variables that we derive from the TSCP data. Here we explain in more detail some of the issues relating the to dataset and how we use it.

The data arrived in raw format, with multiple duplicated records of each building and unit and many of these duplicate observations with missing data. We used the following rules to identify the unique observations. Buildings are identified by 'Building Reference Numbers' (BRN) and building units by BRN-units.

\section{Rules for Excluding Buildings}

1. Drop exact duplicates. i.e. if multiple buildings have all the same variables (including IDs) only keep one of them (dropped 1,202,669 observations).

2. Of all remaining observations with a duplicate BRN, drop all where all 'variables of interest' are missing. Variables of interest are an extensive list and comprise much more than what is used in the analysis of this paper (dropped 166,131 observations).

3. Of all remaining observations with a duplicate BRN, keep the observations with strictly more non-missing variables of interest (dropped 12,842 observations).

4. Of all remaining observations with a duplicate BRN, rank by 'information provider' and keep the observations with a strictly higher rank (dropped 15,486 observations).

5. Of all remaining observations with a duplicate BRN, for a set of observations with the same BRN, replace with missing all variables where the records are inconsistent. For example, if there are two observations with the same BRN and both have ' 2 ' for number of stories there is no inconsistency. But if one has ' 1 ' number of rooms while the other has ' 2 ': replace the number of rooms with missing for both.

6. Of all remaining observations with a duplicate BRN all duplicate BRNs will have exactly the same records, keep only one record for each BRN (dropped 27,483 observations).

7. There are no longer any duplicate BRNs. We drop 35,912 unique buildings from the records that do not match a building in one of the city shapefiles of building footprints.

8. We drop 38,180 buildings from the records that are coded as outbuildings.

9. We drop 596 buildings that do not match to a unit.

10. Finally, we are left with 119,914 buildings all with at least one corresponding unit.

\section{Rules for Excluding Building Units}

1. Drop exact duplicates, for example, if multiple units have all the same variables (including IDs) only keep one of them (dropped 1,288,430 observations). 
2. Of all remaining observations with a duplicate BRN-unit, drop all where all variables of interest are missing. Variables of interest are an extensive list and comprise much more than what is used in the analysis of this paper (dropped 221,134 observations).

3. Of all remaining observations with a duplicate BRN-unit, keep the observations with strictly more non-missing variables of interest (dropped 6,383 observations)

4. Of all remaining observations with a duplicate BRN-unit, for a set of observations with the same BRN-unit, replace with missing all variables with mismatched records within the set. i.e. if there are two observations with the same BRN-unit and both have ' 2 ' for number of toilets: do nothing, if one has ' 1 ' number of rooms while the other has ' 2 ': replace the number of rooms with missing for both.

5. There are no longer any duplicate BRN-units. We drop 32,322 units from the records that do not match a building in one of the city shapefiles of building footprints.

6. We drop 3,216 units from the records that are coded as outbuildings.

7. We do not need to drop any more units, since all remaining units match to a building.

8. Finally, we are left with 154,734 units all with a corresponding building.

From the building data set we exclude all buildings categorized as "Outbuildings" (sheds, garages, and animal pens). This leaves us with a sample of buildings that are used mostly for residential purposes, although a small fraction also serve commercial or public uses.

For these buildings in analysis we use the logarithm of building footprint; connection to electricity; connection to water mains; having at least basic sanitation (usually a septic tank and in rare cases sewerage); having good (durable) roof materials; having more than one story; and having road access.

\section{Hedonic Values}

To calculate hedonic building values we use an auxiliary TSCP dataset covering 57,136 buildings from Arusha, which is not one of the seven Sites and Services cities, but is the only one for which we have valuation data at the level of individual buildings. Specifically, we have valuations for 6,837 buildings. The buildings for which we have valuations are concentrated near the city center.

The intention of the valuations is to determine the rateable value (annual rental value of a property) of each property as a basis for collecting property tax. This is estimated by professional valuers under a set of formal guidelines. The valuer is given building-level characteristics, a photograph of the property, and where possible, property transaction records (see figure below). The valuer uses these inputs along with a standard set of guidelines that give bounds on how much each characteristic of the building is worth, but ultimately makes a subjective valuation of the property based on the information provided. 
Of the valued buildings, 3,663 also have building-level characteristics (log area, electricity, and indicators for good sanitation, good roof, and multi-story) from the TSCP survey. We use these to perform hedonic regressions and make out-of-sample predictions of the valuations in the three TSCP cities (Tanga, Mbeya, and Mwanza) where Sites and Services was implemented. For buildings in our out-of-sample prediction that are missing some, but not all, characteristics we fill these missing values with the average of their respective characteristic. Consequently, 6 percent of the buildings with hedonic values in our TSCP dataset have had missing data filled for at least one of their characteristics.

The results of the hedonic regressions are shown in Table A16. ${ }^{67}$ Buildings with larger footprints, electricity connection, and some sanitation, have higher hedonic values; conditional on these factors, roof materials and multistory buildings are uncorrelated with value, perhaps due to the sample size.

\subsection{Construction Dates}

For two cities (Mbeya and Mwanza) we have building dates for less than 10 percent of the housing units in the de-novo and control areas within 500 meters. In absolute terms, this means we have construction dates for 215 de novo units and 300 control units close to the boundary. In both cities the de-novo areas were part of Round 1, so the infrastructure was built from 1975-76, and for both we have pre-treatment imagery from 1966. According to the TSCP data, the fraction of units that existed as of 2013 that were built before 1975 was 0.5 percent in de-novo and ( 1 of the 215 units with construction dates) 1.3 percent (4 of the 300 units with construction dates) in control areas close to the boundary. Admittedly these data are imperfect, and some buildings may have been replaced over time, but the data do not suggest that old buildings that pre-date the Sites and Services are a major concern.

\section{Outcomes in 2012 Tanzanian Census Micro Data Extract}

This extract was obtained through a contact from Tanzanian Census Bureau. Unlike the Tanzanian census data, which can be obtained online at IPUMS (2017), these data are at the level of individuals. We match these census observations from this extract to geographical areas using EA identifiers in the census extract. Using shapefiles of EAs (with the same identifiers) from the Tanzanian Census 2012, also obtained from the same contact, we match the census data observations to our treatment and control areas. The process of matching EAs to treatment areas (de novo, control and upgrading) was done through Python and ArcGIS.

In case an EA straddled two (or more) of the treatment and control areas, we cut that EA in ArcGIS into multiple parts, each part belongs to a treatment or a control area. We then use this information to remove the census data observations which belonged to EAs whose area inside a treatment and control area was less than $5 \%$ of the entire EA area. We also use the information on how large a part

\footnotetext{
${ }^{67}$ We follow Giglio et al. (2014) in including observable characteristics linearly in a hedonic regression.
} 
of the EA was inside a treatment or control area to create analytic weights (the weight is higher when the relevant overlap is higher) for some of the robustness checks.

Our variables are discussed in Table A17, and include years of schooling and indicators for different schooling thresholds (exactly primary and more than primary school education; the omitted category is less than primary school). We also create indicators for literacy in any language; literacy in Swahili; and literacy in English. We then calculate means of each of these variables across adults in each "cut" EA.

\section{Additional Data}

\section{Geographic control variables}

\section{Distance to shore and rivers and streams indicators}

We use as geographic controls the distance in kilometers to the nearest shore (either the Indian Ocean or Lake Victoria) and an indicator for rivers or streams. ${ }^{68}$ These variables are derived from Openstreetmap - we use current data since historical data are unavailable. We consider proximity to the coast an amenity, while rivers or streams may be an amenity if their water is usable, or a disamenity if they increase flood risk.

\section{Ruggedness}

Ruggedness is calculated using SRTM elevation at a horizontal resolution of 1 arc-second (United States Geological Survey 2000). We use those data to compute the standard deviation of elevation of each $50 \mathrm{~m} \times 50 \mathrm{~m}$ block relative to its eight neighbors. ${ }^{69}$ We again use current data since historical data are unavailable.

\section{Distance to historical CBD}

For some of the robustness analysis we use measures of distance to historical CBDs, to mitigate concerns that our main measure of the CBD may be endogenous to Sites and Services. To construct these measures we use data on the location of railway stations in six of the cities, since these stations' locations were generally determined before the onset of Sites and Services, as we discuss below. Iringa does not have a railway station, so the coordinates of the Iringa municipal office were used instead. We then calculate distance in kilometers to these coordinates in the same way as we do with the light-based CBDs and then use this as an alternative measure in some regression specifications.

To justify our argument that railroad stations existed even before Sites and Services, and hence can be used as ex ante markers of the centers of the cities, we refer to a map of the railways from

\footnotetext{
${ }^{68}$ The distance to the shore is winsorized at 10 kilometers, hence the distances to other water bodies, such as Lake Tanganika, are irrelevant in our seven cities.

${ }^{69}$ For a small fraction of blocks that are at the border of our study area, we instead use the mean of the standard deviation for those blocks for which it is calculated.
} 
1948, which shows that five the seven cities had railways in 1948, and the location of railway stations is unlikely to be moved. ${ }^{70}$ Of the remaining two cities, Mbeya's railway was built from 1970 and completed and opened in 1975 (Edson 1978), while Iringa does not have railway, as mentioned above.

\section{IPUMS 2012 Tanzanian Census by Region}

We use data downloaded from the IPUMS online repository of country censuses, in order to check the correctness of the above-mentioned microdata extract from the same census. This was done in particular for the education variable which had been cleaned by IPUMS staff to include many observations recorded as having "never attended" school. The microdata that we had received directly from the Tanzanian Census Bureau had many missing values for the education variable, and none coded as never having attended school. The missing values in the micro-data followed the same pattern as the "never attended" in the IPUMS data, which contributed to our decision to code them as zero years of schooling. We also checked age and gender patterns in the microdata which confirmed our interpretation of the data.

\section{Land Values}

\section{Matching Land Value Data to Enumeration Areas}

We obtained an Excel sheet titled "RATES LAND VALUE MIKOA 10 2012.xls", which we received from the Kinondoni Municipal council, but were told that it was created by the Ministry of Lands, with minimum, mean, and maximum land values for different neighborhoods in Tanzania. We can identify these neighborhoods by four string identifiers: region, district, location, and streets. To locate neighborhoods we match them based on the 2002 enumeration area (EA) shapefile, which contains string identifiers for region, district, location, and vill_stree (we consider 'vill_stree' comparable with 'streets' from the land values table).

\section{Land Use}

The Excel table has different minimum, mean, and maximum land values by land use. There are typically four categories: Residential, commercial, commercial/residential, and institutional. Though the differentiation of land values across uses is mechanical (commercial is $1.4^{*}$ res, com/res is $1.1^{*}$ res, institutional is the same as res), the variation across areas is not mechanical. Throughout we use mean land values from the residential categories only.

\section{Spatially Mapping Land Values}

We merge EA boundaries to land value observations using the four identifiers: region, district, location, and streets. Each entry in the land value table we treat as an observation, often this contains

\footnotetext{
${ }^{70}$ Britishempire.co.uk. (1948). [online] Available at: https:/ /www.britishempire.co.uk/images2/tanganyikamap1948.jpg [Accessed 3 Jul. 2019].
} 
a group of 'streets'. Typically there are many EAs per land value observation, so each observation in the land values table is matched to a large group of EA boundaries. Then we dissolve the EA boundaries to have a single spatial unit for each entry in the land value sheet. We then plot the mean residential land rate for each spatial unit.

\section{Results}

The merged areas are quite large. Some roughly match our treatment areas:

1. Sinza - one unit at $240,000 \mathrm{TSh}$

2. Manzese A - three partial units all at $65,000 \mathrm{TSh}$

3. Manzese B - split in half, one at $65,000 \mathrm{TSh}$ the other at 50,000TSh

4. Kijitonyama - one unit at $325,000 \mathrm{TSh}$

The other two do not match as well:

1. Mikocheni - contained by a much larger unit at $125,000 \mathrm{TSh}$

2. Tandika/Mtoni - overlaps many areas of values; $40,000 \mathrm{TSh}, 30,000 \mathrm{TSh}, 50,000 \mathrm{TSh}$, and $18,000 \mathrm{TSh}$

These values per square meter put us in the range of 125,000-325,000 TSh (2017 US\$80-220) in de novo and 18,000-65,000 TSh (2017 US\$10-40) in upgrading. For the areas where we have better matched data the ranges are 240,000-325,000 TSh (2017 US\$160-220) in de novo and 50,000-65,000 TSh (2017 US\$30-40) in upgrading.

\section{Project Costs}

The total cost of First Round of Sites and Services was \$60m in US\$2017, of which just over half was due to direct costs (World Bank 1984): infrastructure (38\% of total costs), consultants (9\%), land compensation $(6 \%)$. Other costs $(45 \%)$ included the community centers $(14 \%)$, mentioned above, and a loan scheme (29\%), which later failed because of poor repayment rates, and a few other costs. This investment covered a total of 23,161 plots: 8,527 de novo plots and 14,634 upgrading plots. The Second Round of Sites and Services cost \$70m in US\$2017 where 70\% was spent on direct costs, paying for a total of 22,106 plots: 1,978 de novo plots and 20,128 upgrading plots (World Bank 1987).

The First Round project reports (World Bank 1974a and 1984) indicate that the total infrastructure investment costs per area in de novo and upgrading were very similar. The project report for Round 1 provided costs separately for de novo and upgrading areas (World Bank, 1984). However only infrastructure investment differed for the two types of treatment, while land compensation, equipment, and consultancy costs were reported as split 50-50 between de novo and upgrading. Direct costs by treatment were \$19 million in de novo and \$15 million in upgrading areas (in US\$2017). To 
get costs per unit area we normalize by total area covered by each treatment type in Round 1 (8.5 square kilometers in de novo and 6.5 square kilometers in upgrading). This gave costs for de novo and upgrading areas of \$2.20 and \$2.37 per square meter respectively (in US\$2017).

Further, in order to compare with present day land values (per plot area) we would like an estimate of costs per unit of treated plot area. Due to data limitations we can only do that for de novo neighborhoods where the reports give both plot counts and plot areas. We estimate that the direct costs per square of plot were no more than $\$ 8$ per square meter, and total costs were no more than $\$ 13$ per square meter (in US\$2017). ${ }^{71}$

An alternative way to look at costs is to break them down by plot which we can do for both de novo and upgrading areas. According to the report there were 8,527 de novo plots and 14,634 upgrading plots in Round 1. We can divide the direct costs of de novo and upgrading areas by their plot counts to get $\$ 2,200$ and $\$ 1,000$ per plot respectively (in US\$2017). The difference in costs reflects both the larger size of the de novo plots and the larger share of allocated to public amenities (such as roads).

\section{Cost Recovery}

Costs were meant to be recovered through land rent ( $4 \%$ of land value a year) and service charge (the cost of infrastructure provider), but assessment of parcels was long and interim charge well below the adequate amount to cover the costs (100 Tsh/year or 2017 US\$51) was imposed. Collection rates were low and not timely.

\section{Population data for 2002}

To calculate the population density in each of the neighborhoods, we use data on population by enumeration areas from the 2002 Tanzanian Census (Tanzania National Bureau of Statistics 2011). In cases where an entire enumeration area falls into a Sites and Services neighborhood, we assign its entire population to that neighborhood. When only a fraction of an enumeration area falls into a Sites and Services neighborhood, we assign to the neighborhood the fraction of the enumeration area population that corresponds to the fraction of the land area that lies within the neighborhood. The mean number of enumeration areas matched to each neighborhood is 33 for de novo areas and 35 for upgrading areas. ${ }^{72}$ Population counts for 2002 are outlined in Table A3.

\footnotetext{
${ }^{71}$ To calculate the costs per square meter of each plot, we use the planned areas of de novo plots from Appraisal report 1 (World Bank, 1974a); the planned area was 288 square meters, except for $8.56 \%$ of the plots (those in Mikocheni) where it was 370 square meters. Taking the weighted average at 295 square meters, we can divide the de novo direct costs by total plot area treated to get $\$ 7.5$ per square meter.

${ }^{72}$ We are unable to report the population counts from 2012 census, because we only have a sample from the census, and in this sample, not every 2012 enumeration area is populated.
} 


\section{Conversion to 2017 US Dollars}

All monetary values in the paper are reported in their source units and also converted to 2017 US dollars (2017 US\$). To calculate the dollar values we used the exchange rates to contemporaneous year US\$ from Penn World Tables 9.0 (Feenstra et al., 2015). Then we used the US CPI factors to bring the value to 2017 US\$.

\section{References for the Data Appendix}

DigitalGlobe. 2016. "Worldview Satellite Imagery." (Worldview satellite images on the slums in the Tanzanian cities Iringa (2013), Mbeya (2014), Morogoro (2012), Mwanza (2014), Tabora (2011), Tanga (2012) and two districts of Dar es Salaam: Kinondoni (2015) and Temeke (2014))

Dar es Salaam City Council. 2008. Transport Policy and System Development Master Plan.

Dar Ramani Huria. 2016. "Community-Based Mapping Project in Dar es Salaam." http:/ / ramanihuria.org/data/ (accessed May 25, 2017).

Directorate of Overseas Surveys. 2015. "Aerial Imagery and Topographic maps from 1:2,500 to 1:50,000."

Edson, John. 1978. “The Impact of Tanzania-Zambia Railway on Development of Mbeya District." Department of Urban and Regional Planning, The University of Nairobi.

Feenstra, Robert C., Robert Inklaar and Marcel P. Timmer. 2015, "The Next Generation of the Penn World Table" American Economic Review, 105(10), 3150-3182. www.ggdc.net/pwt (accessed September 12, 2017)

Giglio, Stefano, Matteo Maggiori, and Johannes Stroebel. 2014. "Very long-run discount rates." Quarterly Journal of Economics 130(1): 1-53

IPUMS International. 2017. “Tanzania Population Census 2012"

https:/ /international.ipums.org/international/ (accessed June 20, 2017)

Kinondoni Municipality. Dar es Salaam, Tanzania. 2013. "Tax registry and plot shapefile, Dar es Salaam: Kinondoni Municipality GIS department."

Kironde, J M Lusugga. 1991. "Sites-and-Services in Tanzania: The Case of Sinza, Kijitonyama and Mikocheni Areas in Dar-es-Salaam." Habitat International, 15(1-2): 27-38.

Kironde, J M Lusugga. 1994. "The Evolution of the Land Use Structure of Dar es Salaam 18901990: A Study in the Effects of Land Policy." PhD dissertation, University of Nairobi.

Kironde, J M Lusugga. 2017. Interview with authors, Dar es Salaam, August 2, 2017.

Lupala, J, J Malombe, and A Könye. 1997. "Evaluation of Hanna Nassif Community-Based Urban Upgrading Project Phase I." Government of Tanzania/UNDP/NIGP/Ford Foundation/ILO Evaluation Mission Team Report, Dar-es-Salaam.

Marshall, Macklin, Monaghan Ltd. 1979. The Dar-es-Salaam Master Plan: Main Report - Five Year Development Programme. Toronto, Canada.

Mwanza City Municipality. 1973. "Mwanza Cadastral Maps" 
Openstreetmap. 2017. "Road Shapefiles of Dar es Salaam, Iringa, Mbeya, Morogoro, Mwanza, Tabora and Tanga" https:/ /www.openstreetmap.org (accessed June 20, 2017)

Project Planning Associates Ltd. 1968. National Capital Master Plan: Dar-es-Salaam Main Plan Report. Toronto, Canada.

Tanzania Ministry of Lands. 2012. "Rates Land Value Mikoa (Regions) 10 2012."

Tanzania National Bureau of Statistics. 2011. "Tanzania Population and Housing Census 2002."

United States Geological Survey. 2000. SRTM1 Arc-Second Global, DOI: /10.5066/F7PR7TFT

United States Geological Survey. 2015. "Declassified Satellite Imagery from 1960-1972." United States Geological Survey, Reston, VA.

World Bank. 1974a. "Appraisal of National Sites and Services Project." Report No. 337a-TA, Washington, DC: Urban Projects Department.

World Bank. 1974b. "Development Credit Agreement between United Republic of Tanzania and International Development Association (Conformed Copy)." Credit No. 495 TA, Washington, DC.

World Bank. 1977a. "Development Credit Agreement between United Republic of Tanzania and International Development Association (Conformed Copy)." Credit No. 732 TA, Washington, DC.

World Bank. 1977b. "Tanzania: The Second National Sites and Project." Report No. 1518a-TA, Washington, DC: Urban Projects Department.

World Bank. 1984. "Completion Report: Tanzania - First National Sites and Services Project." Report No. 4941, Washington, DC: Eastern Africa Regional Office.

World Bank. 1987. "Tanzania: The Second National Sites and Project." Report No. 6828, Washington, DC: Operations Evaluation Department.

World Bank. 2010. "Project Appraisal Document for a Tanzania Strategic Cities Project." Report No. 51881-TZ, Washington, DC: Urban and Water Department.

World Bank. 2013. "Tanzania Strategic Cities Project Housing Survey". Produced and shared by President's Office - Regional Administration and Local Government. 
Figure A1: Locations of De Novo, Upgrading, and Control Areas by City

(a) Dar es Salaam: Kinondoni

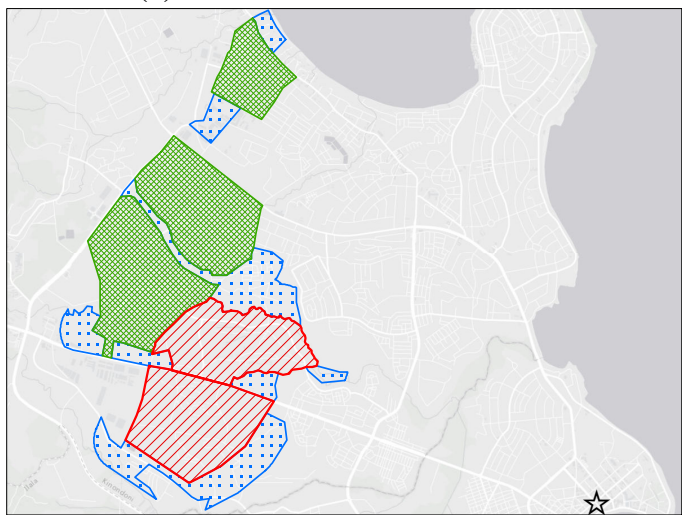

(c) Iringa

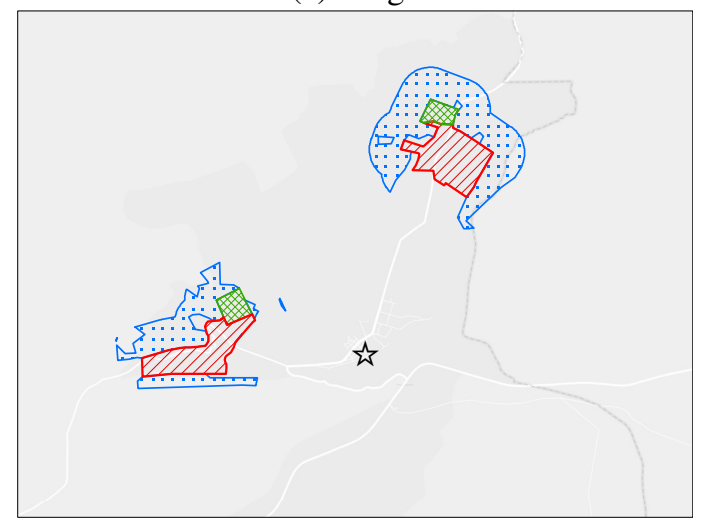

(e) Morogoro

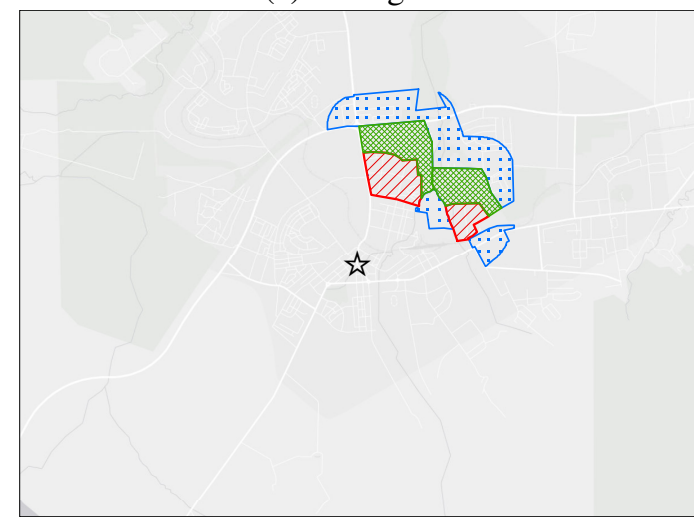

(g) Tabora

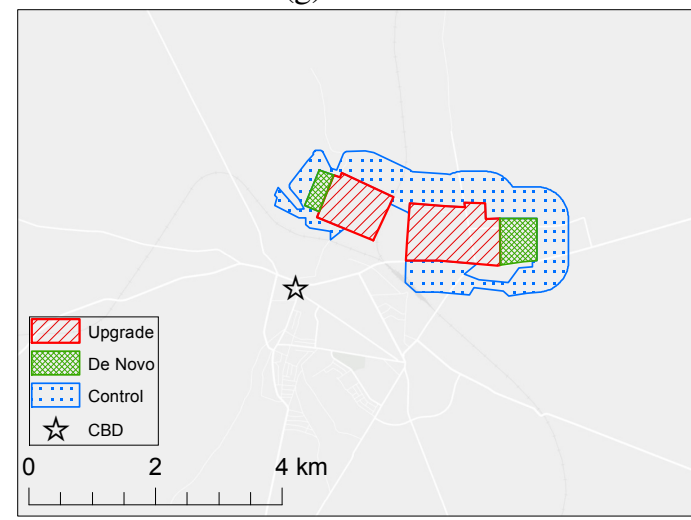

(b) Dar es Salaam: Temeke

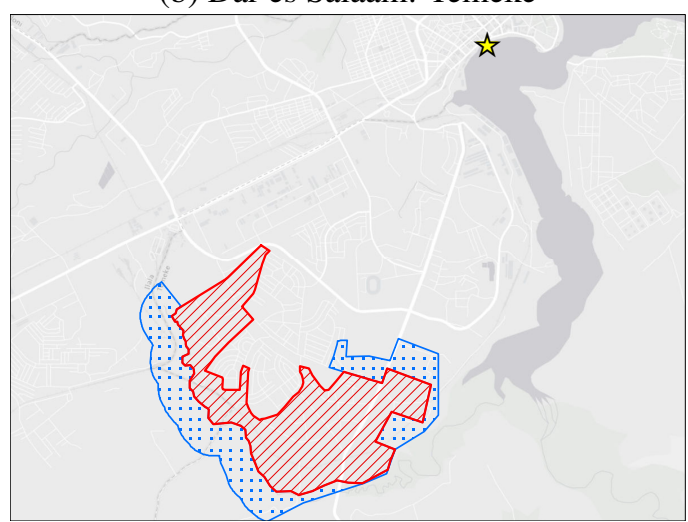

(d) Mbeya

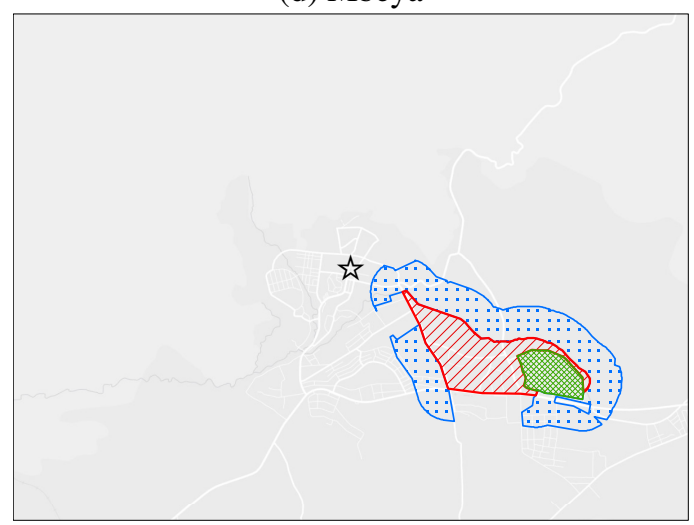

(f) Mwanza

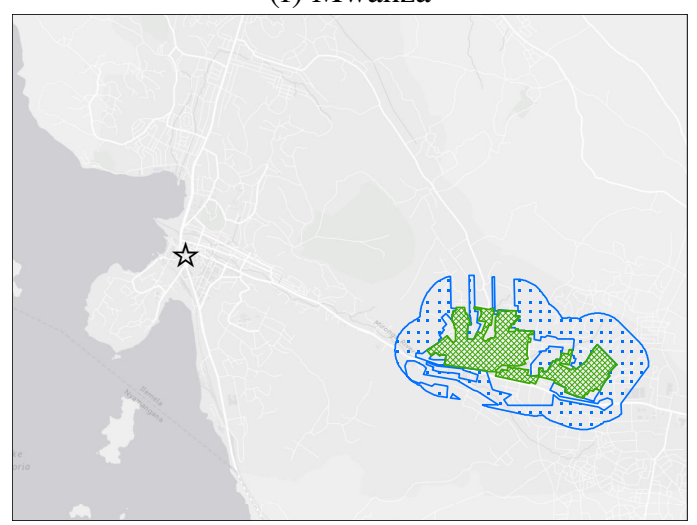

(h) Tanga

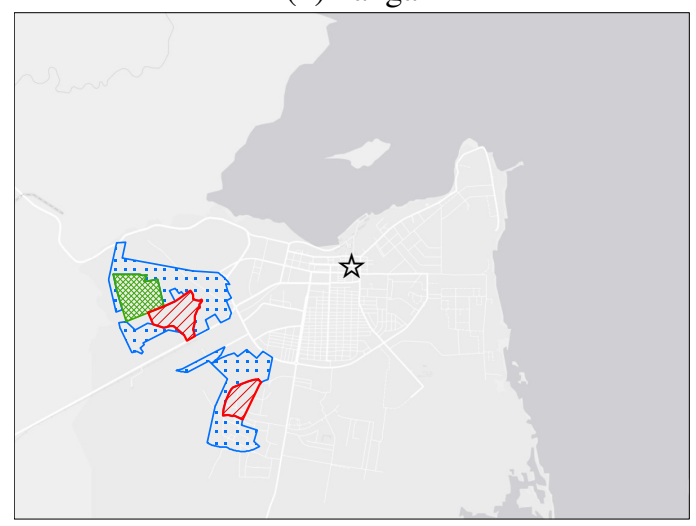

Notes: This figure maps de novo (green cross-hatch), upgrading (red hatch), control areas (blue dots), and the CBD (yellow star) for each city. Panel (a) shows the northern part of Dar es Salaam (Kinondoni), while the southern part (Temeke) is shown in panel (b). Control areas are all 500m buffers of study areas, excluding land that was determined uninhabitable, built-up, or designated for specific use prior to the program. Each map is set to the same scale. Background imagery from ArcGIS is for context only and was not used for analysis, it depicts modern day roads (white lines), heavily vegetated areas (green-grey) and water bodies (dark grey). 
Figure A2: Example images of De novo, Upgrade and Control Areas

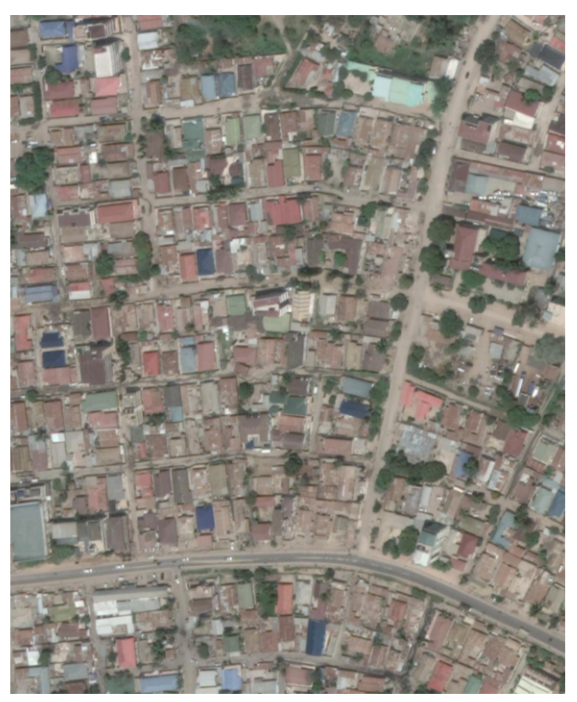

De-novo

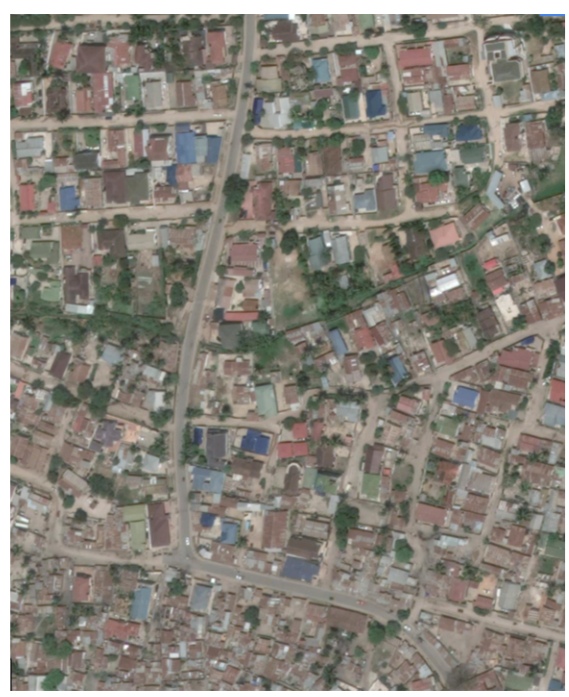

Control (for de-novo)

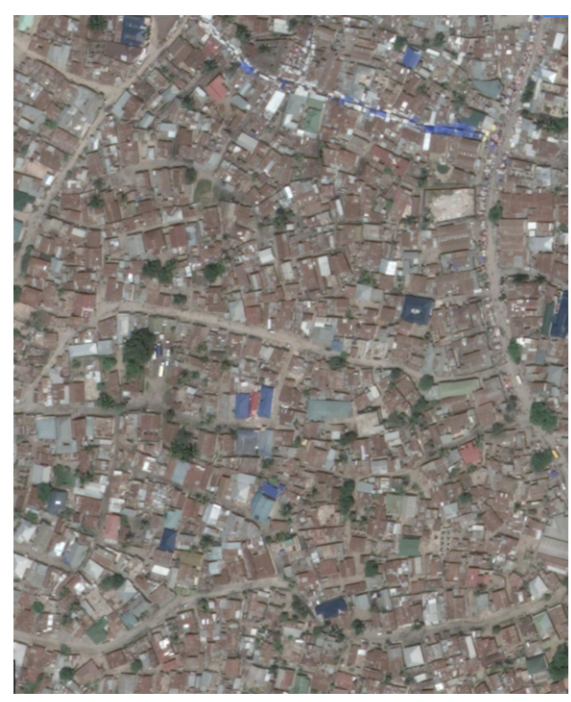

Upgrading

Notes: Each of the three images covers an area of approximately 440 x 360 meters. Source: Google earth V 7.1.2. (2018). Kinondoni District, Dar-es-Salaam, Tanzania. 
Figure A3: Regression Discontinuity Plots of Summary Outcomes from Tables 1 and 2

(a) Z-index from Table 1

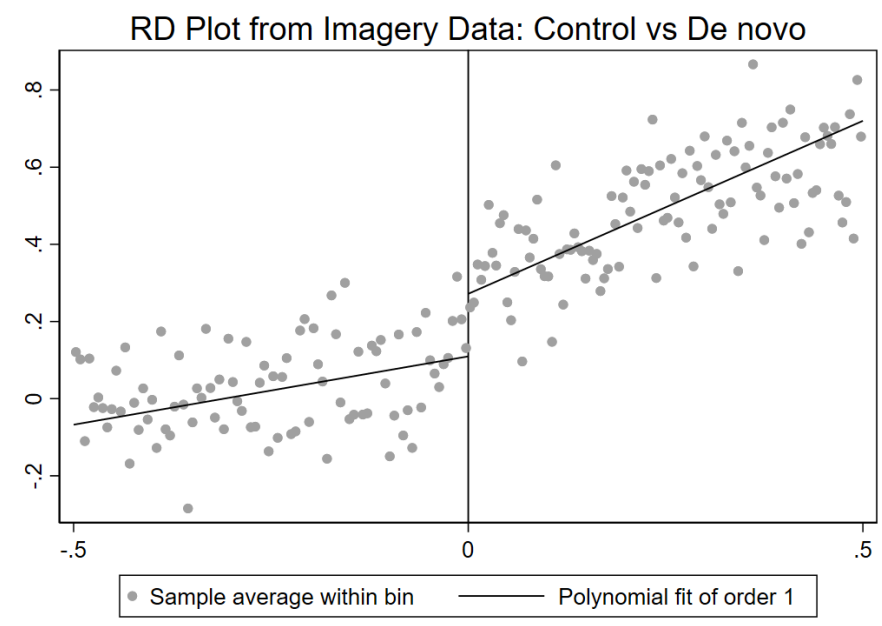

(b) Z-index from Table 2

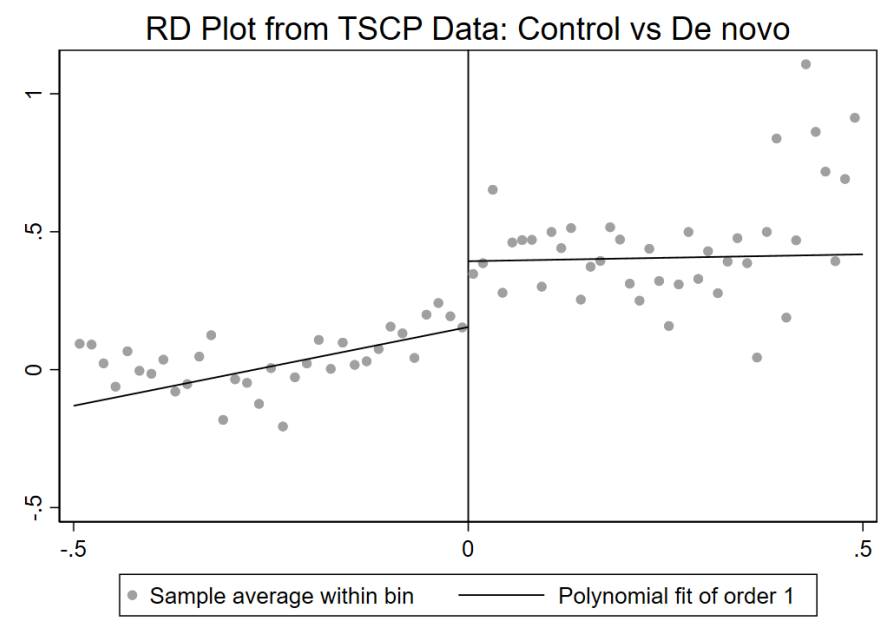

(c) Log hedonic value from Table 2

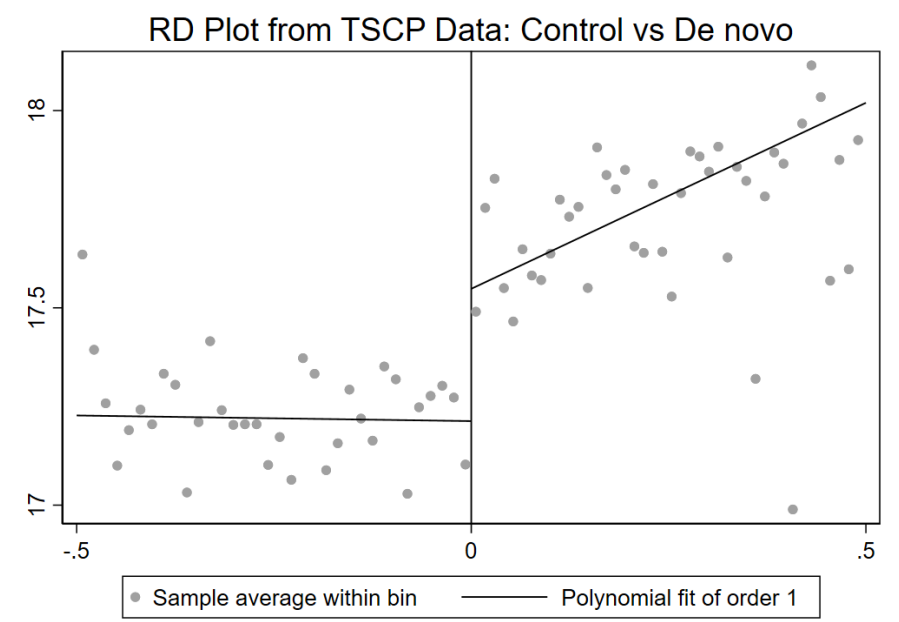

Notes: This figure plots the raw summary outcomes (z-index and log hedonic value) on the $y$-axis against the running variable (x-axis) being distance to boundary between de novo and control areas in kilometers. Observations from control areas are to the left of the cutoff (marked 0 ) and de novo areas to the right. The graphs are created with the command rdplot (Calonico et al 2017), using a triangular kernel. The sample is defined by a 500m bandwidth on either side of the boundary. For subfigure (a), the variable definition and data is the same as in Table 1, panel A, column 4 and the number of observations in (a) is 6562, with 3147 to the left (control) and 3415 to the right (de novo) of the cutoff. The average bin length is $6 \mathrm{~m}$ to the left of the cutoff and $5 \mathrm{~m}$ to the right for subfigure (a). For subfigure (b), the variable definition and data is the same as in Table 2, panel A, column 6 and the number of observations in (b) is 2009, with 1177 to the left (control) and 832 to the right (de novo) of the cutoff. The average bin length is $16 \mathrm{~m}$ to the left of the cutoff and $12 \mathrm{~m}$ to the right for subfigure (b). For subfigure (c), the variable definition and data is the same as in Table 2, panel A, column 7 and the number of observations in (c) is 2009 , with 1177 to the left (control) and 832 to the right (de novo) of the cutoff. The average bin length is $14 \mathrm{~m}$ to the left of the cutoff and $12 \mathrm{~m}$ to the right for subfigure (c). 
Table A1: De novo Neighborhoods

\begin{tabular}{llccc}
\hline \hline City & Area within city & Round & $\begin{array}{c}\text { Pre-treatment } \\
\text { satellite photos }\end{array}$ & $\begin{array}{c}\text { Pre-treatment } \\
\text { topographic map }\end{array}$ \\
Dar es Salaam & Sinza & 1 & 1966 & $\mathrm{~N}$ \\
Dar es Salaam & Kijitonyama & 1 & 1966 & $\mathrm{~N}$ \\
Dar es Salaam & Mikocheni & 1 & 1966 & $\mathrm{~N}$ \\
Mbeya & Mwanjelwa (*) & 1 & 1966 & $\mathrm{~N}$ \\
Mwanza & Nyakato (**) & 1 & 1966 & $\mathrm{~N}$ \\
Tanga & Nguvu Mali $(* * *)$ & 2 & 1966 & $\mathrm{~N}$ \\
Tabora & Isebya & 2 & 1978 & 1967 \\
Tabora & Kiloleni & 2 & 1978 & 1967 \\
Morogoro & Kichangani & 2 & $\mathrm{~N}$ & 1974 \\
Morogoro & Msamvu & 2 & $\mathrm{~N}$ & 1974 \\
Iringa & Kihesa \& Mtuiwila & 2 & 1966 & 1982 \\
Iringa & Mwangata & 2 & 1966 & 1982 \\
\hline
\end{tabular}

Notes: This table reports information about the 12 de novo neighborhoods, the round in which the Sites and Services projects were implemented, and the data we have on the areas before the program was implemented. $(*)$ Treatment area maps were unavailable, so areas were drawn by experts that were involved in the projects, as explained in the Data Appendix. (**) Treatment area maps were unavailable, so we inferred from the detailed Mwanza central plan. (***) We have some uncertainty as to the extent of infrastructure that was actually provided in Nguvu Mali.

Table A2: Upgrading Neighborhoods

\begin{tabular}{llccc}
\hline \hline City & Area within city & Round & $\begin{array}{c}\text { Pre-treatment } \\
\text { satellite photos }\end{array}$ & $\begin{array}{c}\text { Pre-treatment } \\
\text { topographic map }\end{array}$ \\
Dar es Salaam & Manzese A & 1 & 1966 \& 1969 & $\mathrm{N}$ \\
Dar es Salaam & Manzese B & 1 & $1966 \& 1969$ & $\mathrm{~N}$ \\
Mbeya & Mwanjelwa (*) & 1 & 1966 & $\mathrm{~N}$ \\
Dar es Salaam & Mtoni \& Tandika & 2 & 1966 & 1982 \\
Iringa & Kihesa & 2 & 1966 & 1982 \\
Iringa & Mwangata & 2 & 1966 & 1974 \\
Morogoro & Kichangani & 2 & $\mathrm{~N}$ & 1974 \\
Morogoro & Msamvu & 2 & $\mathrm{~N}$ & 1967 \\
Tabora & Isebya & 2 & 1978 & 1967 \\
Tabora & Kiloleni & 2 & 1966 & $\mathrm{~N}$ \\
Tanga & Gofu Juu & 2 & 1966 & $\mathrm{~N}$ \\
Tanga & Mwakizaro & 2 & 1978 & $\mathrm{~N}$ \\
\hline
\end{tabular}

Notes: this table reports information about the 12 upgrading neighborhoods, the round in which the Sites and Services projects were implemented, and the data we have on the areas before the program was implemented. $\left({ }^{*}\right)$ Treatment area maps were unavailable, so areas were drawn by experts that were involved in the projects, as explained in the Data Appendix. 
Table A3: Plot Counts and Population by Project Type

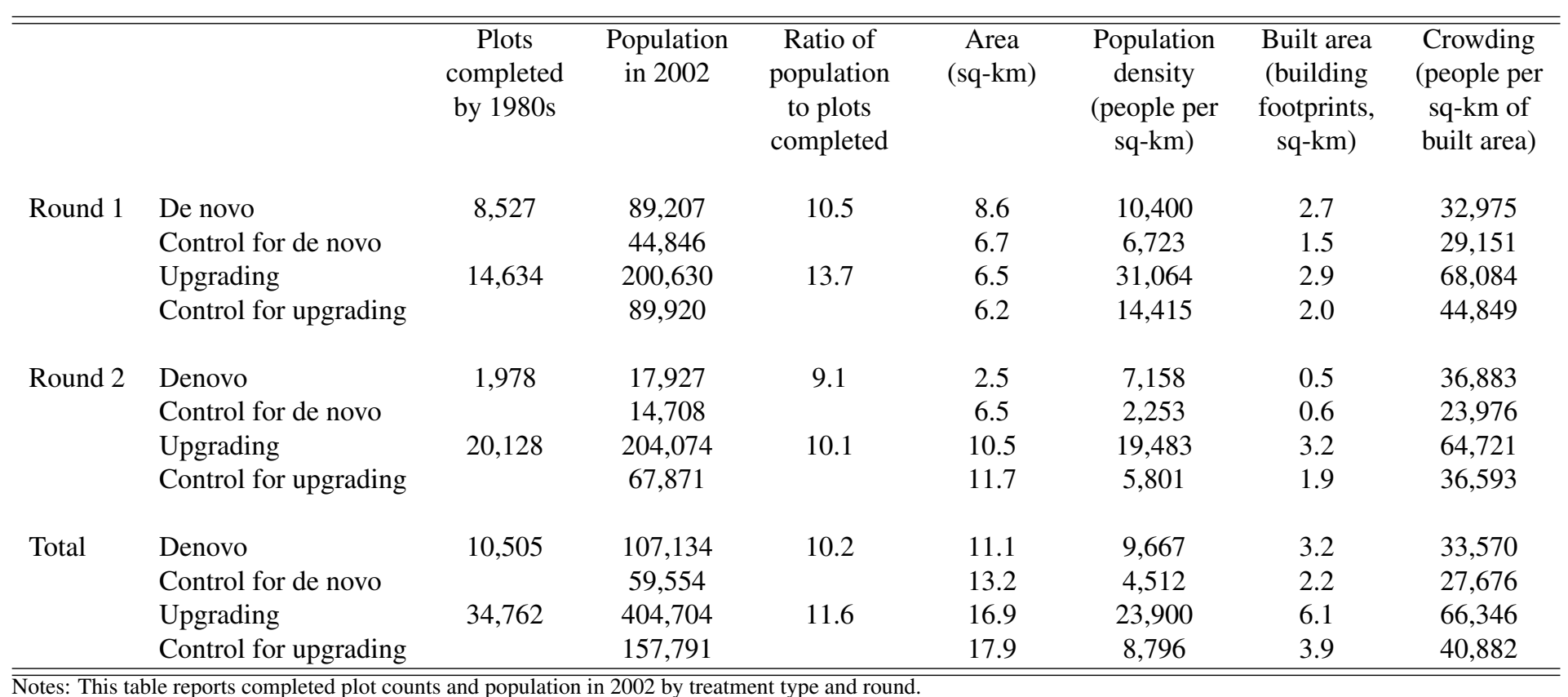

Notes: This table reports completed plot counts and population in 2002 by treatment type and round. 


\begin{tabular}{|c|c|c|c|c|}
\hline & \multicolumn{3}{|c|}{ Imagery data (Blocks) } & \multirow[b]{2}{*}{ Total } \\
\hline & De novo & Upgrade & Control & \\
\hline Mean log building footprint area & $\begin{array}{c}4.580 \\
(0.569)\end{array}$ & $\begin{array}{c}4.243 \\
(0.503)\end{array}$ & $\begin{array}{c}4.381 \\
(0.699)\end{array}$ & $\begin{array}{c}4.394 \\
(0.625)\end{array}$ \\
\hline $\begin{array}{l}\text { Share of buildings with painted } \\
\text { roof }\end{array}$ & $\begin{array}{c}0.337 \\
(0.314)\end{array}$ & $\begin{array}{c}0.186 \\
(0.222)\end{array}$ & $\begin{array}{c}0.174 \\
(0.266)\end{array}$ & $\begin{array}{c}0.221 \\
(0.277)\end{array}$ \\
\hline $\begin{array}{l}\text { Mean similarity of building } \\
\text { orien-tation }\end{array}$ & $\begin{array}{l}-4.735 \\
(5.751)\end{array}$ & $\begin{array}{l}-6.981 \\
(5.208)\end{array}$ & $\begin{array}{l}-8.202 \\
(7.638)\end{array}$ & $\begin{array}{l}-6.911 \\
(6.657)\end{array}$ \\
\hline $\begin{array}{l}\text { Share of buildings with road within } \\
10 \mathrm{~m}\end{array}$ & $\begin{array}{c}0.288 \\
(0.322)\end{array}$ & $\begin{array}{c}0.213 \\
(0.277)\end{array}$ & $\begin{array}{c}0.202 \\
(0.307)\end{array}$ & $\begin{array}{c}0.228 \\
(0.305)\end{array}$ \\
\hline \multirow[t]{3}{*}{ Obs. } & 3,925 & 4,341 & 6,380 & 14,646 \\
\hline & \multicolumn{3}{|c|}{ TSCP data (Blocks) } & \\
\hline & De novo & Upgrade & $\begin{array}{l}\text { Control } \\
\text { (Full City) }\end{array}$ & Total \\
\hline Mean log building footprint area & $\begin{array}{c}5.134 \\
(0.464)\end{array}$ & $\begin{array}{c}4.612 \\
(0.456)\end{array}$ & $\begin{array}{c}4.706 \\
(0.688)\end{array}$ & $\begin{array}{c}4.712 \\
(0.684)\end{array}$ \\
\hline $\begin{array}{l}\text { Share of buildings with multiple } \\
\text { storeys }\end{array}$ & $\begin{array}{c}0.202 \\
(0.384)\end{array}$ & $\begin{array}{c}0.015 \\
(0.100)\end{array}$ & $\begin{array}{c}0.071 \\
(0.240)\end{array}$ & $\begin{array}{c}0.072 \\
(0.243)\end{array}$ \\
\hline Share of buildings with a good roof & $\begin{array}{c}0.975 \\
(0.109)\end{array}$ & $\begin{array}{c}0.868 \\
(0.268)\end{array}$ & $\begin{array}{c}0.951 \\
(0.174)\end{array}$ & $\begin{array}{c}0.950 \\
(0.175)\end{array}$ \\
\hline $\begin{array}{l}\text { Share of buildings connected to } \\
\text { electricity }\end{array}$ & $\begin{array}{c}0.713 \\
(0.344)\end{array}$ & $\begin{array}{c}0.423 \\
(0.322)\end{array}$ & $\begin{array}{c}0.425 \\
(0.431)\end{array}$ & $\begin{array}{c}0.430 \\
(0.429)\end{array}$ \\
\hline $\begin{array}{l}\text { Share of buildings with sewerage } \\
\text { or septic tank }\end{array}$ & $\begin{array}{c}0.547 \\
(0.412)\end{array}$ & $\begin{array}{c}0.227 \\
(0.328)\end{array}$ & $\begin{array}{c}0.387 \\
(0.431)\end{array}$ & $\begin{array}{c}0.387 \\
(0.430)\end{array}$ \\
\hline $\begin{array}{l}\text { Share of buildings connected to } \\
\text { water mains }\end{array}$ & $\begin{array}{c}0.767 \\
(0.320)\end{array}$ & $\begin{array}{c}0.493 \\
(0.329)\end{array}$ & $\begin{array}{c}0.483 \\
(0.434)\end{array}$ & $\begin{array}{c}0.488 \\
(0.433)\end{array}$ \\
\hline Share of buildings with road access & $\begin{array}{c}0.676 \\
(0.440)\end{array}$ & $\begin{array}{c}0.748 \\
(0.341)\end{array}$ & $\begin{array}{c}0.611 \\
(0.453)\end{array}$ & $\begin{array}{c}0.615 \\
(0.451)\end{array}$ \\
\hline Mean log hedonic value & $\begin{array}{l}17.689 \\
(0.496)\end{array}$ & $\begin{array}{l}17.039 \\
(0.468)\end{array}$ & $\begin{array}{l}17.200 \\
(0.723)\end{array}$ & $\begin{array}{l}17.207 \\
(0.719)\end{array}$ \\
\hline Obs. & 798 & 729 & 40,563 & 42,090 \\
\hline
\end{tabular}

Notes: Summary statistics are estimates of the sample mean and its standard deviation in parentheses. The first panel displays summary statistics for outcomes derived from satellite imagery for all seven Sites and Services cities over the sample of observations with their centroid in either a de novo, upgrading, or control area. The second panel displays summary statistics for outcomes derived from TSCP survey data for Mbeya, Mwanza, and Tanga over the whole city sample. Observations are blocks based on an arbitrary grid of 50x50 meter blocks for both imagery and TSCP data. All columns report the maximum populated number of observations. Block outcomes are derived from all buildings with a centroid in the block. Blocks that fall between two treatment types are assigned according to where their centroid falls. The imagery variable painted roof has 14530 observations for the Total column, i.e. 116 less than the other variables. This is due to measurement error in assigning roof type to a building (outlines of some buildings in Dar es Salaam did not correspond to an actual building on the satellite image). Similarly, due to the survey nature of the TSCP data, in the Total column, the following TSCP variables have fewer than 42,090 observations: multiple storeys has 40,990 observations, good roof has 42,047 observations, sewerage or septic tank has 41,948 observations, water mains has 42,063 observations, and road access has 42,062 observations. 
Table A5: De novo regressions balancing first geography

\begin{tabular}{cccc}
\hline \hline$(1)$ & $(2)$ & $(3)$ \\
Distance to & Block contains & Ruggedness \\
Shore $(\mathrm{km})$ & river or stream & within 50m
\end{tabular}

Panel A: no controls, 500m bandwidth (Imagery)

\begin{tabular}{lccc}
\multicolumn{1}{c}{ De novo } & -0.167 & -0.007 & -0.646 \\
& $(0.087)$ & $(0.013)$ & $(0.211)$ \\
& & & \\
Observations & 8,440 & 8,440 & 8,440 \\
Mean (control) & 7.292 & 0.050 & 2.930
\end{tabular}

Panel B: baseline controls, 500m bandwidth (Imagery)

\begin{tabular}{lccc}
\multicolumn{1}{c}{ De novo } & -0.080 & -0.017 & -0.266 \\
& $(0.063)$ & $(0.017)$ & $(0.223)$ \\
& & & \\
Observations & 8,440 & 8,440 & 8,440 \\
Mean (control) & 7.292 & 0.050 & 2.930
\end{tabular}

Panel C: baseline controls, 500m bandwidth (TSCP)

\begin{tabular}{cccc}
\multicolumn{1}{c}{ De novo } & -0.064 & -0.074 & -0.760 \\
& $(0.056)$ & $(0.025)$ & $(0.555)$ \\
Observations & 2,693 & 2,693 & \\
Mean (control) & 5.512 & 0.062 & 3.721
\end{tabular}

Panel D: baseline controls, Full City (TSCP)

\begin{tabular}{lccc} 
De Novo & -0.819 & 0.009 & -0.364 \\
& $(0.222)$ & $(0.011)$ & $(0.337)$ \\
& & & \\
Observations & 35,662 & 35,662 & 35,662 \\
Mean (control) & 4.850 & 0.016 & 3.236 \\
\hline \hline
\end{tabular}

Notes: This table reports estimates from regressions using specification (1) and block level observations with outcomes derived from imagery for all seven Sites and Services cities in Panels A and B, while in Panels C and D the outcomes are derived from TSCP survey data for the three cities where these data exist: Mbeya, Mwanza, and Tanga. The sample includes the de novo areas and control areas within 500 meters of their boundary in Panels A, B and C. In Panel D, the sample includes de novo areas and the full city as control areas. In all panels, all blocks, including empty ones, are used. The outcomes are measures of geographical fundamentals and can be interpreted as quantifying any imbalance in selection of de novo and control areas. Each observation is a block based on an arbitrary grid of 50x50 meter blocks. Blocks are assigned to de novo or control areas based on where their centroid falls. Outcomes are derived from the set of buildings with a centroid in the block (see Data Appendix for further details). In Panel A, the controls are only nearest de novo fixed effects. In Panels B, C and $\mathrm{D}$, the controls are the regular ones: a linear control in distance to the de novo-control area boundary interacted with the de novo indicator, fixed effects for the nearest de novo area, and distance to the Central Business District (CBD) of each city. 
Table A6: De novo regressions of adult census outcomes

\begin{tabular}{ccccccccc}
\hline \hline & $(1)$ & $(2)$ & $(3)$ & $(4)$ & $(5)$ & $(6)$ & $(7)$ \\
& $\begin{array}{c}\text { Mean } \\
\text { years of } \\
\text { schooling }\end{array}$ & $\begin{array}{c}\text { Share with } \\
\text { exactly } \\
\text { primary } \\
\text { education }\end{array}$ & $\begin{array}{c}\text { Share with } \\
\text { more than } \\
\text { primary } \\
\text { education }\end{array}$ & $\begin{array}{c}\text { Share } \\
\text { attending } \\
\text { school }\end{array}$ & $\begin{array}{c}\text { Share } \\
\text { literate } \\
\text { in any } \\
\text { language }\end{array}$ & $\begin{array}{c}\text { Share } \\
\text { literate } \\
\text { in Swahili }\end{array}$ & $\begin{array}{c}\text { Share } \\
\text { literate } \\
\text { in English }\end{array}$ \\
De novo & 0.566 & -0.041 & 0.051 & 0.018 & 0.010 & 0.004 & 0.053 \\
& $(0.121)$ & $(0.016)$ & $(0.015)$ & $(0.009)$ & $(0.006)$ & $(0.010)$ & $(0.023)$ \\
Observations & 814 & 814 & 814 & 814 & 814 & 814 & 814 \\
Mean (control) & 9.343 & 0.412 & 0.497 & 0.128 & 0.960 & 0.936 & 0.449 \\
\hline \hline
\end{tabular}

Notes: This table reports estimates from regressions using cut Enumeration Area (EA) level observations with outcomes derived from Tanzania 2012 Census microdata for all seven Sites and Services cities. In each specification the regressor of interest is de novo, and the control variables include city fixed effects (separate for Temeke and Kinondoni in Dar es Salaam), and distance to the Central Business District (CBD) of each city. The sample includes de novo observations and control areas which are near de novo areas. The outcomes are measures of sorting into the treatment and control areas. Outcomes are the EA mean over the set of all adults at least 18 years old enumerated in the EA. Each observation is an EA of varying size, or a cut EA if the EA intersects both de novo and control areas. Cut EAs are assigned to de novo, and/or control areas if more than 5 percent of the cut EA lies inside the respective area. Analytic weights for the cut EA observations used in the regression are based on the proportion of the EA area that lies inside each treatment or control area. Standard errors, in parentheses, are clustered by arbitrary $850 \times 850$ meter grid squares. There are 90 clusters. 
Table A7: Upgrading regressions balancing first geography

(1) (2) (3)

Distance to Block contains Ruggedness

Shore $(\mathrm{km}) \quad$ river or stream within $50 \mathrm{~m}$

Panel A: no controls, 500m bandwidth (Imagery)

\begin{tabular}{lccc}
\multicolumn{1}{c}{ Upgrade } & -0.057 & -0.029 & -0.389 \\
& $(0.075)$ & $(0.012)$ & $(0.161)$ \\
& & & \\
Observations & 12,854 & 12,854 & 12,854 \\
Mean (control) & 6.778 & 0.060 & 2.663
\end{tabular}

Panel B: baseline controls, 500m bandwidth (Imagery)

\begin{tabular}{lccc}
\multicolumn{1}{c}{ Upgrade } & 0.021 & -0.050 & 0.099 \\
& $(0.049)$ & $(0.019)$ & $(0.233)$ \\
& & & \\
Observations & 12,854 & 12,854 & 12,854 \\
Mean (control) & 6.778 & 0.060 & 2.663
\end{tabular}

Panel C: baseline controls, 500m bandwidth (TSCP)

\begin{tabular}{lccc}
\multicolumn{1}{c}{ Upgrade } & 0.058 & -0.075 & -0.370 \\
& $(0.039)$ & $(0.041)$ & $(0.328)$ \\
Observations & 2,576 & 2,576 & 2,576 \\
Mean (control) & 7.873 & 0.063 & 2.386
\end{tabular}

Panel D: baseline controls, Full City (TSCP)

\begin{tabular}{lccc} 
Upgrade & 0.045 & 0.042 & -1.002 \\
& $(0.126)$ & $(0.024)$ & $(0.315)$ \\
& & & \\
Observations & 11,798 & 11,798 & 11,798 \\
Mean (control) & 7.079 & 0.019 & 2.422 \\
\hline \hline
\end{tabular}

Notes: This table reports estimates from regressions using specification (1) and block level observations with outcomes derived from imagery for all seven Sites and Services cities in Panels A and B, while in Panels C and D the outcomes are derived from TSCP survey data for the three cities where these data exist: Mbeya, Mwanza, and Tanga. The sample includes the upgrading areas and control areas within 500 meters of their boundary in Panels A, B and C. In Panel D, the sample includes upgrading areas and the full city as control areas. In all panels, all blocks, including empty ones, are used. The outcomes are measures of geographical fundamentals and can be interpreted as quantifying any imbalance in selection of upgrading and control areas. Each observation is a block based on an arbitrary grid of 50x50 meter blocks. Blocks are assigned to upgrading or control areas based on where their centroid falls. Outcomes are derived from the set of buildings with a centroid in the block (see Data Appendix for further details). In Panel A, the controls are only nearest upgrading fixed effects. In Panels B, C and D, the controls are the regular ones: a linear control in distance to the upgrading-control area boundary interacted with the upgrading indicator, fixed effects for the nearest upgrading area, and distance to the Central Business District (CBD) of each city. 
Table A8: Upgrading Regressions using Imagery Data for all Seven Cities

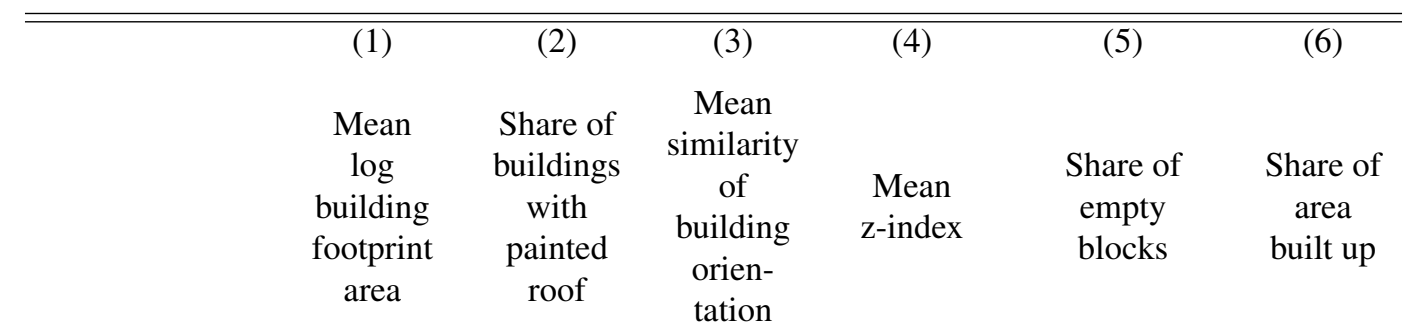

Panel A: 500m bandwidth

\begin{tabular}{lcccccc} 
Upgrade & -0.053 & -0.005 & 0.500 & -0.010 & -0.139 & 0.076 \\
& $(0.042)$ & $(0.010)$ & $(0.389)$ & $(0.034)$ & $(0.033)$ & $(0.016)$ \\
Observations & 10,909 & 10,837 & 10,909 & 10,909 & 12,854 & 12,854 \\
Mean (control) & 4.333 & 0.146 & -7.352 & -0.008 & 0.234 & 0.219 \\
& & & & & \\
& & & & & \\
& \multirow{2}{*}{ Geography } & Lat-Long & Historical & Doughnut & Exclude 100m \\
& $2^{\text {nd }}$ Poly. & CBD & $100 \mathrm{~m}$ & to Denovo
\end{tabular}

Panel B: robustness (mean z-index only as outcome)

\begin{tabular}{llllll}
\multicolumn{1}{c}{ Upgrade } & -0.014 & -0.014 & -0.011 & -0.049 & -0.007 \\
& $(0.035)$ & $(0.035)$ & $(0.034)$ & $(0.061)$ & $(0.035)$ \\
Observations & 10,909 & 10,909 & 10,909 & 7,573 & 10,531 \\
Mean (control) & -0.008 & -0.008 & -0.008 & 0.008 & -0.017
\end{tabular}

$\begin{array}{cccc}\begin{array}{c}\text { Mean } \\ \text { log }\end{array} & \begin{array}{c}\text { Mean } \\ \text { similarity }\end{array} & \text { Share of } & \text { Share of } \\ \text { building } & \text { of } & \text { empty } & \text { area } \\ \text { footprint } & \begin{array}{c}\text { building } \\ \text { orien- } \\ \text { area }\end{array} & \text { blocks } & \text { built up } \\ \text { tation } & & \end{array}$

Panel C: upgrade vs old slums

\begin{tabular}{lcccc}
\multicolumn{1}{c}{ Upgrade } & -0.152 & 0.801 & -0.278 & 0.122 \\
& $(0.073)$ & $(0.396)$ & $(0.106)$ & $(0.047)$ \\
& & & & \\
Observations & 8,000 & 8,000 & 9,319 & 9,319 \\
Mean (control) & 4.214 & -6.195 & 0.231 & 0.303
\end{tabular}

Panel D: upgrade vs old slums, first geography controls

\begin{tabular}{lcccc}
\multicolumn{1}{c}{ Upgrade } & -0.139 & 0.755 & -0.233 & 0.123 \\
& $(0.065)$ & $(0.264)$ & $(0.091)$ & $(0.045)$ \\
& & & & \\
Observations & 8,000 & 8,000 & 9,319 & 9,319 \\
Mean (control) & 4.214 & -6.195 & 0.231 & 0.303 \\
\hline \hline
\end{tabular}

Notes: This table reports estimates from regressions using specification (1) and block level observations with outcomes derived from imagery for all seven Sites and Services cities. The sample in Panels A and B includes the upgrading areas and control areas within 500 meters of their boundary. The sample in Panels C and D includes the upgrading areas in Dar es Salaam and the areas of that city which could be identified as slums before Sites and Services and that were not treated (see the Data Appendix for more details). The outcomes are measures of housing quality that do not reflect direct investments in upgrading areas. Each observation is a block based on an arbitrary grid of 50x50 meter blocks. Blocks are assigned to upgrading or control areas based on where their centroid falls. Outcomes are derived from the set of buildings with a centroid in the block (see Data Appendix for further details). In Panels A, C and D the outcomes vary, while in Panel B the dependent variable in all columns is the z-index (composed of all outcomes in columns (1)-(3) in Panel A). In each specification the regressor of interest is upgrading, and the control variables include a linear control in distance to the upgrading-control area boundary interacted with the upgrading indicator, fixed effects for the nearest upgrading area, and distance to the Central Business District (CBD) of each city. In addition, in Panel B, column (1) includes geographic controls, column (2) includes a second order polynomial in longitude and latitude, column (3) uses distance to historical (instead of contemporary) CBDs, column (4) excludes areas within 100 meters of the boundary between upgrade and control areas, column (5) excludes areas within 100 meters of the boundary between de novo and control areas. Standard errors, in parentheses, are clustered by arbitrary $850 x 850$ meter grid squares, corresponding to the median size of Sites and Services areas. There are 117-1255lusters in Panel A, 117 clusters in Panel B, and 104-105 clusters in Panels C and $\mathrm{D}$. 
Table A9: Upgrading Regressions using TSCP Survey Data for Mbeya, Mwanza, and Tanga

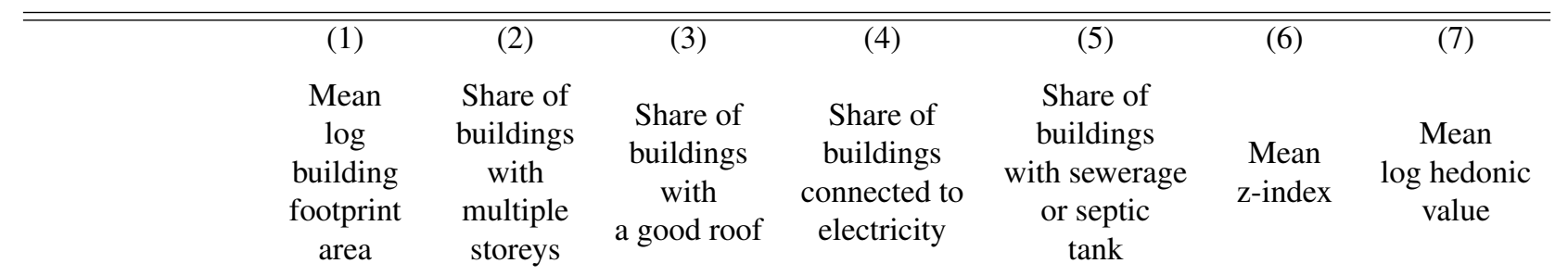

Panel A: 500m bandwidth

\begin{tabular}{|c|c|c|c|c|c|c|c|}
\hline Upgrade & $\begin{array}{l}-0.111 \\
(0.101)\end{array}$ & $\begin{array}{l}-0.112 \\
(0.050)\end{array}$ & $\begin{array}{l}-0.178 \\
(0.084)\end{array}$ & $\begin{array}{l}-0.082 \\
(0.078)\end{array}$ & $\begin{array}{l}-0.130 \\
(0.079)\end{array}$ & $\begin{array}{l}-0.569 \\
(0.253)\end{array}$ & $\begin{array}{l}-0.181 \\
(0.133)\end{array}$ \\
\hline Observations & 2,066 & 1,863 & 2,062 & 2,066 & 2,059 & 2,066 & 2,066 \\
\hline \multirow[t]{2}{*}{ Mean (control) } & 4.801 & 0.094 & 0.972 & 0.524 & 0.350 & 0.041 & 17.281 \\
\hline & Geography & $\begin{array}{l}\text { Lat-Long } \\
2^{\text {nd }} \text { Poly. }\end{array}$ & $\begin{array}{l}\text { Historical } \\
\text { CBD }\end{array}$ & $\begin{array}{c}\text { Doughnut } \\
100 \mathrm{~m}\end{array}$ & $\begin{array}{l}\text { Exclude } 100 \mathrm{~m} \\
\text { to Denovo }\end{array}$ & Full City & $\begin{array}{c}\text { Optimal } \\
\text { bandwidth }\end{array}$ \\
\hline \multicolumn{8}{|c|}{ Panel B: robustness (mean z-index only as outcome) } \\
\hline Upgrade & $\begin{array}{l}-0.572 \\
(0.246)\end{array}$ & $\begin{array}{l}-0.631 \\
(0.243)\end{array}$ & $\begin{array}{l}-0.597 \\
(0.242)\end{array}$ & $\begin{array}{l}-0.456 \\
(0.323)\end{array}$ & $\begin{array}{l}-0.578 \\
(0.264)\end{array}$ & $\begin{array}{l}-0.681 \\
(0.209)\end{array}$ & $\begin{array}{l}-0.633 \\
(0.265)\end{array}$ \\
\hline Observations & 2,066 & 2,066 & 2,066 & 1,462 & 2,001 & 11,225 & 11,225 \\
\hline Mean (control) & 0.041 & 0.041 & 0.041 & 0.046 & 0.030 & -0.084 & 0.045 \\
\hline \multicolumn{8}{|c|}{ Panel C: robustness (mean log hedonic value only as outcome) } \\
\hline Upgrade & $\begin{array}{l}-0.211 \\
(0.129)\end{array}$ & $\begin{array}{l}-0.286 \\
(0.119)\end{array}$ & $\begin{array}{l}-0.236 \\
(0.119)\end{array}$ & $\begin{array}{l}-0.200 \\
(0.224)\end{array}$ & $\begin{array}{l}-0.189 \\
(0.135)\end{array}$ & $\begin{array}{l}-0.370 \\
(0.083)\end{array}$ & $\begin{array}{l}-0.217 \\
(0.149)\end{array}$ \\
\hline Observations & 2,066 & 2,066 & 2,066 & 1,462 & 2,001 & 11,225 & 11,225 \\
\hline Mean (control) & 17.281 & 17.281 & 17.281 & 17.300 & 17.273 & 17.259 & 17.267 \\
\hline
\end{tabular}

Notes: This table reports estimates from regressions using specification (1) and block level observations with outcomes derived from TSCP survey data for the three cities where these data exist: Mbeya, Mwanza, and Tanga. The sample includes the upgrading areas and control areas within 500 meters of their boundary. The outcomes are measures of housing quality that do not reflect direct investments in upgrading areas. Each observation is a block based on an arbitrary grid of 50x50 meter blocks. Blocks are assigned to upgrading or control areas based on where their centroid falls. Outcomes are derived from the set of buildings with a centroid in the block (see Data Appendix for further details). In Panel A the outcomes vary, while in Panel B the dependent variable in all columns is the z-index (composed of all outcomes in columns (1)-(5) in Panel A), and in Panel C the dependent variable is the predicted log value from hedonic regressions. In each specification the regressor of interest is upgrading, and the control variables include a linear control in distance to the upgrading-control area boundary interacted with the upgrading indicator, fixed effects for the nearest upgrading area, and distance to the Central Business District (CBD) of each city. In addition, in Panels B and C, column (1) includes geographic controls, column (2) includes a second order polynomial in longitude and latitude, column (3) uses distance to historical (instead of contemporary) CBDs, column (4) excludes areas within 100 meters of the boundary between upgrade and control areas, column (5) excludes areas within 100 meters of the boundary between de novo and control areas, column (6) changes the control area to the sample of blocks covering the whole city excluding treatment areas, and column (7) uses 2889 observations inside the optimal bandwith for panel B and 1699 observations inside the optimal bandwith for panel C based on Imbens and Kalyanaraman (2012). The control mean in column (7) reports the mean for the control areas inside the optimal bandwidth. The 'Full City' in column (6) is robust to higher order polynomials in distance to boundary: In panel B: second order polynomial gives an estimate of -0.737 and standard error of 0.243 , and third order polynomial gives an estimate of -0.662 and standard error of 0.243 . In panel C: second order polynomial gives an estimate of -0.361 and standard error of 0.117 , and third order polynomial gives an estimate of -0.237 and standard error of 0.143 . Standard errors, in parentheses, are clustered by arbitrary 850 x 850 meter grid squares, corresponding to the median size of Sites and Services areas. There are 30 clusters in Panel A, and 28-30 clusters in Panels B and C, except in column (6) of Panels B and C, which have 132 clusters. 
Table A10: Upgrading Regressions using TSCP Survey Data for Mbeya, Mwanza, and Tanga with Owner Name Fixed Effects

\begin{tabular}{|c|c|c|c|c|c|c|c|}
\hline & (1) & (2) & (3) & (4) & (5) & (6) & (7) \\
\hline & $\begin{array}{l}\text { Log } \\
\text { building } \\
\text { footprint } \\
\text { area }\end{array}$ & $\begin{array}{c}\text { Multistorey } \\
\text { building }\end{array}$ & $\begin{array}{l}\text { Good } \\
\text { roof }\end{array}$ & $\begin{array}{c}\text { Connected } \\
\text { to } \\
\text { electricity }\end{array}$ & $\begin{array}{c}\text { Sewerage or } \\
\text { septic tank }\end{array}$ & Z-index & $\begin{array}{c}\text { Log hedon } \\
\text { value }\end{array}$ \\
\hline \multicolumn{8}{|c|}{ Panel A: Full City, Owner FE } \\
\hline Upgrade & $\begin{array}{l}-0.225 \\
(0.150)\end{array}$ & $\begin{array}{l}-0.186 \\
(0.067)\end{array}$ & $\begin{array}{l}-0.021 \\
(0.047)\end{array}$ & $\begin{array}{l}-0.058 \\
(0.094)\end{array}$ & $\begin{array}{l}-0.039 \\
(0.076)\end{array}$ & $\begin{array}{l}-0.243 \\
(0.140)\end{array}$ & $\begin{array}{l}-0.218 \\
(0.144)\end{array}$ \\
\hline Observations & 18,843 & 14,227 & 18,708 & 18,805 & 18,231 & 18,843 & 18,843 \\
\hline Mean (control) & 4.601 & 0.205 & 0.966 & 0.416 & 0.221 & 0.002 & 17.026 \\
\hline
\end{tabular}

Panel B: Full City, no Owner FE, same sample as A

\begin{tabular}{lccccccc}
\multicolumn{1}{c}{ Upgrade } & -0.243 & -0.123 & -0.011 & -0.098 & -0.172 & -0.256 & -0.310 \\
& $(0.146)$ & $(0.084)$ & $(0.012)$ & $(0.054)$ & $(0.082)$ & $(0.105)$ & $(0.152)$ \\
Observations & 18,843 & 14,227 & 18,708 & 18,805 & 18,231 & 18,843 & 18,843 \\
Mean (control) & 4.601 & 0.205 & 0.966 & 0.416 & 0.221 & 0.002 & 17.026
\end{tabular}

$\begin{array}{ccccccc}\text { Geography } & \text { Lat-Long } & \text { Historical } & \text { Doughnut } & \text { Exclude } 100 \mathrm{~m} & \text { Second Order } & \text { Third Order } \\ & 2^{\text {nd }} \text { Poly. } & \text { CBD } & 100 \mathrm{~m} & \text { to Denovo } & \text { Polynomial } & \text { Polynomial }\end{array}$

Panel C: robustness owner FE (z-index only as outcome)

$\begin{array}{lccccccc}\text { Upgrade } & -0.244 & -0.264 & -0.250 & -0.475 & -0.228 & -0.066 & 0.040 \\ & (0.136) & (0.137) & (0.140) & (0.161) & (0.141) & (0.155) & (0.180) \\ & & & & & & & \\ \text { Observations } & 18,843 & 18,843 & 18,843 & 17,914 & 18,780 & 18,843 & 18,843 \\ \text { Mean (control) } & 0.002 & 0.002 & 0.002 & 0.000 & 0.000 & 0.002 & 0.002\end{array}$

Panel D: robustness, no owner FE, same sample as C (z-index only as outcome)

\begin{tabular}{lccccccc}
\multicolumn{1}{c}{ Upgrade } & -0.329 & -0.218 & -0.272 & -0.390 & -0.255 & -0.060 & 0.116 \\
& $(0.101)$ & $(0.105)$ & $(0.106)$ & $(0.094)$ & $(0.105)$ & $(0.133)$ & $(0.137)$ \\
& & & & & & & \\
Observations & 18,843 & 18,843 & 18,843 & 17,914 & 18,780 & 18,843 & 18,843 \\
Mean (control) & 0.002 & 0.002 & 0.002 & 0.000 & 0.000 & 0.002 & 0.002 \\
\hline \hline
\end{tabular}

Notes: This table reports estimates from regressions using specification (1) and unit level observations with outcomes derived from TSCP survey data for the three cities where these data exist: Mbeya, Mwanza, and Tanga. The sample includes the upgrading areas and the entire city as control areas. The outcomes are measures of housing quality that do not reflect direct investments in upgrading areas. Each observation is a property unit in a building, and only multi-unit owners are used. Units are assigned to upgrading or control areas based on where their building's centroid falls. Outcomes are measured at the building level (see Data Appendix for further details). In Panels A and B the outcomes vary, while in Panels C and D the dependent variable in all columns is the z-index (composed of all outcomes in columns (1)-(5) in Panel A). Panels A and C display results with unit owner last name fixed effects, including units inside upgrading and control areas but restricting the sample by keeping only last name owners that appear more than once in the sample. Panel B (D) displays results with the same sample as in A (C) but without owner last name fixed effects. In each specification the regressor of interest is upgrading, and the control variables include a linear control in distance to the upgrading-control area boundary interacted with the upgrading indicator, fixed effects for the nearest upgrading area, and distance to the Central Business District (CBD) of each city. In addition, in Panels C and D, column (1) includes geographic controls, column (2) includes a second order polynomial in longitude and latitude, column (3) uses distance to historical (instead of contemporary) CBDs, column (4) excludes areas within 100 meters of the boundary between upgrade and control areas, column (5) excludes areas within 100 meters of the boundary between de novo and control areas, and columns (6) and (7) control for second and third order polynomials in distance to the boundary, respectively Standard errors, in parentheses, are clustered by arbitrary 850x850 meter grid squares, corresponding to the median size of Sites and Services areas. There are 111-112 clusters. 
Table A11: Upgrading Regressions on Persistence Measures using Imagery and TSCP Survey Data

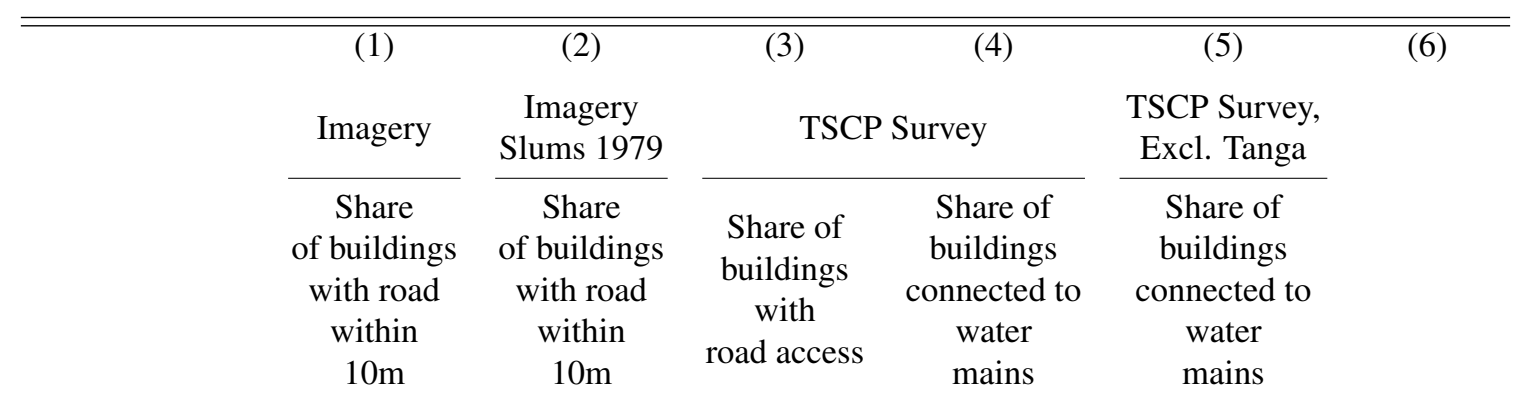

Panel A: 500m bandwidth

$\begin{array}{lccccc}\text { Upgrade } & -0.019 & 0.018 & 0.004 & -0.078 & -0.059 \\ & (0.018) & (0.039) & (0.056) & (0.087) & (0.109) \\ \text { Observations } & 10,909 & 8,000 & 2,065 & 2,066 & 1,923 \\ \text { Mean (control) } & 0.190 & 0.032 & 0.775 & 0.586 & 0.586 \\ & & & & & \\ & & & & & \\ & \text { Geography } & \text { Lat-Long } & \text { Historical } & \text { Doughnut } & \text { Exclude 100m } \\ & & 2^{\text {nd }} \text { Poly. } & \text { CBD } & 100 \mathrm{~m} & \text { to Denovo }\end{array}$

Panel B: robustness for share of buildings with road within 10m (Imagery)

\begin{tabular}{|c|c|c|c|c|c|c|}
\hline Upgrade & $\begin{array}{l}-0.021 \\
(0.019)\end{array}$ & $\begin{array}{l}-0.015 \\
(0.018)\end{array}$ & $\begin{array}{l}-0.019 \\
(0.019)\end{array}$ & $\begin{array}{l}-0.008 \\
(0.038)\end{array}$ & $\begin{array}{l}-0.022 \\
(0.019)\end{array}$ & \\
\hline Observations & 10,909 & 10,909 & 10,909 & 7,573 & 10,531 & \\
\hline \multirow[t]{2}{*}{ Mean (control) } & 0.190 & 0.190 & 0.190 & 0.197 & 0.190 & \\
\hline & Geography & $\begin{array}{l}\text { Lat-Long } \\
2^{\text {nd }} \text { Poly. }\end{array}$ & $\begin{array}{l}\text { Historical } \\
\text { CBD }\end{array}$ & $\begin{array}{c}\text { Doughnut } \\
100 \mathrm{~m}\end{array}$ & $\begin{array}{l}\text { Exclude } 100 \mathrm{~m} \\
\text { to Denovo }\end{array}$ & Full City \\
\hline \multicolumn{7}{|c|}{ Panel C: robustness for share of buildings with road access (TSCP) } \\
\hline Upgrade & $\begin{array}{c}0.006 \\
(0.046)\end{array}$ & $\begin{array}{l}-0.014 \\
(0.052)\end{array}$ & $\begin{array}{l}-0.007 \\
(0.053)\end{array}$ & $\begin{array}{l}-0.053 \\
(0.098)\end{array}$ & $\begin{array}{c}0.012 \\
(0.057)\end{array}$ & $\begin{array}{l}-0.013 \\
(0.048)\end{array}$ \\
\hline Observations & 2,065 & 2,065 & 2,065 & 1,461 & 2,000 & 11,207 \\
\hline Mean (control) & 0.775 & 0.775 & 0.775 & 0.764 & 0.768 & 0.771 \\
\hline
\end{tabular}

Panel D: robustness for share of buildings connected to water mains (TSCP)

\begin{tabular}{lcccccc} 
Upgrade & -0.079 & -0.102 & -0.089 & -0.045 & -0.076 & -0.181 \\
& $(0.083)$ & $(0.081)$ & $(0.081)$ & $(0.132)$ & $(0.089)$ & $(0.058)$ \\
& & & & & & \\
Observations & 2,066 & 2,066 & 2,066 & 1,462 & 2,001 & 11,214 \\
Mean (control) & 0.586 & 0.586 & 0.586 & 0.587 & 0.579 & 0.586 \\
\hline
\end{tabular}

Notes: This table reports estimates from regressions using specification (1) and block level observations. The outcomes in both columns (1) and (2) of Panel A, and in Panel B (road within 10m) are derived from imagery for all seven Sites and Services cities. The outcomes in columns (3) and (4) of Panel A, and in Panels C and D (road access and connection to water mains) are derived from TSCP survey data for Mbeya, Mwanza, and Tanga. In column (5) of Panel A, Tanga is excluded from the TSCP survey data because of the uncertainty about water mains in that city (see Data Appendix). The sample in Panels B-D and in Panel A columns (1) and (3)-(5) includes the upgrading areas and control areas within 500 meters of their boundary. The sample in column (2) in Panel A includes upgrading areas and the areas of Dar es Salaam that could be identified as slums in 1979 but excluded from the Sites and Services projects (see Data Appendix). The outcomes are measures of persistence of infrastructure treatment. Each observation is a block based on an arbitrary grid of $50 \mathrm{x} 50$ meter blocks. Blocks are assigned to upgrading or control areas based on where their centroid falls. Outcomes are derived from the set of buildings with a centroid in the block (see Data Appendix for further details). In Panel A the outcomes vary, while in Panel B the dependent variable in all columns is the share of buildings with a road within 10 meters (from imagery data), in Panel $\mathrm{C}$ the dependent variable in all columns is the share of buildings with road access (from TSCP data), and in Panel D the dependent variable is the share of buildings connected to water mains (from TSCP data). In each specification the regressor of interest is upgrading, and the control variables include a linear control in distance to the upgrading-control area boundary interacted with the upgrading indicator, fixed effects for the nearest upgrading area, and distance to the Central Business District (CBD) of each city. In addition, in Panels B, C and D, column (1) includes geographic controls, column (2) includes a second order polynomial in longitude and latitude, column (3) uses distance to historical (instead of contemporary) CBDs, column (4) excludes areas within 100 meters of the boundary between upgrade and control areas, column (5) excludes areas within 100 meters of the boundary between de novo and control areas. Moreover, in Panels C and D, cotugnn (6) changes the control area to the sample of blocks covering the whole city excluding de novo areas. Standard errors, in parentheses, are clustered by arbitrary 850x850 meter grid squares, corresponding to the median size of Sites and Services area. There are 28-30 clusters in TSCP data, except in column (6) of Panels C and D, which have 132 clusters. There are 117 clusters in imagery data, except in column (2) of Panel A which has 104 clusters. 
Table A12: Upgrading regressions of adult census outcomes

\begin{tabular}{cccccccc}
\hline \hline & $(1)$ & $(2)$ & $(3)$ & $(4)$ & $(5)$ & $(6)$ & $(7)$ \\
& $\begin{array}{c}\text { Mean } \\
\text { years of } \\
\text { schooling }\end{array}$ & $\begin{array}{c}\text { Share with } \\
\text { exactly } \\
\text { primary } \\
\text { education }\end{array}$ & $\begin{array}{c}\text { Share with } \\
\text { more than } \\
\text { primary } \\
\text { education }\end{array}$ & $\begin{array}{c}\text { Share } \\
\text { attending } \\
\text { school }\end{array}$ & $\begin{array}{c}\text { Share } \\
\text { literate } \\
\text { in any } \\
\text { language }\end{array}$ & $\begin{array}{c}\text { Share } \\
\text { literate } \\
\text { in Swahili }\end{array}$ & $\begin{array}{c}\text { Share } \\
\text { literate } \\
\text { in English }\end{array}$ \\
Upgrade & -0.469 & 0.049 & -0.060 & -0.018 & -0.012 & -0.011 & -0.066 \\
& $(0.131)$ & $(0.012)$ & $(0.016)$ & $(0.004)$ & $(0.004)$ & $(0.004)$ & $(0.017)$ \\
Observations & 2,842 & 2,842 & 2,842 & 2,842 & 2,842 & 2,842 & 2,842 \\
Mean (control) & 8.349 & 0.533 & 0.357 & 0.084 & 0.955 & 0.934 & 0.315 \\
\hline \hline
\end{tabular}

Notes: This table reports estimates from regressions using cut Enumeration Area (EA) level observations with outcomes derived from Tanzania 2012 Census microdata for all seven Sites and Services cities. In each specification the regressor of interest is upgrade, and the control variables include city fixed effects (separate for Temeke and Kinondoni in Dar es Salaam), and distance to the Central Business District (CBD) of each city. The sample includes upgrading observations and control areas which are near upgrading areas. The outcomes are measures of sorting into the treatment and control areas. Outcomes are the EA mean over the set of all adults at least 18 years old enumerated in the EA. Each observation is an EA of varying size, or a cut EA if the EA intersects both treatment and control areas. Cut EAs are assigned to upgrading and/or control areas if more than 5 percent of the cut EA lies inside the respective area. Analytic weights for the cut EA observations used in the regression are based on the proportion of the EA area that lies inside each treatment or control area. Standard errors, in parentheses, are clustered by arbitrary 850 x 850 meter grid squares. There are 124 clusters. 


\begin{abstract}
Dar es - Sources: the 1974 (World Bank 1974a) and 1977 (World Bank 1977b) project proposal maps.
Salaam - De novo and upgrading: the 1974 map is used to trace areas in the north of Dar es Salaam (Kinondoni Municipality), and the 1977 map is used in the south of Dar es Salaam (Temeke municipality).

- Exclusions: the 1974 map is used to exclude areas in Kinondoni where we identify previously established residential areas and land reserved for special institutions and industry. The 1977 map is used to exclude areas in Temeke where there are low density residential areas and special institutions.

Iringa

- Sources: the 1977 project proposal map (World Bank 1977b), and a 1978 topographic map (Directorate of Overseas Surveys, 2015).

- De novo and upgrading: the 1977 project proposal map is used to trace areas.

- Exclusions from control areas: the 1977 project proposal map is used to exclude industrial and established residential areas east of Mwangata. The 1978 topographic map is used to exclude already developed areas west and east of Mwangata, and also north, south and east of Kihesa. Additionally, north of Mwangata is excluded because of a power plant.
\end{abstract}

- Sources: a 1966 satellite image (United States Geological Survey, 2015), and drawings by experts on Mbeya the Sites and Services projects in Mbeya. Those experts are Shaoban Sheuya, Anna Mtani, and Amulike Mahenge and were all interviewed by the authors in Dar es Salaam, June 30, 2016.

- De novo and upgrading: the drawings from our experts were used to trace areas.

- Exclusions: the 1966 satellite image is used to exclude already built-up areas at the center of the city and areas with shops along the highway southeast of Mwanjelwa, already developed areas northwest of Mwanjelwa, and the airport.

- For consistency across TSCP and imagery data, we kept all TSCP buildings in Mbeya within the minimum bounding rectangle of the Worldview imagery for Mbeya, this excluded a very small fraction of buildings at the fringes.

Morogoro

- Sources: the 1977 project proposal map (World Bank 1977b), and a 1974 topographic map (Directorate of Overseas Surveys, 2015).

- De novo and upgrading: the 1977 project proposal map is used to trace areas.

- Exclusions: the 1977 project proposal map is used to exclude a large industrial area southwest of Msamvu and a large previously developed area to the south of Msamvu. The 1974 topographic map is used to exclude a previously developed area south of Kichangani, and to confirm the exclusions from the 1977 project proposal map. Finally $0.07 \mathrm{~km}^{2}$ of undeveloped farm land is excluded from the area to the adjacent to the railway station.

Mwanza - Sources: a 1973 cadastral map (Mwanza City Municipality, 1973).

- De novo: the cadastral map is used to trace areas, it delineates all surveyed plots and so contains a few that are outside of the actual Sites and Services treatment. We include plots that are small $\left(288 \mathrm{~m}^{2}\right.$ is the known treated plot area) and recorded with a plot number, and community buildings. We do not include plots that are large or that are small but do not have a recorded plot number.

- Exclusions: the cadastral map is used to exclude areas with large plots or plots without a recorded number. Also excluded are previously developed areas along the road in the southeast of Mwanza, as well as areas to the north that are off of the map. The 1966 satellite imagery was used to exclude built-up center of the city.

Tabora

- Sources: the 1977 project proposal map (World Bank 1977b), a 1967 topographic map (Directorate of Overseas Surveys, 2015), and 1978 aerial imagery (Directorate of Overseas Surveys, 2015).

- De novo and upgrading: the 1977 project proposal map is used to trace areas.

- Exclusions: the project proposal map is used to excluded previously built areas to the west and southwest of the Kiloleni. The 1967 topographic map is used to exclude an industrial area to the south of Isebeya in between the two of upgrading area. The 1978 aerial image is used to confirm the exclusions.

Tanga

- Sources: the 1977 project proposal map (World Bank 1977b), and a 1966 satellite image (United States Geological Survey, 2015).

- De novo and upgrading: the 1977 project proposal map is used to trace areas.

- Exclusions: the 1966 satellite image is used to exclude already developed areas south, southwest, north and east of Gofu Juu and east of Mwakizaro, as well as the center of the city near the coast. The 1977 project proposal map is used to exclude industrial area between Gofu Juu and Mwakizaro.

Notes: This table explains what imagery and maps were used to (a) delineate the de novo and upgrading areas, and (b) create exclusion areas (i.e. areas to be excluded from the control areas) among areas that are within 500 meters of Sites and Services, as explained in the Data Appendix. Sources are all georeferenced maps of the city in question. Almost all areas in the studied cities were covered by these maps, with minor exceptions in the western areas of Tabora, and north of the northern treatment area (Kihesa neighborhood) in Iringa. 
Table A14: Description of Variables Derived from Imagery Data

\begin{tabular}{|c|c|}
\hline Variable label & Definition \\
\hline Log building footprint area & $\begin{array}{l}\text { Calculated directly for the shape file (calculated as a direct measure for } \\
\text { the building, or a sample average of that measure for each block.) }\end{array}$ \\
\hline Painted roof & $\begin{array}{l}\text { Indicator for painted as opposed to tin or rusted tin (an indicator for } \\
\text { the building or a share of buildings with painted roofs for each block). } \\
\text { Please see the Data Appendix. }\end{array}$ \\
\hline Similarity of orientation & $\begin{array}{l}\text { Calculated using the main axis of the minimum bounding box that con- } \\
\text { tains each building. We then calculated the difference in orientation be- } \\
\text { tween each building and its neighboring building, modulo } 90 \text { degrees, } \\
\text { with more similar orientations representing a more regular layout (an } \\
\text { indicator for the building or a sample average for each block). }\end{array}$ \\
\hline Z-index & $\begin{array}{l}\text { We construct a family of outcomes measure following Kling et al. } 2007 \\
\text { and Banerjee et al. 2014. We integrate all "good" variables into one } \\
\text { index. We subtract the mean in the control group and divide the result } \\
\text { by the standard deviation in the control group. Then we create the index } \\
\text { by taking a simple average of the normalized variables (a measure for } \\
\text { the building or a sample average for each block). Please refer to the } \\
\text { Data Appendix for more details. }\end{array}$ \\
\hline Road within $10 \mathrm{~m}$ & $\begin{array}{l}\text { An indicator that the distance form the boundary of the building to the } \\
\text { nearest roads is no more than } 10 \mathrm{~m} \text { ). }\end{array}$ \\
\hline Distance to the CBD & $\begin{array}{l}\text { The CBD for each city is the centroid of the most lit pixel in } 1992 \text { from } \\
\text { the NOAA "Average Visible and Stable Lights, Cloud Free Coverage" } \\
\text { dataset. The distance to the CBD is calculated from the centroids of } \\
\text { each building or block. }\end{array}$ \\
\hline Empty block indicator & Indicator for a block that has no buildings. \\
\hline Share of area built up & Share of the area of the block that is built. \\
\hline Number of buildings & Count of buildings in a $50 \times 50 \mathrm{~m}$ block. \\
\hline
\end{tabular}

Note: this table describes the variables derived from imagery data. 
Table A15: Description of TSCP variables and how they are created

\begin{tabular}{|c|c|}
\hline Variable label & Definition \\
\hline Connected to electricity & Indicator for whether a building is connected to electricity. \\
\hline Sewerage or septic tank & $\begin{array}{l}\text { Indicator for good sanitation, i.e. having sewerage or a septic tank as } \\
\text { opposed to an alternative of pit latrine, no sanitation at all, or other. }\end{array}$ \\
\hline Good roof & $\begin{array}{l}\text { Indicator for roof being made of concrete, metal sheets, clay tiles or } \\
\text { cement tiles as opposed to an alternative of grass/palm, asbestos, timber } \\
\text { or other. This is a different measure from the "Painted roof" variable in } \\
\text { Table A14. }\end{array}$ \\
\hline Multistorey building & Indicator for one or more storeys above the ground floor. \\
\hline Z-index & $\begin{array}{l}\text { We construct a family of outcomes measure following Kling et al. } 2007 \\
\text { and Banerjee et al. 2014. We integrate all "good" variables into one } \\
\text { index. We subtract the mean in the control group and divide the result } \\
\text { by the standard deviation in the control group. Then we create the index } \\
\text { by taking a simple average of the normalized variables. }\end{array}$ \\
\hline Hedonic Value & $\begin{array}{l}\text { We run a hedonic regression using property values of } 3663 \text { buildings in } \\
\text { Arusha based on log area, electricity, and indicators for good sanitation, } \\
\text { good roof, and multi-story. We predict this value in our three TSCP } \\
\text { cities (Tanga, Mbeya, and Mwanza). }\end{array}$ \\
\hline Connected to water mains & $\begin{array}{l}\text { Indicator for good water supply (metered/mains as opposed to borehole; } \\
\text { stand tap; river; rain; water trucks; or other/none). }\end{array}$ \\
\hline Road access & Indicator for access to tarmac; gravel; or earth road. \\
\hline
\end{tabular}


Table A16: Hedonic housing value regressions using TSCP survey data

\begin{tabular}{lc}
\hline \hline & $(1)$ \\
& $\ln$ value \\
\hline Log building footprint area & 0.797 \\
& $(0.019)$
\end{tabular}

Connected to electricity

0.235

(0.040)

Sewerage or septic tank

0.524

(0.041)

Good roof

0.0474

(0.090)

Multiple storeys

$-0.0359$

(0.178)

\begin{tabular}{lc} 
Intercept & 13.11 \\
& $(0.221)$ \\
\hline Observations & 3,663 \\
$R^{2}$ & 0.416 \\
\hline \hline This table reports estimates from a hedonic regression \\
with buildings as units of observation using property \\
values of 3,663 buildings in Arusha. The dependent \\
variable is property value. This sample is selected \\
because these buildings had both valuation data and data \\
from the TSCP survey. Regressors are the buildings' \\
log area, electricity, and indicators for good sanitation, \\
good roof, and multi-storey. We then use the coefficient \\
estimates to construct measures of hedonic values, \\
as we explain in the Data Appendix.
\end{tabular}


Table A17: Description of Variables from Tanzanian Census 2012

\begin{tabular}{ll}
\hline \hline Variable label & Definition \\
Years of schooling & How many years of schooling the adult respondent has obtained. Miss- \\
ing values in the microdata are coded as 0 since there was no category \\
for "Never attended school", and since the missing values were found to \\
match reasonably well with the proportion of people with no schooling \\
in the IPUMS 2012 Tanzanian Census data (which does not, however, \\
have low level geographical identifiers). Moreover, the proportion of \\
missing values in the microdata increased with age and with gender and \\
age, which corresponds to the pattern of people lacking any school- \\
ing in Tanzania. Respondents with Training after primary school/Pre- \\
secondary school or Training after secondary school are coded as 8 or \\
12 years respectively, i.e. one more year than primary or secondary \\
schooling. Respondents with university education, are coded as 15, i.e. \\
one more year than the maximum number of secondary schooling.
\end{tabular}

Exactly primary school Binary indicator that takes the value 1 if the adult respondent has completed exactly 7 years of schooling, 0 otherwise. Missing values coded as 0 as in the variable above.

More than primary school Binary indicator that takes the value 1 if the respondent has completed more than 7 years of schooling, 0 otherwise. Missing values coded as 0 as in the variables above.

Literate in any language Binary indicator that takes the value 1 if the adult respondent is literate in any language.

Literate Swahili Binary indicator that takes the value 1 if the adult respondent is literate in Swahili.

Literate English Binary indicator that takes the value 1 if the adult respondent is literate in English. 